LEONARDO HENRIQUE TOMASSETTI FERREIRA NETO

ESTIMADOR DE ESTADO INTELIGENTE PARA ANÁLISE DE PERDAS EM SISTEMAS DE DISTRIBUIÇÃO DE ENERGIA 
LEONARDO HENRIQUE TOMASSETTI FERREIRA NETO

\section{ESTIMADOR DE ESTADO INTELIGENTE PARA ANÁLISE DE PERDAS EM SISTEMAS DE DISTRIBUIÇÃO DE ENERGIA}

Dissertação apresentada à Escola Politécnica da Universidade de São Paulo para obtenção do título de Mestre em Engenharia Elétrica

Área de Concentração:

Sistemas de Potência

Orientador:

Prof. Dr. Marcos Roberto Gouvêa

São Paulo

2011 
Este exemplar foi revisado e alterado em relação à versão original, sob responsabilidade única do autor e com a anuência de seu orientador.

São Paulo, 30 de setembro de 2011.

Assinatura do autor

Assinatura do orientador

FICHA CATALOGRÁFICA

Ferreira Neto, Leonardo Henrique Tomassetti

Estimador de estado inteligente para análise de perdas em sistemas de distribuição de energia / L.H.T. Ferreira Neto. -ed.rev. -- São Paulo, 2011.

99 p.

Dissertação (Mestrado) - Escola Politécnica da Universidade de São Paulo. Departamento de Engenharia de Energia e Automação Elétricas.

1. Distribuição de energia elétrica 2. Estimação de estados I. Universidade de São Paulo. Escola Politécnica. Departamento de Engenharia de Energia e Automação Elétricas II. t. 


\section{DEDICATÓRIA}

Aos meus pais, Janete e Luiz Carlos. 


\section{AGRADECIMENTOS}

Ao meu orientador, Prof. Dr. Marcos Roberto Gouvêa, pelo apoio e pelas contribuições que foram fundamentais para o desenvolvimento deste trabalho.

Ao Prof. Dr. Carlos César Barioni de Oliveira e Dr. Alden Uehara Antunes pelas valiosas contribuições na etapa de qualificação desta dissertação.

Ao Dr. André Méffe pela colaboração no desenvolvimento de diversas etapas deste trabalho.

À minha namorada Stephania, minhas amigas Cecília e Lívia e meus amigos e colegas de trabalho Denis, Fernando e Vitor pelas dicas, paciência, apoio e incentivo.

Aos meus pais e irmãos que me apoiaram e me incentivaram durante essa etapa da minha vida.

A todos que direta ou indiretamente contribuíram para o desenvolvimento deste trabalho. 
"Não basta saber, é preciso também aplicar. Não basta querer, é preciso também agir." (Johann Goethe) 


\section{RESUMO}

O presente trabalho tem por objetivo propor uma metodologia de estimação de estado (EE) para sistemas de distribuição de energia que auxilie na identificação das regiões de fornecimento das concessionárias de distribuição que possam conter perdas não técnicas, de modo a orientar as ações para sua redução. As perdas não técnicas de energia elétrica são um grande desafio não só no Brasil como também em outros países em desenvolvimento. Face à dificuldade e ao custo para fiscalizar anualmente toda a área de concessão, faz-se necessário um diagnóstico para avaliar em quais grupos de clientes e regiões encontram-se este tipo de perda. Destarte, fica evidenciada a necessidade do desenvolvimento de uma ferramenta que, além de tratar de uma modelagem completa do sistema, utilize informações provenientes de medições diversas. Para isso, a estimação de estado se torna a metodologia ideal. A metodologia utilizada na estimação de estados foi a dos Mínimos Quadrados Ponderados (do inglês, Weighted Least Squares - WLS) (Schweppe \& Wildes, 1970) e algumas técnicas foram aplicadas para permitir a EE em sistemas de distribuição, tais como a utilização da corrente complexa dos trechos como variáveis de estado, que decompõe a estimação de estados em três subproblemas, um para cada fase, permitindo a utilização de uma modelagem trifásica da rede e a introdução de pseudomedidas obtidas dos dados de faturamento dos clientes através de um processo estatístico. $O$ trabalho apresenta exemplos de aplicação, sendo estes em sistemas de distribuição reais, mostrando os resultados obtidos e termina destacando as principais vantagens da metodologia.

Palavras-chave: Sistemas de potência. Distribuição de energia. Estimação de estados. 


\begin{abstract}
This work focuses on the development of a distribution system state estimation (SE) algorithm for application to radial distribution networks which assists the identification of regions of the distribution network containing non-technical energy losses, helping the electric utilities to evaluate and reduce it. Non-technical energy losses represent an important challenge for distribution companies in developing countries, such as Brazil. However, economical limitations and measurement problems make impossible to have a perfect picture of the complete system, then a diagnoses method is required to evaluate which group of consumers and the regions have that type of loss. Therefore, is evidenced the necessity of a tool development which, farther on using the complete system modeling, works with information from various measurement instruments. Consequently, the SE becomes the ideal method. The SE applied is the Weighted Least Square approach (WLS) (Schweppe \& Wildes, 1970) and some techniques where applied to allow the SE for distribution systems, such as, using the branch currents as the system state, which decouples the state estimation problem into three sub problems, one for each phase, allowing the three phase system modelling and the introduction of pseudo measurements from historical load data produced based on customer billing data through statistical processes. This work shows the results obtained by applying the computational tool to a real distribution system. Such results are compared with the ones obtained by using other methodologies, and the main advantages of this new methodology are outlined.
\end{abstract}

Keywords: Power systems. Energy distribution. State estimation. 


\section{SUMÁRIO}

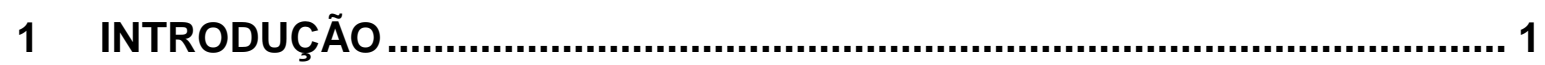

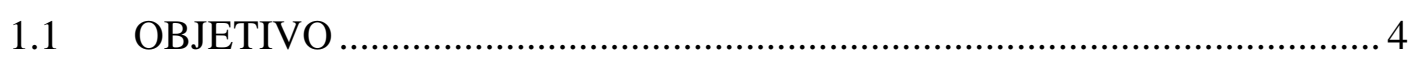

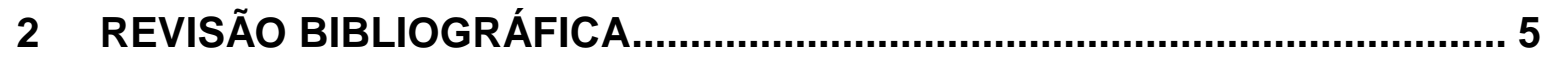

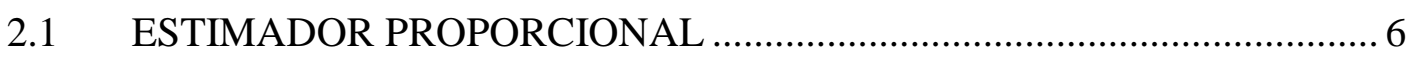

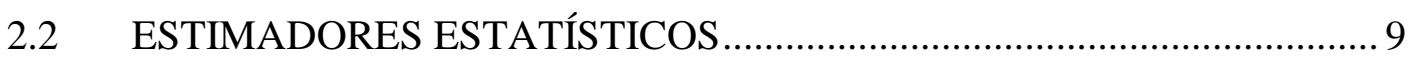

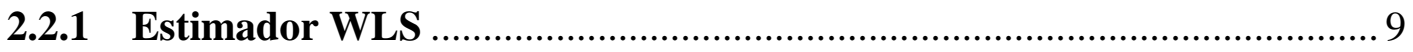

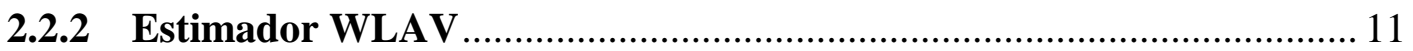

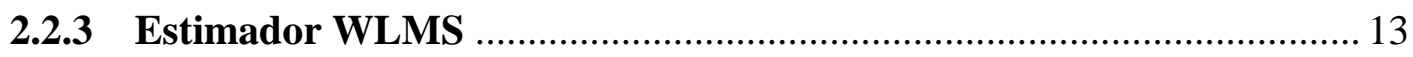

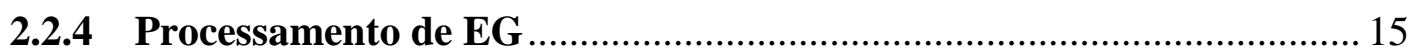

2.3 ESTIMADORES HEURÍSTICOS .................................................... 19

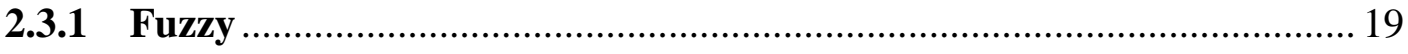

2.3.2 Otimização por enxame de partícula híbrida ...................................... 22

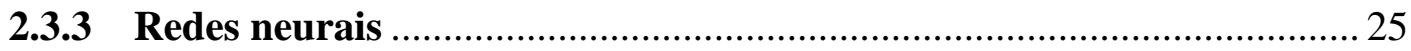

3 ESTIMAÇÃO DE ESTADO EM SISTEMAS DE DISTRIBUIÇÃO ................. 26

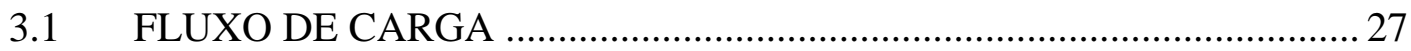

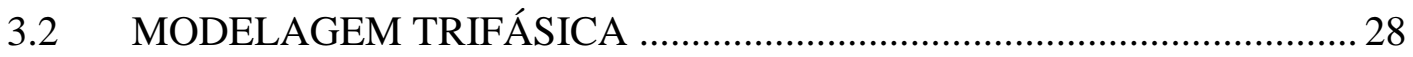

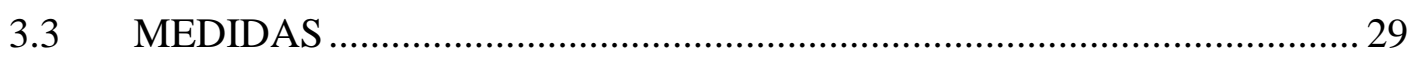

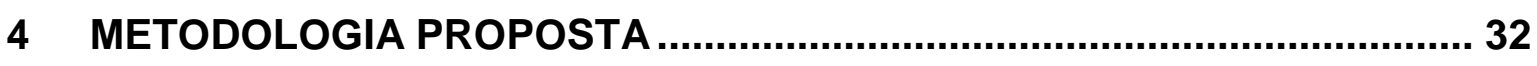

$4.1 \quad$ ESTIMADOR PARA REDE MT ......................................................... 33

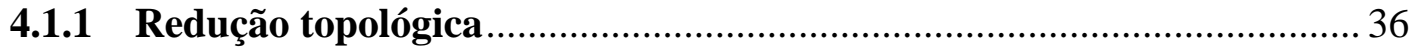

4.1.2 Modelagem da carga e medições .......................................................... 37

4.1.4 Equacionamento das funções de medição ............................................ 44

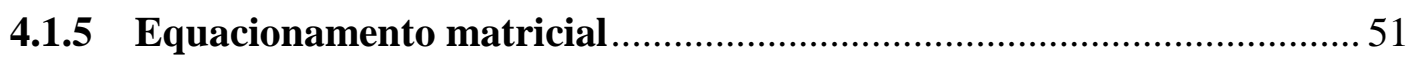

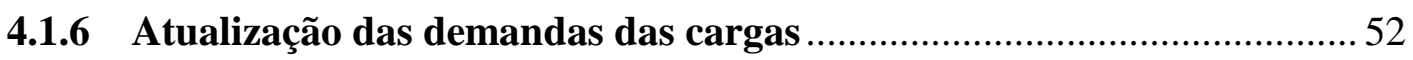

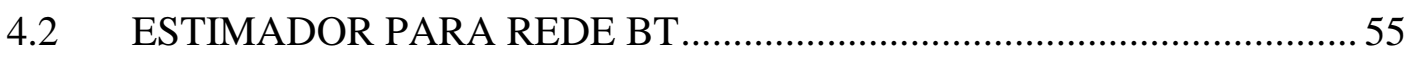

4.2.1 Equacionamento das funções de medição …….....................................56

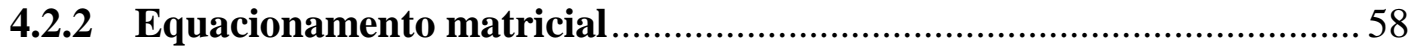

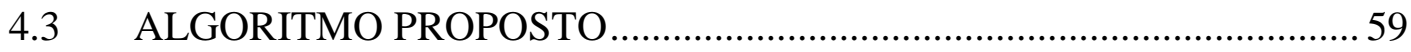

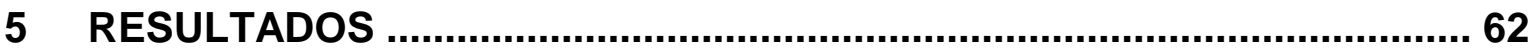




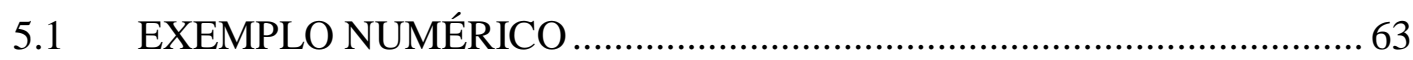

5.2 APLICAÇÃO EM ALIMENTADORES REAIS ..................................... 70

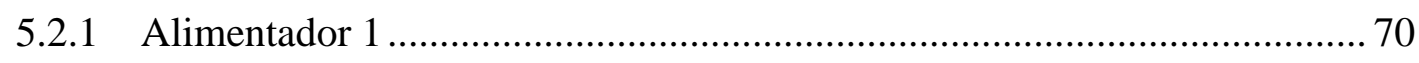

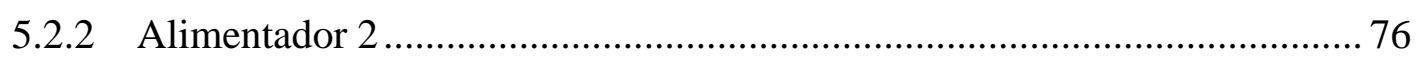

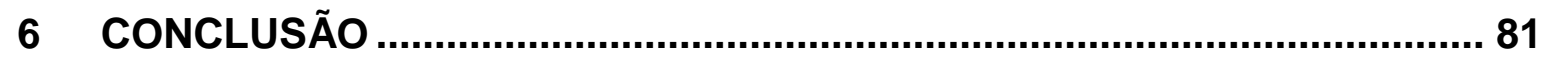

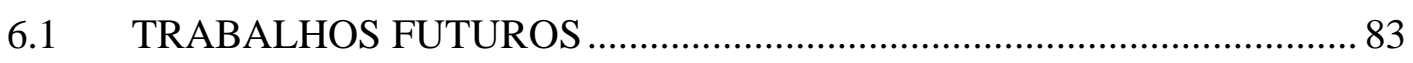

7 REFERÊNCIAS BIBLIOGRÁFICAS..................................................... 85

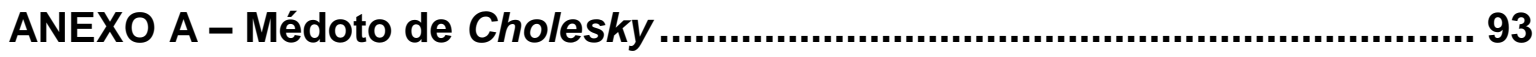

ANEXO B - Tabelas de Medições e Resultados ........................................... 94 


\section{INTRODUÇÃO}

Com a atual realidade do setor de distribuição de energia face às privatizações, as concessionárias buscam otimizar seus investimentos, reduzir seus gastos, e, por conseguinte, melhorar o atendimento dos consumidores.

Em especial, os esforços voltam-se para a diminuição das perdas, pois tal ação pode postergar grandes investimentos no setor elétrico e significar uma grande economia, já que a redução das perdas implica numa menor capacidade do parque gerador necessário para atender a mesma carga.

A título de exemplo, as perdas de energia no Brasil alcançaram mais de $R \$ 8$ bilhões, de acordo com os números de 2009 da Agência Nacional de Energia Elétrica (Aneel), o que representa $18 \%$ de toda a energia produzida no país. Desse total, $65 \%$ das perdas de energia dizem respeito aos sistemas de distribuição.

$\mathrm{Na}$ tentativa da identificação e diminuição das perdas, iniciou-se o processo de instalação ou o planejamento da instalação de sistemas de supervisão, controle e aquisição de dados, a fim de automatizar os processos de operação das redes de distribuição e que auxiliem a fiscalização, o planejamento de melhorias e expansão da rede.

Criou-se, então, o conceito de Smart Grid (Rede Elétrica Inteligente) que, em termos gerais, busca incorporar tecnologias de sensoriamento, monitoramento, tecnologia da informação e telecomunicações para o melhor desempenho da rede, identificando antecipadamente suas falhas e capacitando-a a se autorecompor diante de ocorrências que afetem seu desempenho.

Assim sendo, mais informação está sendo obtida da rede, como medições em transformadores de subestação, saída de circuitos primários, equipamentos diversos da rede primária, transformadores de consumidores de média tensão e em clientes de baixa tensão.

Essa informação é utilizada pelos sistemas que monitoram parâmetros como nível de tensão nas barras da rede de distribuição, carregamento de circuitos e transformadores, volume de perdas técnicas, entre outros. Contudo, tais sistemas são diretamente dependentes da confiabilidade das informações utilizadas. 
Neste contexto, existem aspectos de difícil tratamento, podendo-se citar:

- Eventuais erros de cadastro;

- Eventuais erros em medidores de grandezas elétricas;

- Existência de consumidores clandestinos;

- O descompasso existente entre a efetivação de manobras permanentes na rede de distribuição e a atualização correspondente nos bancos de dados de cadastro;

- Dificuldade de caracterização da demanda dos pontos de carga (transformadores de distribuição e transformadores de consumidores primários), tanto em modelos tradicionais (estimativas estatísticas por meio da função kVAs que tendem a majorar a demanda), ou por meio da utilização das curvas de cargas de consumidores (além do aspecto estatístico, a demanda de cada ponto da curva de carga é definida por valores médios observados durante um período de medição).

Estes aspectos, relacionados à falta de faturamento da energia distribuída, são contabilizados como perdas não técnicas.

Portanto, os sistemas de simulação, tradicionalmente utilizados pelas concessionárias de distribuição de energia, podem ser aprimorados a partir de mecanismos apropriados para tratarem estes aspectos e auxiliarem na mitigação das perdas não técnicas, isto sendo possível de ser realizado através da estimação de estado.

A estimação de estado, de forma geral, é uma metodologia estatística que produz a melhor estimativa possível do estado real do sistema elétrico (ponto de operação), que é usualmente a tensão complexa nas barras do sistema, utilizando o conjunto de informações disponíveis. Além disso, o estimador de estado, através de um processo de filtragem, é capaz de processar medidas com erros, detectando suas presenças, identificando-as e eliminando seus efeitos no processo de estimação, desde que haja medidas redundantes em quantidade suficiente.

Baran, Zhu e Kelley (1996) mostram que a estimação de estados eleva a capacidade de monitoração do sistema mesmo com limitado número de medidas, sendo utilizada tanto na análise de contingências como na detecção de erros de 
topologia. Além disso, a estimação de estados beneficia as funções de controle (controle de tensão/reativo durante a operação normal e restauração de alimentadores em condições de emergência), empregadas na distribuição.

A grande maioria dos algoritmos já desenvolvidos para a estimação de estado destina-se à aplicação em sistemas elétricos de geração e transmissão, havendo poucos algoritmos para sistemas de distribuição. Isso se deve em parte à pequena quantidade de dados de medição disponíveis em tempo real nesses sistemas. Assim, para lidar com o problema de baixa redundância de medições, vêm sendo desenvolvidas técnicas que combinam os dados de medição com dados históricos da rede.

Para tratar os aspectos aqui mencionados, este trabalho está organizado em 6 capítulos.

O capítulo 1 apresenta a motivação, os principais objetivos do trabalho e a introdução sobre o assunto tratado. Por conseguinte no capítulo 2 encontra-se o levantamento do estado da arte dos modelos de estimação de estados em sistemas de potência.

No capítulo 3 são apresentados os tratamentos requeridos pelo segmento de distribuição de energia para estimação de estado. No capítulo 4 especifica-se o modelo de estimação de estados em redes de distribuição que concilie os dados de medição disponíveis, bem como dados estimados de demanda dos diversos pontos de carga de cada alimentador provenientes dos dados de consumo dos consumidores e curvas de carga típicas correspondentes.

Os testes da metodologia proposta são apresentados no capítulo 5, e por fim no capítulo 6, são apresentadas as conclusões obtidas dos testes realizados e sugeridas perspectivas para o prosseguimento da investigação nesta área. 


\subsection{OBJETIVO}

Este trabalho tem por objetivo propor uma metodologia de estimação de estado para sistemas de distribuição de energia que auxilie na identificação das possíveis regiões de fornecimento das concessionárias de distribuição que contenham perdas não técnicas, de modo a orientar as ações para sua redução.

Para isso é necessário o levantamento do estado da arte das metodologias de estimação de estado existentes e a investigação de técnicas auxiliares que possibilitam a aplicação destas metodologias nos sistemas de distribuição de energia.

Assim sendo, este trabalho, além de apresentar a modelagem matemática das metodologias de estimação de estados, compila um conjunto de metodologias encontradas em diferentes trabalhos que, quando associadas, facultam o alcance do objetivo proposto.

Em particular, a identificação das possíveis regiões detentoras de perdas não técnicas pode ser realizada através de um tratamento dos resultados da estimação, entretanto a interpretação da informação obtida deve ser efetuada por uma análise criteriosa, a fim de possibilitar a correta utilização desta metodologia. Apesar de este trabalho tratar da solução de um problema energético, ou seja, a falta de faturamento da energia distribuída, o estudo em demanda, realizado pela metodologia de estimação de estados proposta, permite esta análise quando executada por período de estudo, utilizando-se os valores médios das medições, ou mesmo pela composição de vários resultados momentâneos, que podem ser resultados de cálculos diários ou de hora em hora, por exemplo. 


\section{REVISÃO BIBLIOGRÁFICA}

Os primeiros trabalhos em estimação de estado de Sistemas Elétricos de Potência (SEP) foram publicados por Schweppe (1970), Schweppe e Rom (1970) e Schweppe e Wildes (1970) no final da década de 1960. Estes trabalhos apresentam a natureza geral do problema estatístico, a modelagem matemática, as técnicas iterativas iniciais e conceitos relacionados à deteç̧ão e à identificação de medidas com erros grosseiros. Desde então, várias pesquisas foram desenvolvidas relativas aos problemas ligados ao processo de estimação de estado, como mostram Monticelli (1999), Baran (2001), Abur e Expósito (2004) e Singh, Pal e Jabr (2009).

Os trabalhos mais recentes utilizam técnicas heurísticas como Fuzzy, apresentado por Zimmerman (1984) e Saric e Ciric (2003), otimização por enxame de partículas (Particle Swarm Optimization) de Kennedy e Eberhart (1995), Naka (2001) e Naka, Genji e Fukuyama (2003) e redes neurais de Abbasy (1996), Abbasy e EL-Hassawy (1996), Antonio (2001), Shafiu( 2005) e Rakpenthai (2005).

Em termos gerais, a principal função de um algoritmo de estimação de estado é a obtenção de uma estimativa confiável, $\hat{x}$, do verdadeiro estado do sistema, $x$, tornando mais eficientes as ações que devem ser tomadas. Para que esse objetivo seja atingido, o estimador de estado utiliza diversos tipos de informações existentes.

A figura 2.1 representa a estrutura utilizada para simular o modo de funcionamento de um estimador de estado.

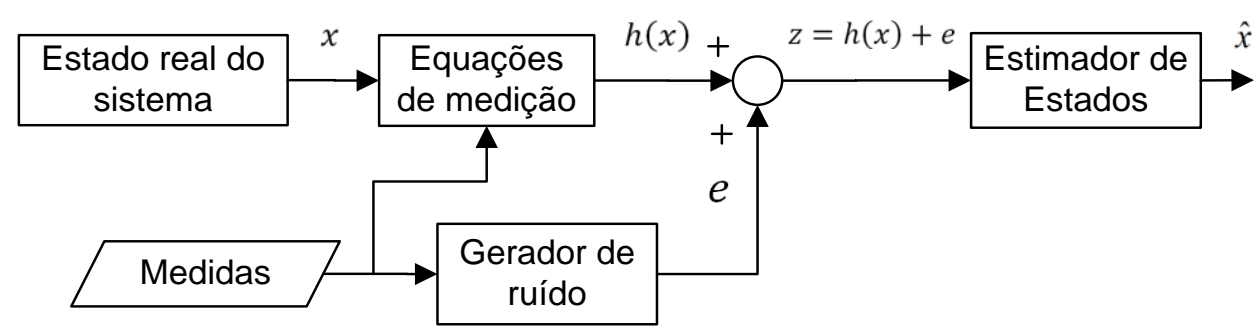

Figura 2.1: Funcionamento do estimador de estado 
Assim sendo, as medições realizadas e as variáveis de estado de um SEP podem ser relacionadas através do modelo de medição, representado pela equação (2.1).

$$
z=h(x)+e
$$

Onde:

$Z$ - vetor de medidas;

$x$ - vetor de variáveis de estado;

$e$ - vetor dos erros nas medidas de distribuição Gaussiana e média nula (Abur \& Expósito, 2004);

$h($.$) - vetor de funções não lineares que relaciona as medidas com as$ variáveis de estado.

Dentre os diferentes métodos para a estimação de estado do sistema de distribuição, os mais relevantes serão expostos a seguir.

\subsection{ESTIMADOR PROPORCIONAL}

A metodologia básica de estimação de estado pode ser expressa como sendo o ajuste proporcional das demandas das cargas pela da razão de valores medidos e calculados na saída do alimentador ou em ramais. Esse modelo utiliza o fluxo de carga para determinar esses valores e assim, ajustar linearmente as demandas das cargas.

A figura 2.2 mostra o algoritmo de um estimador proporcional fundamental. $\mathrm{Na}$ metodologia apresentada por Deng, He e Zhang (2002), utilizam-se medições de fluxo de potência para corrigir as cargas estimadas que estejam a sua jusante, com isso, garante-se que a demanda no trecho onde haja medição seja exatamente o valor medido. 


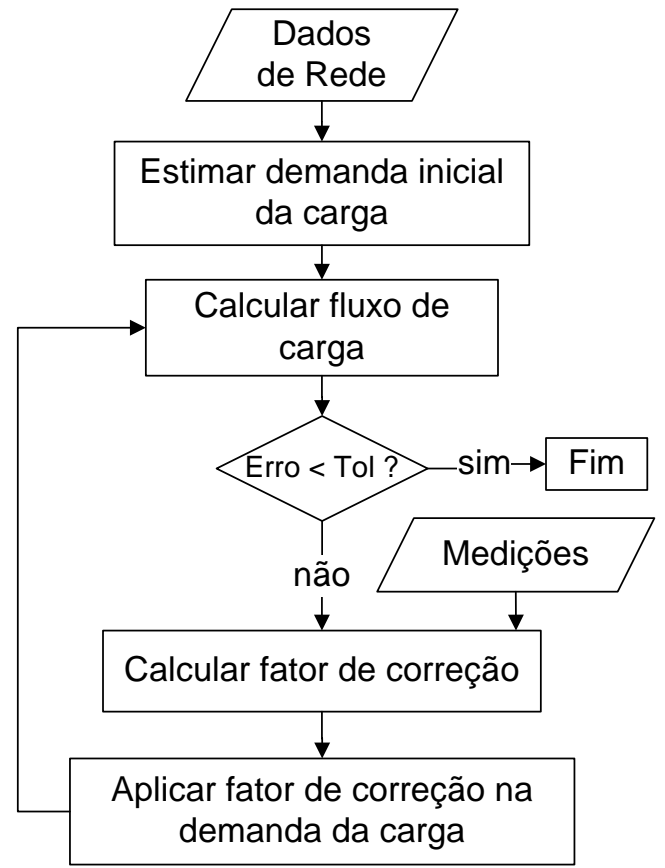

Figura 2.2 - Algoritmo do estimador proporcional.

Como exemplo dessa metodologia, considera-se o sistema radial da figura 2.3, onde estão instalados três medidores que fornecem os fluxos de potência $P_{m 1}$, $P_{m 2}$ e $P_{m 3}$.

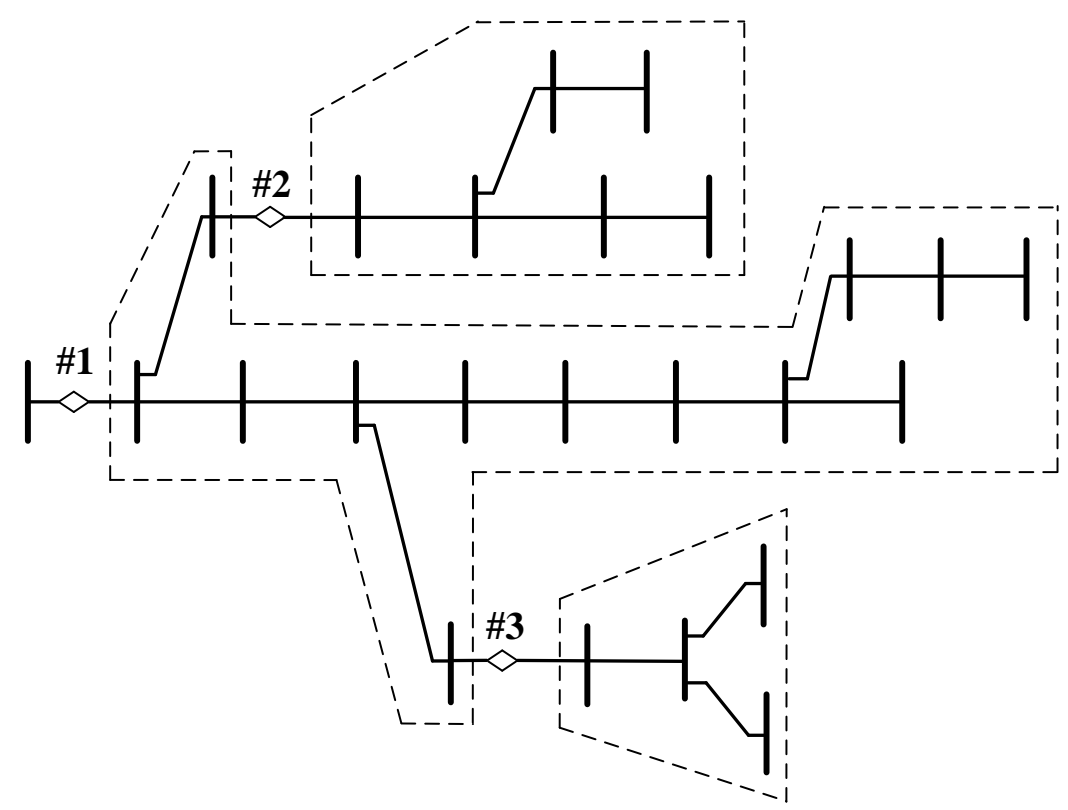

Figura 2.3 - Rede radial.

Pode-se, então, definir a zona de atuação de cada um dos medidores instalados como sendo a região do alimentador à jusante do medidor até o final do 
alimentador e entre o ponto de instalação de outro medidor quando for o caso. $\mathrm{Na}$ figura 2.2, estão destacadas as zonas de atuação dos medidores \#1, \#2 e \#3. O valor medido de cada zona deve ser modificado de acordo com as outras zonas associadas que estão à jusante, assim como proposto em Deng, He e Zhang (2002). Por exemplo, assumindo que $P_{m 1}^{\prime}$ é o valor modificado da medição \#1, então:

$$
P_{m 1}^{\prime}=P_{m 1}-P_{m 2}-P_{m 3}
$$

Outra metodologia de correção da demanda das cargas em função das medições instaladas foi proposta por Méffe (2007). O grande diferencial desta metodologia é devido à consideração da variação das perdas na rede em função do aumento ou diminuição da carga estimada dos clientes no momento do cálculo da correção.

Inicialmente calcula-se o fator de correção em função da demanda dos clientes e das perdas da rede de distribuição e posteriormente aplica-se este fator nas cargas estimadas de uma determinada zona.

Para calcular o fator de correção, deve-se igualar a demanda medida ao total de demanda calculada, multiplicando-se as demandas faturadas das cargas pelo fator de correção ainda desconhecido e a perda de demanda pelo fator de correção ao quadrado, pois a perda de demanda é proporcional ao quadrado da demanda aparente.

O fator de correção $k_{e}$, em um instante $t$, é calculado da seguinte forma:

$$
P_{m}^{\prime}=\left(k_{e}\right)^{2} P_{p v a r}+k_{e} P+P_{\text {fixa }}+P_{p f i x a}
$$

Onde:

- $P_{m}^{\prime} \quad$ Valor modificado da medição;

- Ppvar Perdas variáveis com a demanda da rede (ex: perdas na rede, no cobre dos transformadores, nos ramais de ligação);

- $P \quad$ Demanda estimada dos clientes;

- $P_{\text {fixa }}$ Demanda que não sofrerá correção (ex: demanda de gerações distribuídas e clientes com curva de demanda medida); 
- $P_{\text {pfixa }}$ Perdas fixas (ex: perda no ferro dos transformadores devido à magnetização).

Resolvendo a equação do segundo grau (2.3), obtém-se $k_{e}$, que é a raiz positiva da solução.

As perdas da rede de distribuição, utilizadas neste equacionamento, podem ser obtidas previamente através de um fluxo de carga convencional ou através de valores típicos de perda.

Ambas as metodologias corrigem as demandas das cargas por fatores fixos, calculados diretamente com os valores medidos, podendo originar estimativas distorcidas.

\subsection{ESTIMADORES ESTATÍSTICOS}

Dentre os vários métodos estatísticos existentes para o cálculo das variáveis de estado, os mais utilizados na literatura serão apresentados a seguir.

\subsubsection{Estimador WLS}

O método estatístico de EE dos Mínimos Quadrados Ponderados (do inglês, Weighted Least Squares - WLS) (SCHWEPPE; WILDES, 1970) é o que tem sido mais utilizado na EE em sistemas elétricos de potência (SEP), cujo equacionamento e algoritmo desta metodologia são apresentados a seguir. 


\section{- Equacionamento}

A solução do problema de estimação de estado pelo método dos mínimos quadrados ponderados consiste em, basicamente, estimar o vetor de variáveis de estado, $x$, de forma a minimizar a função objetivo, que se refere ao modelo de medição, equação (2.1). Ou seja, minimiza-se a função objetivo representada pela equação (2.4).

$$
J(x)=\frac{1}{2} \sum_{i=1}^{m} \frac{\left(z_{i}-h_{i}(x)\right)^{2}}{\sigma_{i}^{2}}=\frac{1}{2}[z-h(x)]^{T} R_{z}^{-1}[z-h(x)]
$$

Onde $\sigma$ é a variância da medida $i$ e $R$ é a matriz de covariância das medidas.

A estimativa do vetor de variáveis de estado $x$ é obtida de forma recursiva, através do cálculo da matriz Jacobiana, $H\left(x^{k}\right) \approx \partial h(x) / \partial x$, e da solução do seguinte conjunto de equações (algoritmo iterativo Gauss-Newton (SCHWEPPE, 1970)):

$$
G\left(x^{k}\right) \cdot\left(x^{k+1}-x^{k}\right)=H^{T}\left(x^{k}\right) \cdot R^{-1} \cdot\left[z-h\left(x^{k}\right)\right],
$$

Onde $x^{k}$ é o valor de $x$ na iteração $k$, e

$$
G\left(x^{k}\right)=H^{T}\left(x^{k}\right) \cdot R^{-1} \cdot H\left(x^{k}\right)
$$

é a matriz Ganho.

Com base nas equações (2.5) e (2.6), pode-se elaborar o procedimento de estimação representado pela figura 2.4, denominado de algoritmo do Estimador WLS - Acoplado (MONTICELLI, 2000): 


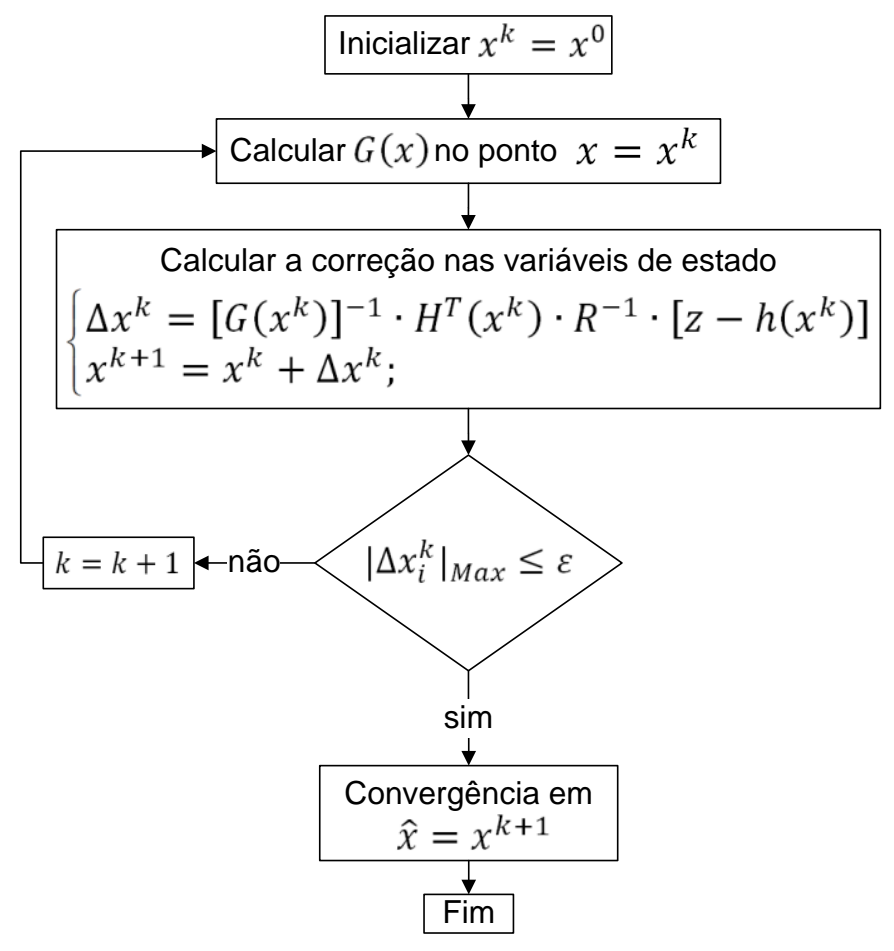

Figura 2.4: Algoritmo do estimador WLS

\subsubsection{Estimador WLAV}

O estimador de estado de Mínimo Valor Absoluto Ponderado (do inglês, Weighted Least Absolute Value - WLAV) foi proposto originalmente por Irving et al. (1978) e desenvolvido por Kotiuga e Vidyasagar (1982) e Falcao e Assis (1988) na tentativa de solução do problema de medições portadoras de erros grosseiros (EG) interativos. Os EG são erros de medidas com magnitude maior que três desvios padrões e serão explanados na sessão 2.2.4, assim como as metodologias de detecção.

Tal estimador mostra-se mais robusto que o WLS na presença de EG simples e múltiplos. Entretanto, o WLAV falha na ocorrência de EG em uma ou mais medidas redundantes, que possuam a característica de serem altamente influentes, atraindo a convergência do processo de estimação de estado. Essas medidas são chamadas de pontos de alavancamento (MONTICELLI, 2000). Em seguida apresenta-se o equacionamento do estimador de estados WLAV. 


\section{- Equacionamento}

O método WLAV é habitualmente formulado do seguinte modo:

$$
\min J(x)=\sum_{i=1}^{m} \sigma_{i}^{-2}\left|e_{i}\right|
$$

Sendo $\sigma_{i}^{-2}$ e $e_{i}$ a variância e o resíduo da medida $i$, respectivamente, e equação (2.7) sujeito a equação (2.1).

Uma aproximação de primeira ordem à equação (2.1) em torno do ponto de funcionamento $x^{0}$, é dada por:

$$
\Delta z=H\left(x^{0}\right) \Delta x+e
$$

em que

$$
\begin{gathered}
\Delta z=z-h\left(x^{0}\right), \\
\Delta x=x-x^{0}, \\
H\left(x^{0}\right)=\frac{\partial h\left(x^{0}\right)}{\partial x}
\end{gathered}
$$

e, portanto

$$
e=\Delta z-H\left(x^{0}\right) \Delta x
$$

A minimização de $J(x)$ é obtida resolvendo uma sequência de problemas de programação linear, através de sucessivas linearizações de $h(x)$, introduzindo variáveis de folga (RAMÍREZ; BAROCIO, 2000). Assim, a formulação final será:

$$
\min J^{k}=\sum_{i=1}^{m} \sigma_{i}\left(s_{2 i-1}-s_{2 i}\right)
$$


sujeito a:

$$
\left[H\left(x^{k}\right) U\right]\left[\begin{array}{c}
\left(\Delta x^{k}\right) \\
s
\end{array}\right]=\left[\Delta z^{k}\right], \quad \operatorname{com}\left(\Delta x^{k}\right), s \geq 0
$$

em que $k$ é o índice da seqüência, $s$ é o vetor das variáveis de folga e tem dimensão $2 m \times 1, e_{i}=s_{2 i-1}-s_{2 i}(i=1, \ldots m) \mathrm{e}$

$$
U=\left[\begin{array}{ccccccc}
1 & -1 & 0 & 0 & \cdots & 0 & 0 \\
0 & 0 & 1 & -1 & \cdots & 0 & 0 \\
0 & 0 & 0 & 0 & \ddots & 0 & 0 \\
0 & 0 & 0 & 0 & \cdots & 1 & -1
\end{array}\right]
$$

\subsubsection{Estimador WLMS}

O estimador de estados fundamentado no método da Mínima Mediana do Resíduo ao Quadrado (do inglês, Weighted Least Median of Squares - (WLMS)) foi proposto inicialmente por Mili, Phaniraj e Rousseeuw (1991), segundo os quais, este foi o primeiro estimador estatisticamente robusto que pode filtrar EG existentes em mais de uma medida.

Esta metodologia requer uma grande quantidade de medições, para que seja mantida a observabilidade do sistema em qualquer subconjunto de medições utilizado no cálculo.

De forma geral, diz-se que um sistema é observável se o conjunto de medidas é suficiente para estimação de todas as suas variáveis de estado. Caso contrário, ele não é observável.

Em seguida apresenta-se o equacionamento e o algoritmo do EE WLMS.

\section{- Equacionamento}

O estimador de estados WLMS sorteia uma série de amostras observáveis com $N$ medidas, dentre as $m$ medidas disponíveis (NANNI, 2009). Para cada amostra sorteada o estimador WLMS calcula as variáveis de estado $x$ e o conjunto de 
resíduos $r$, gerados a partir de $x$, para todas as $m$ medidas. Em seguida esses resíduos elevados ao quadrado e ordenados de forma crescente $\left(r_{w(1)}^{2} \leq \ldots \leq r_{w(m)}^{2}\right)$. Ao final do processo, o estado estimado $\hat{x}$ corresponde àquela amostra que gerou o conjunto de resíduo $r$ que tem o menor resíduo mediano ponderado ao quadrado.

Formalizando este processo, o estimador de estado tem a seguinte formulação:

$$
\underset{x_{i}}{\operatorname{minimizar}} \underset{v}{\operatorname{mediana}}\left(\bar{r}_{w v}^{2}\right)
$$

onde $x_{i}$ é o vetor de variáveis de estados obtidos através das amostras de $N$ medidas, $v$ é a posição mediana dos resíduos ponderados elevados ao quadrado e $r_{w v}^{2}$ é o resíduo mediano ponderado ao quadrado. No caso de regressão linear, a mediana dos resíduos é dada por Mili, Phaniraj e Rousseeuw (1991):

$$
v=\left[\frac{m}{2}\right]+\left[\frac{N+1}{2}\right],
$$

Onde [.] denota a parte inteira do argumento.

A figura (2.5) mostra o algoritmo do estimador WLMS.

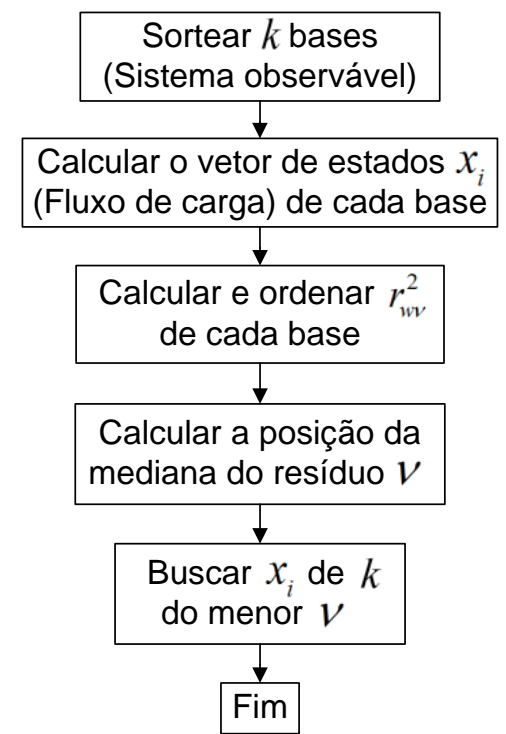

Figura 2.5: Algoritmo do estimador WLMS 
Como é possível identificar, o estimador WLMS requer um elevado custo computacional, que de forma geral, são:

i. O cálculo das variáveis de estado para cada amostra de medidas deve ser precedido de análise de observabilidade;

ii. O cálculo das variáveis de estado para cada uma das amostras selecionadas;

iii. A determinação de todas as amostras de $N$ medidas a serem utilizadas;

iv. A identificação da mínima redundância local, pois, através da mesma será determinado o número máximo de medidas portadoras de EGs que o estimador WLMS conseguirá filtrar.

\subsubsection{Processamento de EG}

Como se pode observar, a estimação de estado é dependente da qualidade das medidas. Assim, se o vetor das medidas estiver afetado por EG, os resultados devolvidos pelo estimador não serão confiáveis. Normalmente a influência desses erros faz-se notar na convergência do algoritmo e na precisão da estimativa obtida.

O principal objetivo da rotina de detecção e identificação de EG é eliminar o efeito destes sobre o vetor de estado estimado. Outros objetivos podem ser considerados, tais como, a possibilidade de fornecer ao operador do sistema a lista de medidas afetadas por eles, permitindo-lhe a localização do equipamento de medida que poderá eventualmente não estar funcionando corretamente.

De acordo com sua ocorrência, os EG podem ser classificados como (ALMEIDA, 2003):

i. Erros simples: Apenas uma medida com erro;

ii. Erros múltiplos: Mais de uma medida com erro;

a) Não interativos: Os erros não interagem e podem ser analisados separadamente. Normalmente esses erros ocorrem em postos eletricamente distantes. 
b) Interativos: Ocorrem em medidas que possuem alta correlação entre si.

i) Não conformativos: Os erros ocorrem em medidas relacionadas, mas os erros não concordam entre si.

ii) Conformativos: Os erros ocorrem em medidas relacionadas e concordam entre si.

Como mostrado anteriormente, o vetor de medidas, equação (2.1), é normalmente modelado da seguinte forma, quando contém erros grosseiros:

$$
z=h(x)+v+g
$$

Em que:

$v$ - representa o ruído de medida normal $(v \cong N(0, R))$

$g$ - representa os erros grosseiros (vetor cujas únicas componentes não nulas são as que simulam os erros grosseiros).

O vetor $v$ é modelado como uma variável aleatória. $O$ valor de $g$ é considerado como uma grandeza determinística de valor desconhecido e pode ser interpretado como um desvio do ruído de medida. Deste modo, os EG afetam apenas o valor médio do ruído de medida, $e$, de um valor igual a $g$, não modificando nem a respectiva densidade de probabilidade que se mantém Gaussiana, nem altera a correspondente matriz covariância $R$, ou seja:

- Na ausência de erros grosseiros

$$
e=v \cong N(0, R)
$$

- Na presença de erros grosseiros

$$
\begin{gathered}
e=v+g \\
e \cong N(v, R)
\end{gathered}
$$

Esta modelagem do erro facilita o estudo das alterações provocadas pela existência de erros grosseiros, no entanto é usual considerar o erro de medida 
como sendo um valor único obtido pela junção de $v$ e $g$, obtendo-se o modelo habitual para o vetor das medidas, com $e=\left[e_{i}\right]$, sendo:

i. $\quad e_{i}=v_{i} \cong N\left(0, \sigma_{i}^{2}\right)$, se a medida $i$ não estiver afetada por erro grosseiro;

ii. $\quad e_{i}$ indeterminado, caso contrário.

O vetor do ruído, $e$, na ausência de EG é modelado da seguinte forma:

$$
e \cong N(0, R)
$$

com:

$$
R=\operatorname{diag}\left(\sigma_{i}^{2}\right) \quad i=1,2,3 \ldots m
$$

A análise desta expressão permite determinar, para uma dada probabilidade $P$, um intervalo $\left[-k \sigma_{i}, k \sigma_{i}\right]$ que tem uma probabilidade $\mathrm{P}$ de incluir o erro de medida $e_{i}$.

Usualmente, o valor atribuído a $k$ é 3, podendo estabelecer-se que existe um erro grosseiro a afetar a medida $i$ sempre que $e_{i}$ estiver fora dos limites do intervalo $\left[-3 \sigma_{i}, 3 \sigma_{i}\right]$ (MILI, CUTSEM; PAVELLA, 1984), pois este desvio em torno da média abrange mais de $99,7 \%$ da área sob curva de Gauss.

A detecção dos EG pode ser feita recorrendo a um dos testes apresentados a seguir.

\subsubsection{Teste do índice do Jacobiano}

Admitindo a hipótese de que o vetor dos erros nas medidas possua distribuição normal, caso não haja nenhuma medida com EG, em Handschin et al. (1975) demonstrou-se que o índice $J(x)$ apresenta uma distribuição Chi-quadrada $\left(\chi^{2}(K)\right)$, com $K=m-N$ graus de liberdade, sendo $N=2 n-1$ o número de variáveis de estado a serem estimadas. A figura 2.6 apresenta uma distribuição Chiquadrada com grau de liberdade igual a 25. 


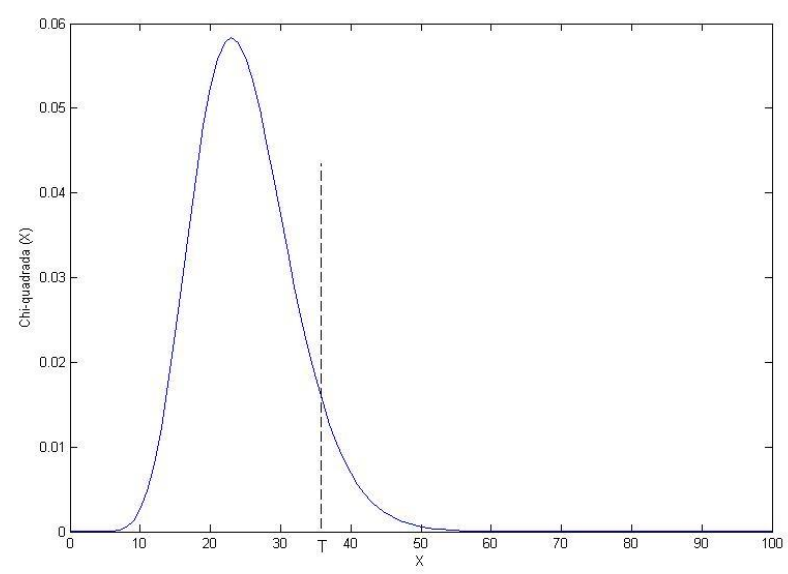

Figura 2.6 - Distribuição Chi-quadrada

Com base nessa distribuição é feito o seguinte teste de hipótese de $J(x)$ :

$$
\operatorname{prob}\left(J(x)>T \mid J(x) \rightarrow \chi^{2}\right)=\alpha
$$

Pela equação (2.24) entende-se que a probabilidade de um resíduo $J(x)$ ser maior que T é $\alpha$. Esta é a probabilidade da ocorrência de falsos alarmes, ou seja, que não há de fato, a presença de EG no sistema de medição.

\subsubsection{Testes dos resíduos normalizados}

Outro caminho para detecção de EG, como desenvolvido por Nanni (2009), é através da análise dos resíduos normalizados. Admitindo a mesma hipótese de que o vetor de erros nas medidas possua distribuição normal, caso não haja medida com EG, o vetor dos resíduos $r$ é calculado para $\hat{x}$, normalizado $\mathrm{e}$ submetido a um teste de validação:

$$
\left.r_{i}^{N}=\left|r_{i}\right| / \sqrt{\Omega_{i i}} \leq \alpha \text { (threshold }\right)
$$


Onde: $\sqrt{\Omega_{i i}}$ é o desvio padrão do i-ésimo componente do vetor dos resíduos; $\Omega$ é a matriz covariância dos resíduos, dada por:

$$
\Omega=R-H(\hat{x}) \cdot\left[H^{T}(\hat{x}) \cdot R^{-1} \cdot H(\hat{x})\right]^{-1} \cdot H^{T}(\hat{x}) ;
$$

Em que $\alpha$ é o limite de identificação e depende de níveis de probabilidade aceitáveis de falso-alarme e de não identificação (usualmente $\alpha=3$ (ABUR; EXPÓSITO, 2004)).

Sendo $r_{i \text { Max }}^{N}$ ○ maior resíduo normalizado, se $r_{i \text { Max }}^{N}>\alpha$, a correspondente medida $i$ é portadora de EG.

$\mathrm{Na}$ ocorrência de EG simples ou quando ocorrem EG múltiplos não iterativos, os métodos para detecção e identificação de EG, utilizando a análise dos resíduos, apresentam um desempenho satisfatório. Entretanto, tal análise falha na presença de EG interativos, porquanto os resíduos são combinações lineares dos erros das medições. Nesta situação, nem sempre as medidas com EG são aquelas com os resíduos normalizados de maior magnitude (MILI, CUTSEM; PAVELLA, 1984).

\subsection{ESTIMADORES HEURÍSTICOS}

$\mathrm{Na}$ tentativa de suprir as deficiências dos métodos estatísticos para estimação de estado, foram explorados métodos heurísticos, que combinam aproximações tradicionais com técnicas de inteligência computacional. Os métodos mais relevantes estão apresentados a seguir.

\subsubsection{Fuzzy}

O emprego da teoria dos conjuntos de natureza Fuzzy, na solução de um problema de estimação de estado, permite que medições com elevado grau de 
imprecisão ou pseudomedidas sejam definidas a partir do conhecimento qualitativo do comportamento do sistema elétrico.

A lógica Fuzzy pode ser definida como uma técnica inteligente com objetivo de modelar o modo aproximado de raciocínio, reproduzindo a habilidade humana de tomar decisões em um ambiente de incerteza e imprecisão, permitindo que informações imprecisas, descritas em linguagem natural, sejam convertidas para um formato numérico.

O estimador de estado em um ambiente Fuzzy integra as aproximações tradicionais de estimação de estado com a representação das informações qualitativas presentes nos sistemas elétricos. Nesta modelagem de estimador de estado, os sistemas elétricos dotados com baixo nível de monitoração, mas com alto grau de informação qualitativa, podem ser modelados e avaliados nos quesitos de segurança da operação de seu sistema.

Saric e Ciric (2003) propõem um estimador de estado e fluxo de potência, integrando lógica Fuzzy para aplicação em sistemas de distribuição de energia. $A$ influência de dados históricos e a participação das categorias de consumidores na curva de carga são descritas, usando notação de álgebra Fuzzy, e com solução inicial de um estimador de carga Fuzzy, que fornece dados de carregamento para um problema de fluxo de potência Fuzzy para redes de distribuição.

Através do fluxo de potência Fuzzy, são calculados os intervalos de confiança para as correntes de carga e fatores de potência, sendo estes, em geral, maiores que os intervalos de confidência obtidos, utilizando medidas reais das correntes nos circuitos. Para a redução da incerteza das correntes de carga nos circuitos, os autores propõem um estimador corretivo Fuzzy para a corrente de carga, sendo que o resultado pode ser Fuzzy, representado por um conjunto de pontos discretos para os diferentes intervalos de confiança, através da regra do centróide (ZIMMERMAN, 1984). O algoritmo utiliza dados históricos disponíveis e medidas em tempo real. Assim a solução Fuzzy proposta pode ser utilizada diretamente, como dado de entrada para outros sistemas de gerenciamento da distribuição, ou indiretamente nos algoritmos estatísticos.

Para exemplificar a utilização do emprego da lógica Fuzzy na estimação de estados, é utilizado o algoritmo híbrido, que combina o estimador WLS com 
conceitos da lógica Fuzzy (FARIDOON; NADIPURAN; HOWARD, 1996), e é baseado na seguinte relação:

$$
\hat{x}(k)_{\text {ótimo }}=\alpha \hat{x}(k)+(1-\alpha) z(k), \quad k=1,2 \ldots, m
$$

O valor ótimo da estimação é controlado pelo parâmetro $\alpha$, que representa o peso dado à estimação de estado obtida através do método WLS. O valor de a pode ser determinado pelas variâncias dos resíduos ou por conhecimento do funcionamento do sistema. Em um sistema em que a relação medida/ruído seja elevada, o valor a atribuir a a deverá ser elevado para que as alterações transitórias do vetor das medidas, $z(k)$, sejam ignoradas.

Neste caso, o estimador Fuzzy será de uma forma geral, preciso e os resíduos serão pequenos. Um valor pequeno a atribuir a a deverá ser escolhido numa situação inversa à descrita anteriormente. Se o sistema variar ao longo do espectro residual, $\alpha$ adapta-se às alterações permitindo a obtenção estimações de estado ótimas. A figura (2.7) apresenta o algoritmo dessa metodologia.

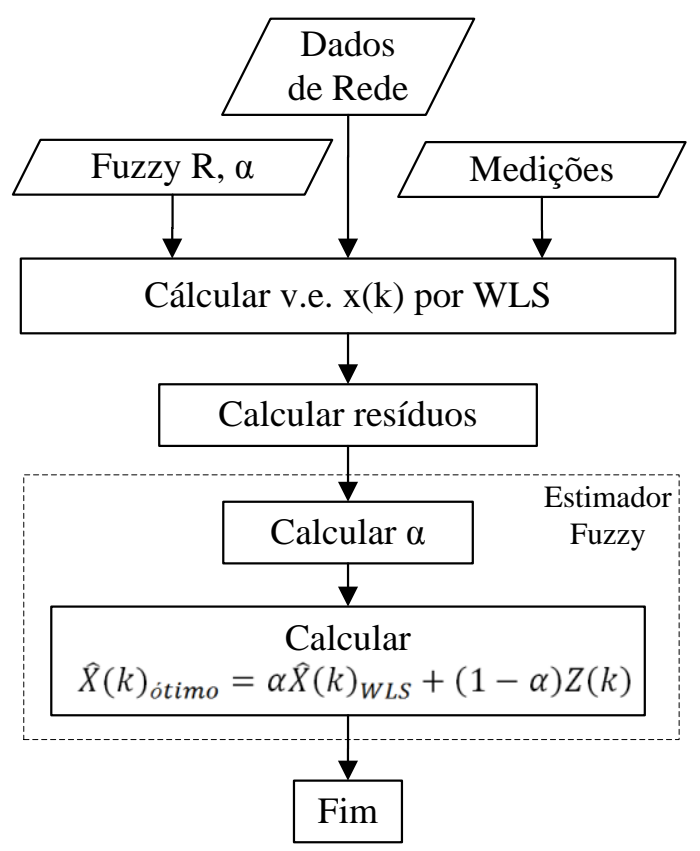

Figura 2.7 - Algoritmo EE híbrido WSL Fuzzy. 


\subsubsection{Otimização por enxame de partícula híbrida}

Os modernos algoritmos heurísticos são considerados ferramentas eficazes para otimização de problemas não lineares, pois não requerem que a função objetivo seja diferenciável e contínua, como é o caso da Otimização por Enxame de Partículas (do inglês Particle Swarm Optimization - (PSO)) explorado por Kennedy e Eberhart (1995), que pode assim, ser aplicada na solução da estimação de estado.

Naka (2001) e Naka, Genji e Fukuyama (2003) propõem uma metodologia de estimação de estados através da otimização por enxame de partícula híbrida (do inglês Hybrid Particle Swarm Optimization - (HPSO)), que leva em consideração as características não lineares dos equipamentos e a pouca redundância de medições do sistema de distribuição. O método considera as atuais medidas realizadas no sistema de distribuição e assume que as magnitudes de tensão e corrente podem ser adquiridas das barras secundárias das subestações. Além disso, pode estimar injeção e geração distribuída em cada nó, minimizando a diferença entre as tensões e correntes medidas e calculadas, como os métodos convencionais.

Os resultados das simulações indicam que este método pode ser mais preciso do que o método original de otimização por enxame de partículas, mesmo com possíveis erros de medidas.

A diferença fundamental entre PSO e HPSO é a aplicação de uma metodologia de seleção natural, que usualmente utilizada por algoritmos evolucionários como, por exemplo, algoritmos genéticos, após a avaliação da posição de cada partícula. Para esclarecer essa metodologia, utiliza-se o algoritmo exposto por Naka, Genji e Fukuyama (2003), que emprega dois princípios sócio-métricos, representando dois tipos de informação importante no processo de decisão. $O$ primeiro princípio, $g_{B}$, conecta conceitualmente todos os membros de uma população entre si. Como consequência, o comportamento de cada partícula é influenciado pelo comportamento de todas as outras partículas. A segunda métrica, $p_{B}$, cria uma vizinhança composta pelo próprio indivíduo e seus vizinhos mais próximos. Ambas as métricas são realizadas por uma função de avaliação, 
$f(p)$, também chamada função objetivo ou de aptidão, que corresponde à da solução ótima do problema. Uma partícula $p_{i}$ se move em uma determinada direção que é função da posição atual da partícula $x_{i}^{k}$, de uma velocidade $v_{i}^{k+1}$, da posição da partícula que levou ao seu melhor desempenho até o momento, $p_{B}$, e do melhor desempenho global do sistema até o momento, $g_{B}$. A velocidade da partícula será dada por:

$$
v_{i}^{k+1}=v_{i}^{k}+\varphi_{1}\left(p_{B}-x_{i}^{k}\right)+\varphi_{2}\left(g_{B}-x_{i}^{k}\right)
$$

Onde: $\varphi_{1}$ e $\varphi_{2}$ são constantes limitadas a um intervalo finito. Uma vez calculada a velocidade da partícula, é aplicada a metodologia de seleção natural, que pode encontrar os pontos mais atrativos e finalmente, a posição da partícula $i$ na próxima iteração é estabelecida como uma influência aditiva da posição antiga e da velocidade calculada, sendo expressa por:

$$
x_{i}^{k+1}=x_{i}^{k}+v_{i}^{k+1}
$$

O resultado é obtido quando o limite de iterações é atingido ou o valor das velocidades das partículas em duas iterações sucessivas estejam próximas de zero.

A figura (2.8) apresenta o algoritmo completo dessa metodologia. 


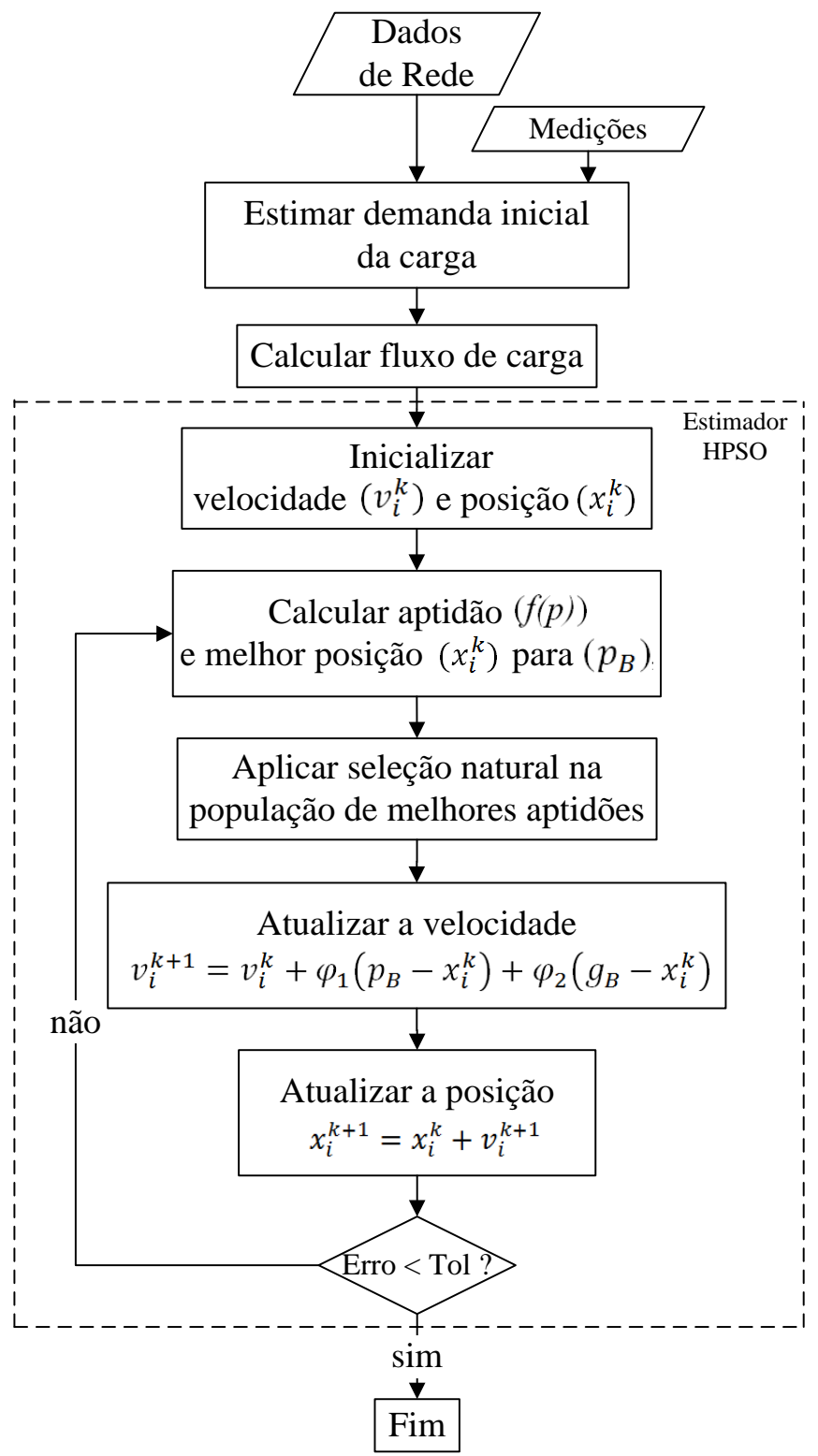

Figura 2.8 - Algoritmo EE HPSO.

Na prática, um limitado número de medições é obtido no sistema de distribuição para o cálculo das tensões e correntes nas barras e trechos. Assim sendo, a solução pode ter uma grande diferença entre o valor real e o calculado onde não exista medição, mesmo encontrando-se a solução ótima mínima. 


\subsubsection{Redes neurais}

Recentemente, vêm sendo desenvolvidos algoritmos baseados em redes neurais para resolução do problema de estimação de estados. Os resultados têm sido satisfatórios, mas a precisão dos mesmos está fortemente ligada à adequação dos conjuntos de treinos e à arquitetura da rede neural selecionada (ABBASY; EL-HASSAWY, 1996).

Aplicação de Redes Neurais Artificiais para determinação do plano de medição, considerando a adição ou eliminação sequencial de medidores, com o objetivo de minimizar o custo total de investimento, sujeito as restrições de precisão nas estimativas das variáveis de estado, é proposto em (ABBASY, 1996). Em (ANTONIO, 2001), é desenvolvido um método para posicionamento de medidores em um sistema elétrico de potência, método este baseado em uma aproximação meta-heurística. Uma simples função objetivo é proposta, levando em conta os custos de instalação e distribuição de aparelhos de medição, com processo de minimização solucionado pela técnica Simulated Annealing. Outras aplicações de algoritmos heurísticos para determinação do plano de medição são propostas em (SHAFIU, 2005) e (RAKPENTHAI, 2005). 


\section{ESTIMAÇÃO DE ESTADO EM SISTEMAS DE DISTRIBUIÇÃO}

A estimação de estado em sistemas de distribuição ganhou força nas últimas décadas, pelo fato de várias empresas estarem em processo de instalação ou planejando a instalação de sistemas de supervisão, controle e aquisição de dados (SCADA), a fim de automatizar os processos de operação das redes de distribuição.

A disponibilidade destas informações obtidas em campo permite obter uma melhor estimativa das condições operativas das redes de distribuição através da aplicação do processo de estimação de estados. Entretanto, ainda existem medições insuficientes nos sistemas de distribuição para o monitoramento satisfatório.

Com o intuito de desenvolver um estimador de estado para as redes de distribuição, muitas pesquisas utilizaram diretamente os métodos destinados a sistemas de transmissão, como por exemplo, Baran e Kelley (1994). Entretanto, algumas características das redes distribuições impossibilitam esta aplicação direta. Conforme apontam Baran (2001) e Wang e Schulz (2004), as principais características que diferem as redes de distribuição das redes de transmissão são:

- Sistema: As redes de distribuição são basicamente compostas por alimentadores com características radiais, mas com ramais que podem ser monofásicos, bifásicos (para atendimento residencial) ou trifásicos (usualmente para atendimento comercial e industrial). Estas redes são usualmente curtas, não-transpostas, com alta relação resistência/reatância e desbalanceadas por natureza.

- Medições: As redes de distribuição possuem poucas medições disponíveis ao longo dos alimentadores. Usualmente, estas medições são de fluxo de potência no início dos alimentadores e de magnitude de corrente e tensão em alguns equipamentos de rede.

Assim sendo, não é possível a aplicação direta das metodologias de estimação de estado desenvolvidas para os sistemas de transmissão nos sistemas de 
distribuição. Para isso, devem ser utilizadas diferentes técnicas que auxiliem os métodos de estimação de estado no cálculo de redes de distribuição.

As principais técnicas empregadas são a introdução da metodologia de estimação no cálculo do fluxo de carga, a utilização da modelagem trifásica da rede e a utilização de diferentes tipos de medições, apresentadas a seguir.

\subsection{FLUXO DE CARGA}

O cálculo de fluxo de carga é utilizado para determinar o valor das variáveis de estado do sistema em função do conjunto de medidas disponíveis. O mais utilizado por estimadores de estado em distribuição é o método de fluxo de carga por varredura (do inglês backward/forward), pois utiliza a natureza radial dos sistemas de distribuição. Este método tem duas versões, a primeira tem uma formulação em temos de corrente (Soma de Correntes) enquanto a segunda utiliza uma formulação baseada em potência (Soma de Potências).

Nesses métodos de cálculo de fluxo de carga, a rede é representada por uma árvore orientada, onde a raiz corresponde à subestação, o tronco ao ramal principal e os ramos estão associados aos ramais secundários que partem do tronco. A varredura reversa (backward) consiste em, partindo-se dos nós extremos e considerando um valor inicial das tensões nodais, calculam-se as correntes ou fluxos nas linhas até o nó raiz. A partir do resultado da injeção de corrente ou de potência do nó raiz e do valor conhecido da tensão nessa barra, procede-se a varredura direta (forward) a qual consiste em recalcular os valores de tensão das barras da rede até os nós extremos. Esse processo é repetido até que os valores de tensão entre duas iterações consecutivas respeitem a tolerância pré-estabelecida.

O uso do fluxo de carga por varredura em estimadores de estado foi inicialmente empregado por Baran e Kelley (1995), que propõem um método baseado no fluxo de carga de cálculo das correntes dos ramais, tratando de sistemas trifásicos fracamente malhados. Posteriormente, Celik e Liu (1999) implementam um método de estimação que usa uma versão modificada do fluxo de carga radial. $O$ 
algoritmo apresenta um modelo de ajuste de injeções, baseado no algoritmo Gauss-Seidel.

Thukaram, Jovitha e Surapong (2000) mostram que a estimação de estado baseado no fluxo de carga necessita de um número adequado de medições, o que foi tratado por Sun e Zhang (2002) com a proposição do método DMPF (do inglês distribution matching power flow), também derivado do fluxo de carga radial.

Já Almeida (2003) propõe um modelo de estimador de estado específico para alimentadores primários, o qual envolve medidas em tempo real e, principalmente, pseudomedidas de injeções de potências, que são construídas a partir de definições de fatores de utilização e de potência, típicos para sistemas de distribuição. $O$ algoritmo do estimador proposto baseia-se no modelo de redução usado pelo fluxo de carga de soma de potências. Almeida constrói o modelo de medição para cada secção do alimentador e estima-a através do método dos mínimos quadrados ponderados.

\subsection{MODELAGEM TRIFÁSICA}

O modelo por fase, empregado na análise de sistemas de potência, tem por hipótese básica que o sistema de transmissão incluindo suas cargas são equilibrados. Esse modelo tem como principal vantagem a simplificação dos cálculos envolvidos e fornece resultados satisfatórios em muitos casos e por essa razão tem sido utilizado em larga escala. Em algumas aplicações, entretanto, os resultados desse modelo podem não ser precisos o bastante, como é o caso de sistemas de distribuição, devido à sua própria natureza de atender às cargas desbalanceadas.

A utilização de uma modelagem trifásica permite um grau de detalhamento superior a dos modelos por fase (monofásica) e, consequentemente, o estado estimado é mais preciso. A modelagem trifásica permite ainda que se determine, por exemplo, as perdas por fase. 
Assim sendo, Baran e Kelley (1994), Hansen e Debs (1995), Li (1996) e Meliopoulos e Zhang (1996) apresentam modelos de estimadores de estados trifásicos, obtendo assim uma estimativa mais precisa.

\subsection{MEDIDAS}

$\mathrm{Na}$ operação convencional de sistemas de distribuição há pouca informação disponível para a monitoração. Geralmente, medidas de tensão e potência entregues ao alimentador e algumas medidas de corrente e fluxo ao longo do alimentador são as únicas medidas em tempo real disponíveis nos centros de operação de distribuição. Sendo assim, o número de medidas pode ser muito pequeno para uma monitoração em tempo real efetiva do sistema. Em muitas situações o sistema pode ser não-observável, ou seja, não é possível estimar os estados com o número disponível de medidas. Para recuperar a observabilidade seria então necessário que novas medidas realizadas ao longo do alimentador fossem incluídas no plano de medição.

Os métodos de estimação de estado aplicados a sistemas de transmissão de energia elétrica usam predominantemente medições de fluxo ativo e reativo nas linhas, injeção de potência ativa e reativa e magnitude de tensão nas barras. Entretanto, devido ao restrito número que as mesmas são encontradas nos sistemas de distribuição, são incorporadas ao estimador de estados medições de corrente, a fim de aumentar a redundância do plano de medição, como mostram Baran e Kelley (1994) e Teng (2000).

As medidas, assim, podem ser divididas em três subtipos:

- Medidas aferidas: São medidas efetuadas ciclicamente em vários pontos da rede e transmitidas ao centro de operação, tais como fluxo ativo e reativo nas linhas, injeção de potência ativa e reativa, magnitude de corrente nas linhas e magnitude de tensão nas barras;

- Pseudomedidas: São valores que à priori, e com alguma precisão, podem ser atribuídas a certas variáveis do sistema. Estes valores poderão ser 
obtidos recorrendo aos registros históricos dessas variáveis ou a previsões de carga;

- Medidas virtuais: Correspondem ao fluxo passante de potência em barramentos sem geração e sem carga. Estas medidas estão disponíveis sem qualquer custo em equipamentos de medida ou transmissão, não estando assim sujeitas aos erros introduzidos por esses equipamentos.

Um grande problema das medidas de magnitude de corrente é o fato destas não informarem a direção do fluxo. Porquanto, Munõs e Expósito (1992) apresentam um estimador de estados com um plano de medição composto apenas de medidas de tensão e corrente que usa restrições de desigualdade para informar o sentido do fluxo ao estimador, contudo este método é aplicável somente para redes de sub-transmissão de tamanhos médios. Mesmo assim, o uso destas medidas pode causar problemas matemáticos e de observabilidade, conforme essa publicação, Abur e Expósito (1997), Teng (2000) e também Jaén e Expósito (2005).

Tendo em vista estes problemas, Geisler (1984) propõe uma formulação para inclusão das medidas de corrente nos ramos baseada no quadrado da magnitude da corrente. Através deste método é possível realizar a estimação de estados partindo de valores iniciais de corrente iguais ou diferentes de zero. Isto é possível caso as medidas de corrente sejam redundantes no plano de medição. Abur e Expósito (1997) mostram que o uso de medidas de magnitude de correntes em certas topologias de redes e configurações de medições levam 0 estimador à múltiplas soluções. Assim é necessário o uso de um estimador de estado acoplado e à redefinição das medidas criticas.

Alternativamente, é possível minimizar o número de medidas necessárias mediante o uso de resultados de previsão da carga em cada ponto do sistema de distribuição. Estas informações podem ser consideradas como pseudomedidas, conforme citado por Baran e Kelley (1994), Li (1996) e Baran (2001). Como estas pseudomedidas não são obtidas em tempo real, seu grau de incerteza representado pela variância, é considerado maior do que o das medidas obtidas em tempo real. 
Dependendo de como são geradas essas pseudomedidas podem não ser suficientemente precisas para a estimação de estado, como verificado por $\mathrm{Li}$ (1996) e por Baran, Zhu, e Kelley (1996). Portanto, quanto maior o número de medidas em tempo real disponíveis, maior será a confiabilidade e a precisão dos resultados obtidos pelo estimador.

A modelagem de carga proposta por Ghosh, Lubkeman e Jones (1997) e posteriormente por Lubkeman et al. (2000) utiliza informações de consumo diário (curvas de consumo) e características dos consumidores, aumentado as informações de demanda para um estimador de estado estatístico. 


\section{METODOLOGIA PROPOSTA}

Considerando a atual realidade do setor de distribuição de energia, que busca a redução de gastos aliada a melhora do atendimento aos consumidores, iniciou-se o processo de instalação de sistemas de supervisão, controle e aquisição de dados das redes de distribuição.

Neste viés, um dos principais objetivos das concessionárias de distribuição é a redução das perdas, tanto pelo seu crescimento nos últimos anos quanto pelo seu impacto no sistema elétrico brasileiro.

Aliando-se isso ao crescente volume de informação obtida da rede, a estimação de estados torna-se uma eficaz ferramenta para esta tarefa.

Contudo, para se realizar a estimação de estados em sistemas de distribuição, algumas adaptações são necessárias com relação ao estimador utilizado nos sistemas de transmissão, devido às diferenças de sistema e da quantidade de medições disponíveis.

Devido as suas propriedades estatísticas, o método WLS possibilita o cálculo da estimativa do estado dos sistemas de distribuição, destacando-se pelo baixo custo computacional, quando considerada a grande dimensão das redes (grande número de trechos e barras) que eleva a ordem de grandeza do problema.

As diferenças de sistema, isto é, a necessidade de uma modelagem trifásica, é tratada através da modificação das variáveis de estado, que desacopla o problema de estimação em 3 subproblemas, um para cada fase, como proposto por Baran e Kelley (1995), auxiliado pela inserção do cálculo em um fluxo de carga radial.

Entretanto, mesmo com uma modelagem matemática que atenda os requisitos das redes de distribuição, uma das maiores dificuldade para a utilização dos métodos de estimação de estado em redes de distribuição é a obtenção de um número suficiente de medições para o cálculo do estado estimado, ou seja, que o sistema seja observável, já que existe um pequeno número de medições transmitidas remotamente disponíveis nos centros de operação.

Para isso é adotado um método que calcula a demanda inicial das cargas ao longo do dia, que então é utilizada como pseudomedição, aumentando assim a 
quantidade de informação do sistema, e por consequência tornando possível o adequado processo de estimação de estado.

Serão apresentados então, no decorrer deste capítulo, a metodologia do estimador de estado WLS, baseada no cálculo das correntes nos trechos do sistema como variável de estado e as técnicas associadas a ela, desenvolvidos especificamente para a estimação de estado em redes de distribuição que viabilizam o cálculo.

\subsection{ESTIMADOR PARA REDE MT}

O método de estimação de estado proposto é desenvolvido em função do cálculo da corrente nos trechos da rede, e assim como nos métodos de estimação de estado tradicionais, este estimador é desenvolvido baseado no método WLS.

Entretanto, em vez de utilizar a tensão complexa nas barras como variáveis de estado do sistema, o método proposto utiliza as correntes complexas nos trechos (BARAN; MCDERMOTT, 2009), isto é:

$$
x_{i}=\left[I_{r i}, I_{x i}\right] \text {, }
$$

Onde $x_{i}$ é a variável de estado, $I_{r i}$ é a parte real da corrente no trecho $i$ e $I_{x i}$ é a parte imaginária.

Definidas as novas variáveis de estado, pode-se calcular a estimativa das correntes nas fases dos trechos do sistema. Entretanto, a função objetivo apresentada na equação (2.4), pode ser resolvida separadamente para cada fase, isto porque as equações que relacionam as medições com os estados do sistema $h(x)$ não possuem mais acoplamento entre as fases. Desta forma, pode-se decompor o processo de estimação em três subproblemas.

$$
\min J(x)=\frac{1}{2}[z-h(x)]^{T} R_{z}^{-1}[z-h(x)]
$$


Onde $R_{Z}^{-1}$ é a matriz de ponderação das medidas, $z-h(x)$ é o de vetor de resíduos e $J(x)$ é o índice a ser minimizado.

Desta forma, o método proposto soluciona o problema WLS em cada fase separadamente, a fim de obter o ponto de operação do sistema de distribuição. Ou seja, soluciona iterativamente o sistema de equações como apresentado na seção 2.21 .

A única diferença entre o estimador de estado tradicional, que utiliza as tensões como variáveis de estado, e o aplicado a redes de distribuição é o tipo de variáveis que as funções de medições estão associadas. Deve-se então, desenvolver estas equações de forma a satisfazer a equação (2.1) e definir o modelo matemático de representação da rede, utilizado no processo de estimação de estado.

\section{- Modelo de representação da rede}

Geralmente, o tronco dos alimentadores é trifásico, entretanto, alguns ramais podem ser bifásicos ou monofásicos, os trechos podem ser curtos e não transpostos, as cargas podem ser trifásicas, bifásicas ou monofásicas. Assim é necessária a utilização do modelo trifásico de rede.

No cálculo das matrizes de impedâncias serão adotadas as seguintes hipóteses:

- Circuito, com até 3 condutores de fase $(A, B, C)$ e neutro $(N)$, sem transposição;

- Condutores singelos;

- Neutro aterrado no início do circuito.

Para o cálculo das impedâncias próprias e mútuas, é utilizado o método das imagens. Os seguintes dados são necessários:

- Configuração dos condutores no poste (altura de cada condutor em relação ao solo e distâncias entre os condutores $A, B, C, N$, em m);

- Resistência ôhmica de cada condutor, para uma temperatura de referência, em ohm/km;

- Raio médio geométrico (RMG) de cada condutor, em m;

- Comprimento do trecho, em m. 
Desta forma, um trecho de rede é representado pela seguinte equação matricial:

$$
\left[\begin{array}{c}
\Delta V_{A} \\
\Delta V_{B} \\
\Delta V_{C} \\
\Delta V_{N}
\end{array}\right]=\left[\begin{array}{llll}
Z_{A A} & Z_{A B} & Z_{A C} & Z_{A N} \\
Z_{B A} & Z_{B B} & Z_{B C} & Z_{B N} \\
Z_{C A} & Z_{C B} & Z_{C C} & Z_{C N} \\
Z_{N A} & Z_{N B} & Z_{N C} & Z_{N N}
\end{array}\right]\left[\begin{array}{c}
I_{A} \\
I_{B} \\
I_{C} \\
I_{N}
\end{array}\right]
$$

Onde $\Delta \mathrm{V}$ é a queda de tensão em um trecho, $\mathrm{Z}$ é a matriz de impedância e I é a corrente que percorre o trecho.

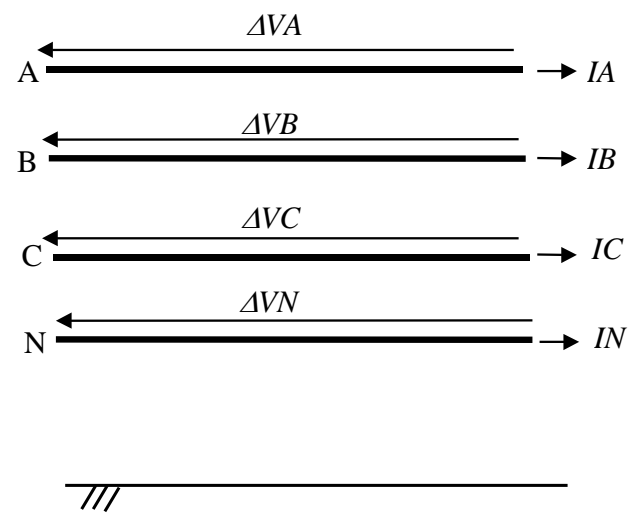

Figura 4.1 - Trecho de rede.

A equação acima relaciona as quedas de tensão dos elementos de fase e de neutro para um dado trecho da rede, em função das correntes correspondentes. Pela utilização deste equacionamento, é possível avaliar o impacto de redes assimétricas e com cargas não trifásicas desequilibradas.

O cálculo da capacitância de linha é realizado de forma simplificada, e considerando dados do arranjo de cada trecho, de acordo com o arranjo da rede. Desta forma, a capacitância é então, dependendo do nível de tensão de cada trecho de rede, convertida em potência capacitiva concentrada nas extremidades dos trechos.

Os demais equipamentos da rede também seguem a modelagem trifásica, possibilitando o cálculo de fluxo de carga trifásico. 


\subsubsection{Redução topológica}

Como apresentado anteriormente, o estimador de estados proposto é desenvolvido em função do cálculo da corrente nos trechos da rede, assim sendo, para cada trecho de rede existem duas variáveis associadas, uma para parte real e uma para a parte imaginária da corrente. Levando-se em consideração que as redes de distribuição têm frequentemente um número muito grande de barras, e assim consequentemente, um número muito grande de trechos, o problema de torna-se muito grande. Assim sendo, para reduzir o número de trechos da rede será utilizado o artifício de redução topológica.

A redução topológica retira da rede as barras que só tem função de ligação entre trechos, e agrega a impedância dos trechos adjacentes.

As barras que não são retiradas da rede são aquelas nas quais há derivação de ramais, ou com cargas ou injeções de potência ou que haja mudança de cabos entre trechos subsequentes.

Para exemplificar a metodologia proposta, seja utilizado como exemplo o sistema apresentado nas figuras 4.2 e 4.3. Nota-se que algumas barras foram excluídas da rede, diminuindo assim o número total de trechos.

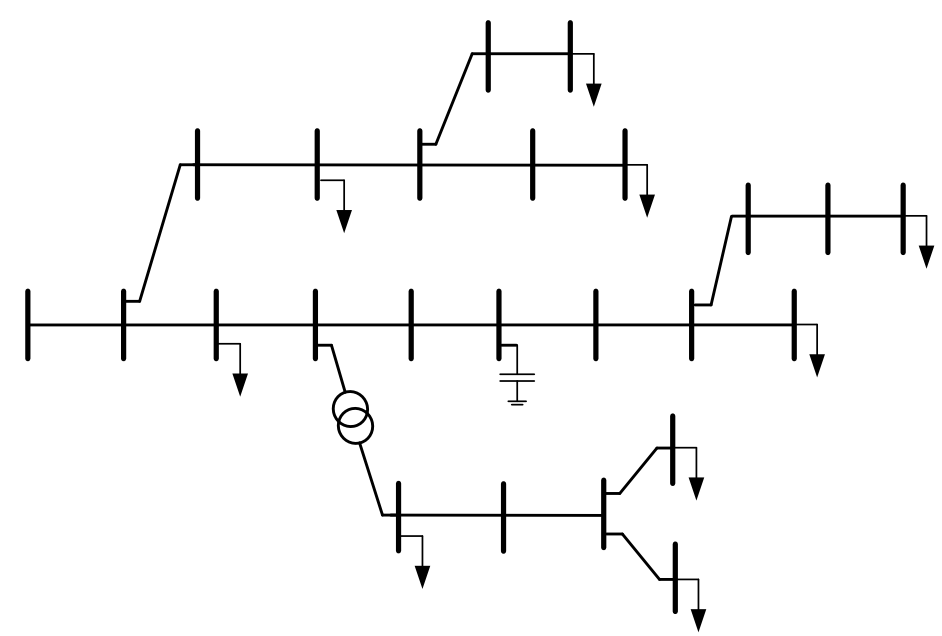

Figura 4.2 - Rede completa. 


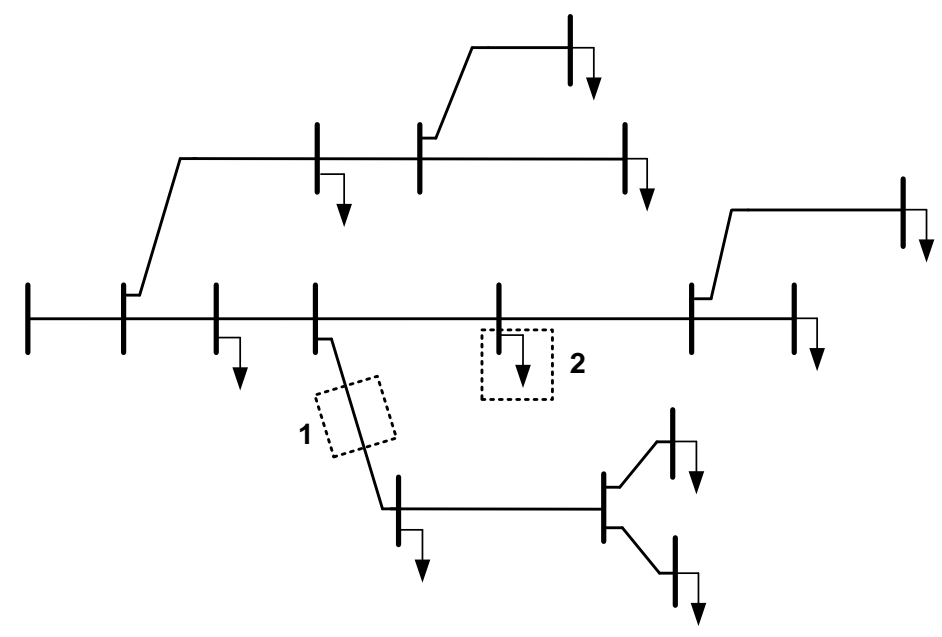

Figura 4.3 - Rede reduzida.

Além da exclusão de barras de passagem da rede, os equipamentos de rede também são suprimidos, como mostrado pelas indicações 1 e 2 da figura 4.3 que representam um transformador de linha e um banco de capacitor, respectivamente.

Após o cálculo da estimação, é aplicada na rede uma interpolação entre as tensões das barras iniciais e finais de cada trecho simplificado, encontrando-se assim o valor das tensões da rede original e para equipamentos, as alterações necessárias nas tensões e correntes são aplicadas em cada tipo de equipamento.

\subsubsection{Modelagem da carga e medições}

Além das medições comumente utilizadas pelos métodos de estimação de estado como medições de fluxo ativo e reativo nas linhas, injeção de potência ativa e reativa, magnitude de corrente nas linhas e magnitude de tensão nas barras e, como a proposta deste trabalho não é a aplicação do estimador de estado em tempo real, é possível a utilização de pseudomedições.

Pseudomedições são valores definidos para certas medidas com o intuito de tornar observável uma região do sistema. Esses valores são definidos a partir de uma base histórica de dados, faturamento dos clientes associados às curvas típicas de carga, para determinar a curva de demanda dos clientes. Devido o fato 
das pseudomedições não possuírem uma precisão elevada, os valores referentes a estas na matriz de ponderação devem ser pequenos.

As curvas típicas de carga são obtidas através de uma campanha de medições, onde são obtidas as curvas de demanda de uma amostra representativa de consumidores. Em seguida, procede-se uma análise estatística para agrupar as curvas de carga similares (média e desvio padrão) dentro de tipos representativos por faixa de consumo ou por tipo de atividade, obtendo-se então as curvas típicas de carga.

Representando cada categoria por mais de uma curva típica, obtêm-se curvas com desvios menores e que mapeiam os diferentes comportamentos e/ou características de carga dentro da categoria.

O método utilizado no processo de obtenção das curvas típicas de carga é chamado Método das Nuvens Dinâmicas (ALDENDERFER; BLASHFIELD, 1984) e é utilizado com o objetivo de identificar grupos de indivíduos (curvas de carga) com comportamentos semelhantes dentro de uma categoria de consumo.

O Método das Nuvens Dinâmicas utiliza a análise de clusters chamada k-Médias (ALDENDERFER; BLASHFIELD, 1984). Basicamente, o Método das Nuvens Dinâmicas consiste em aplicar a análise k-Médias inúmero de vezes até que seja reduzida a dependência que o k-Médias tem com relação ao sorteio inicial.

Assim, o método inicia definindo-se $k$ núcleos com $q$ indivíduos cada, cujo "centro de gravidade" será tomado como referência para o cálculo das distâncias dos indivíduos aos núcleos, obtendo-se uma partição e agrupando-se os indivíduos em torno desses núcleos. Após a classificação dos indivíduos, os núcleos são recalculados e o processo se repete até que os novos núcleos sofram uma variação em relação aos núcleos da iteração anterior menor que uma tolerância especificada. No início do processo, o sistema de núcleos é constituído por indivíduos sorteados aleatoriamente, após a convergência do processo, podem-se obter até $\mathrm{k}$ agrupamentos.

Esse método identifica, dentro da população, os "grupos de indivíduos" semelhantes entre si.

O Método das Nuvens Dinâmicas é muito utilizado nos estudos de revisão tarifária no processo de caracterização da carga. É comum obter mais de uma curva para cada categoria de consumo. Assim, cada curva possui uma representatividade ou 
participação de mercado, que é obtida pelo percentual de energia total da categoria que a respectiva curva representa. Tomando-se as curvas de uma mesma categoria, a soma de suas participações de mercado deve ser igual a $100 \%$.

Abaixo se podem verificar as curvas de cargas obtidas para consumidores residenciais (OLIVEIRA; MÉFFE; CAMPOS, 2005).

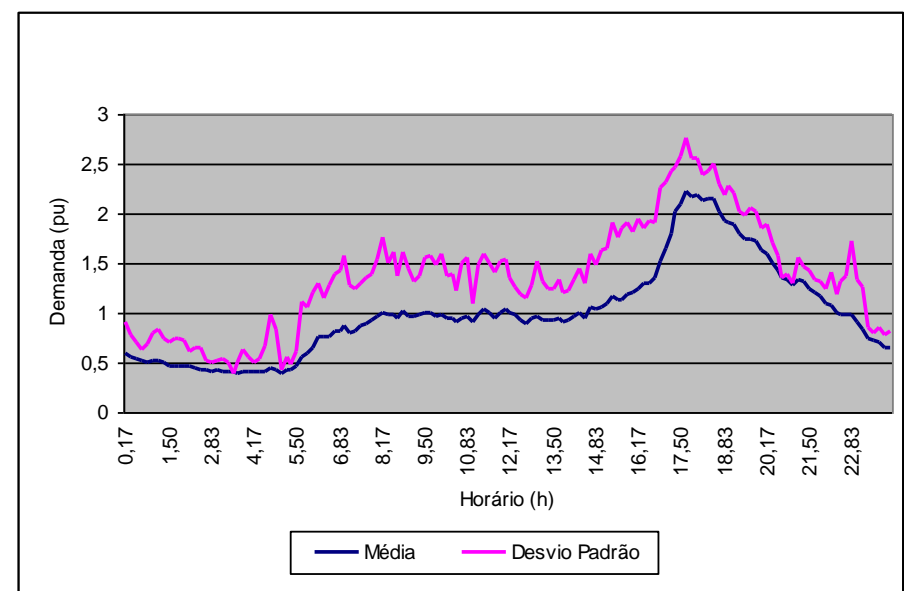

Figura 4.4 - Consumidor residencial - Curva 1

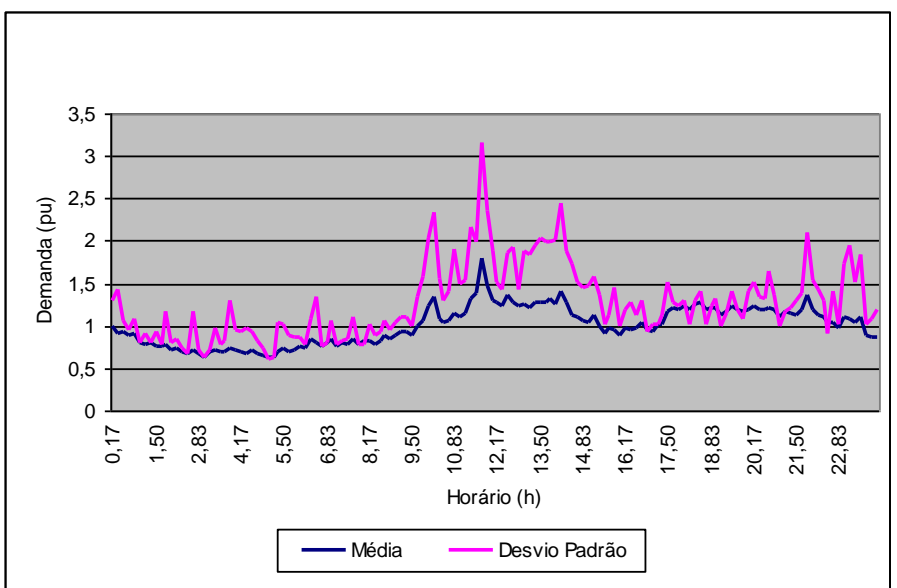

Figura 4.5 - Consumidor residencial - Curva 2

Os valores médios de consumo e de desvio padrão nas curvas de carga típicas estão em pu da potência média mensal.

Após a obtenção de um conjunto de curvas típicas de carga, pode-se associar a cada consumidor uma das curvas em função de seu consumo mensal (energia faturada) em kWh e/ou atividade desenvolvida. Então, determina-se a potência média mensal $\mathrm{P}$ em kW através da equação (4.4). 


$$
P=\frac{E}{N_{h}}[\mathrm{~kW}]
$$

Onde $N_{h}$ é o número de horas em um mês [h].

Uma vez determinada a potência média em kW, basta multiplicá-la pela curva de carga típica, que está em pu, para obter a curva de carga em kW do consumidor, fornecendo assim a demanda instantânea em kW para cada ponto da curva média diária. Este processo deve ser repetido a cada consumidor.

A partir da determinação de curvas de carga em cada consumidor, e em potências por fase, podem ser agregadas as curvas para a determinação de potências no transformador de distribuição.

No caso de a curva de carga possuir apenas o valor da potência ativa, deve-se ainda estimar um fator de potência para o cálculo da potência reativa da carga, sendo este normalmente considerado constante ao longo do dia.

Contudo, vale ressaltar que, quanto maior o número de medidas em tempo real disponíveis, maior será a confiabilidade e a precisão dos resultados obtidos pelo estimador, e com a atual realidade da incorporação da Smart Grid nos sistemas, há a viabilização e aplicabilidade efetiva da estimação de estados.

Outra técnica utilizada para se manter a observabilidade do sistema foi a introdução de medições virtuais de injeção de potência, pois nos casos em que uma barra não tenha medição ou carga, sua modelagem introduz valores nulos nas matrizes, causando problemas de inversão.

A figura 4.6 exemplifica a obtenção de medidas virtuais.

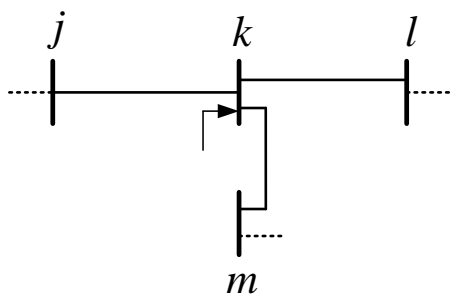

Figura 4.6: Representação de medição de injeção de potência

Como é possível observar, as medidas virtuais de injeção de potência são aplicadas às barras sem geração e sem carga, representada pela barra $k$, ou seja, 
barras denominadas de nós ou de passagem, em redes radiais, como apresentado nas figuras 4.2 e 4.3 .

Como a proposta deste trabalho não é a aplicação on-line da EE, a simultaneidade da hora de cálculo das medições importadas fica em aberto, dependendo do estudo que se queira realizar. Pode-se estabelecer o dia e hora de cálculo ou utilizar um valor médio que represente um período de estudo, como por exemplo, a média mensal.

Após a inicialização das variáveis de estado, através do fluxo de carga, têm-se os valores iniciais de fluxo de potência em cada trecho. A formulação será apresentada na seção seguinte.

\subsubsection{Variância de medições}

Conforme já se mencionou, a estimação de estado pelo método dos mínimos quadrados ponderados requer cálculo de variâncias dos erros das grandezas medidas e pseudomedidas do conjunto de medição, para construção da matriz de covariância, $R$.

Para isso, todas as diferentes fontes de erro existentes deveriam ser modeladas e assim, obtida a composição das correspondentes distribuições de probabilidade. Como esta é uma modelagem de enorme dificuldade (PAPOULIS, 1969), introduzem-se algumas hipóteses simplificativas.

Assim, como demonstrado na seção 2.2.3, considera-se que a generalidade das componentes do erro total em análise, pode ser modelada como variáveis aleatórias gaussianas independentes, assim o erro total será também uma variável aleatória gaussiana.

$\mathrm{Na}$ prática, pequenas variações dos valores atribuídos a $\sigma_{i}$, não afetam significativamente a qualidade da estimativa obtida (DOPAZO; KLITIN; SLYCK, 1976), no entanto, deve salientar-se que:

- Se o desvio padrão atribuído for nitidamente inferior ao valor verdadeiro, então é atribuído um peso excessivamente elevado à medida correspondente, o que resulta numa diminuição da precisão da estimativa 
obtida. Além disso, na fase de detecção de erros grosseiros essa medida poderá ser indevidamente selecionada.

- Se o desvio padrão atribuído a um erro de medida for nitidamente superior ao respectivo valor verdadeiro, a medida correspondente é rejeitada "numericamente", podendo por isso diminuir a precisão da estimação obtida;

O método de cálculo de variâncias (ALMEIDA, 2003), que leva em conta a propagação de incertezas, é apresentado a seguir.

\subsubsection{Variâncias de grandezas medidas}

Dentre os diversos tipos de erros sistemáticos, há o erro sistemático instrumental, que resulta da calibração do instrumento de medição (VUOLO, 1992). Esse erro é indicado pelo fabricante no painel do próprio instrumento ou no manual de utilização.

Normalmente, o fabricante define um limite de erro para a escala do instrumento, o qual é conhecido como classe de exatidão.

Segundo Vuolo (1992), não existe nenhum método padrão bem estabelecido para determinação da variância sistemática, $\sigma_{r}^{2}$, correspondente aos erros sistemáticos. Assim sendo, podem ser utilizados valores padrões de classe de exatidão para os medidores de acordo com as normas da ANSI C57.13 (2008), ABNT NBR 6855 (2009) e o PRODIST Módulo 5, sendo estas de 0,3\% e 0,6\%. Os cálculos realizados neste trabalham utilizam a classe de exatidão padrão de $0,3 \%$. 
4.1.3.2 Variâncias de grandezas pseudomedidas e virtuais

As pseudomedidas adotadas neste trabalho são determinadas a partir de grandezas estimadas ou calculadas, como apresentado anteriormente, ocorrendo então, uma propagação de incertezas sobre estes valores. Desta maneira, através de aproximações de propagação destas incertezas, pode-se calcular a variância associada às pseudomedidas. Como mostra Vuolo (1992), a propagação de incertezas sobre grandezas dependentes de outras, na forma $w=f(x, y)$, é, em uma primeira aproximação, dada por:

$$
\sigma_{w}^{2}=\left(\frac{\partial w}{\partial x}\right)^{2} \sigma_{x}^{2}+\left(\frac{\partial w}{\partial y}\right)^{2} \sigma_{y}^{2}
$$

Desde que os erros de $x$ e $y$ sejam considerados completamente independentes. Em (4.5), $\sigma_{w}^{2}$ é a variância da grandeza genérica $w$ e $\sigma_{x}^{2}$ e $\sigma_{y}^{2}$ são as variâncias de $x$ e $y$, respectivamente.

Aplicando a equação (4.5) para calcular a variância de uma grandeza que resulta do produto de outras, tal como $w=x \cdot y$, obtém-se:

$$
\sigma_{\mathrm{w}}^{2}=\mathrm{y}^{2} \sigma_{\mathrm{x}}^{2}+\mathrm{x}^{2} \sigma_{\mathrm{y}}^{2}
$$

No caso de grandeza que resulte da somatória de outras, tal como $w=x \pm y$, obtém-se:

$$
\sigma_{\mathrm{w}}^{2}=\sigma_{\mathrm{x}}^{2}+\sigma_{\mathrm{y}}^{2}
$$

Já no caso da multiplicação da variância por uma constante, $c$, tal como $w=x \cdot c$, obtém-se:

$$
\sigma_{\mathrm{w}}^{2}=\sigma_{\mathrm{x}}^{2} \cdot \mathrm{c}^{2}
$$


Assim, com a obtenção das pseudomedições, como apresentado anteriormente, é possível calcular seus valores de variância, $\sigma_{\mathrm{P}}^{2}$, através dos desvios padrões das curvas típicas, $\sigma_{\mathrm{Ct}}$, de cada consumidor, aplicando a equação (4.8), sendo a constante multiplicadora o valor de potência média mensal calculada pela equação (4.4), então:

$$
\sigma_{\mathrm{P}}^{2}=\sigma_{\mathrm{Ct}}^{2} \cdot \mathrm{P}^{2}
$$

Para se calcular o valor de variância nos transformadores de distribuição $\left(\sigma_{\mathrm{P}, \text { Trafo }}^{2}\right)$, utiliza-se a equação (4.7), para todos consumidores associados ao transformador, então:

$$
\sigma_{\mathrm{P}, \text { Trafo }}^{2}=\sum_{\mathrm{i}=1}^{\mathrm{n}_{\text {cons }}} \sigma_{\mathrm{P}_{\mathrm{i}}}^{2} \cdot \mathrm{P}_{\mathrm{i}}^{2}, \quad \mathrm{i}=1,2, \ldots, \mathrm{n}_{\text {cons }}
$$

Já para medidas virtuais, como seus valores são adotados como sendo isentos de erros, o valor de suas variâncias é unitário, para se evitar problemas de inversão matricial.

\subsubsection{Equacionamento das funções de medição}

Uma das vantagens do estimador de estado utilizando as correntes nos trechos como variáveis de estado é que as funções de medição são simplificadas no caso de medições de corrente e fluxo de potência.

Entretanto, para utilizar as correntes nos trechos como variáveis de estado, é necessário primeiramente determinar as funções de medição para cada tipo de medição existente nas redes de distribuição.

Os principais tipos de medições encontradas nas redes de distribuição são de fluxo e injeção de potência, do módulo da corrente passante em um equipamento, e do módulo da tensão em um ponto do sistema. A seguir serão desenvolvidos os 
modelos matemáticos para representar estes tipos de medições no estimador de estado proposto.

- Medição de fluxo de potência em ramo

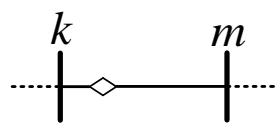

Figura 4.7: Representação de medição em trecho

Seja uma medição de fluxo de potência em um equipamento, representada pela figura 4.7, da barra $k$ a barra $m$, e esta medição está próxima à barra $k$. Para uma determinada fase a tem-se a seguinte medição:

$$
\dot{S}_{k m}^{a}=P_{k m}^{a}+j Q_{k m}^{a}
$$

Onde $\dot{S}_{k m}^{a}$ é a potência complexa medida na fase $a, P_{k m}^{a}$ é a parte ativa e $Q_{k m}^{a}$ é a parte reativa desta medição.

Para esta medição ser convertida em função da variável de estado, tem-se que:

$$
\dot{S}_{k m}^{a}=\left(V_{r, k}^{a}+j V_{x, k}^{a}\right)\left(I_{r, k m}^{a}+j I_{x, k m}^{a}\right)^{*},
$$

Onde $V_{r, k}^{a}$ é a parte real da tensão complexa na fase a da barra $k, V_{x, k}^{a}$ é a parte imaginária da tensão complexa da mesma barra, $I_{r, k m}^{a}$ é a parte real da corrente complexa da barra $k$ para a barra $m$ pela fase a e $I_{x, k m}^{a}$ é a parte imaginária desta corrente.

Rearranjando esta equação e isolando seus termos obtêm-se as funções de medições utilizadas no estimador de estado. Portanto, temos que:

$$
\begin{aligned}
& P_{k m}^{a}=V_{r, k}^{a} I_{r, k m}^{a}+V_{x, k}^{a} I_{x, k m}^{a} \\
& Q_{k m}^{a}=-V_{r, k}^{a} I_{x, k m}^{a}+V_{x, k}^{a} I_{r, k m}^{a},
\end{aligned}
$$


Para se determinar as equações de entrada da matriz Jacobiana é necessário conhecer as derivadas parciais destas equações em função das variáveis de estado, tratadas em uma fase qualquer $f$ de um trecho qualquer st. Desta forma, têm-se as seguintes equações para medições de fluxo de potência.

a) Quando a medição e a variável de estado estão no mesmo trecho, $k m=s t$, e na mesma fase, $a=f$.

$$
\begin{array}{ll}
\frac{\partial P_{k m}^{a}}{\partial I_{r, s t}^{f}}=V_{r, k}^{a} & \frac{\partial Q_{k m}^{a}}{\partial I_{r, s t}^{f}}=V_{x, k}^{a} \\
\frac{\partial P_{k m}^{a}}{\partial I_{x, s t}^{f}}=V_{x, k}^{a} & \frac{\partial Q_{k m}^{a}}{\partial I_{x, s t}^{f}}=-V_{r, k}^{a},
\end{array},
$$

b) Quando a medição e a variável de estado não estiverem no mesmo trecho ou nem na mesma fase, todas as outras derivadas parciais referentes a uma medição de fluxo de potência serão nulas.

\section{- Medição de módulo de corrente}

A medição de módulo de corrente é uma medição comum em sistemas de distribuição, sendo necessário desenvolver uma formulação que torne possível utilizá-la no processo de estimação de estado.

Seja uma medição de módulo de corrente em um equipamento da rede de distribuição, também representada pela figura 4.7, da barra $k$ para barra $m$, em na fase a. A equação que relaciona esta medição com as variáveis de estado é apresentada na equação abaixo.

$$
\left|\dot{I}_{k m}^{a}\right|=\sqrt{I_{r, k m}^{a}{ }^{2}+I_{x, k m}^{a}{ }^{2}}
$$

As derivadas parciais desta equação são definidas como:

a) Quando a medição e a variável de estado estão no mesmo trecho, $k m=s t$, e na mesma fase, $a=f$. 


$$
\begin{aligned}
& \frac{\partial\left|\dot{I}_{k m}^{a}\right|}{\partial \boldsymbol{I}_{r, s t}^{f}}=\cos (\alpha) \\
& \frac{\partial\left|\dot{I}_{k m}^{a}\right|}{\partial \boldsymbol{I}_{x, s t}^{f}}=\sin (\alpha)
\end{aligned}
$$

Onde,

$$
\alpha=\tan ^{-1}\left(\frac{I_{x, k m}^{a}}{I_{r, k m}^{a}}\right)
$$

b) Quando a medição e a variável de estado não estiverem no mesmo trecho e nem na mesma fase, todas as outras derivadas parciais referentes a esta medição de fluxo de potência serão nulas.

\section{- Medição de injeção de potência}

São assumidos como medição de injeção de potência, e por conseqüência, tratadas conforme a metodologia que será apresentada a seguir: as medições de injeção de potência propriamente ditas, que são realizadas em campo, as medições de injeção virtuais aplicadas a barras sem nenhum tipo de medição e a demanda pré-calculada de um consumidor através dos dados históricos e de curvas típicas.

Suponha uma medição de injeção de potência em uma barra $k$, representada pela figura 4.6, e que existem $n$ barras que se conectam a esta barra. As correntes fluem no sentido que vai da barra $k$ para as suas barras adjacentes.

Portanto, a potência injetada na fase $a$ da barra $k$ pode ser calculada conforme $a$ seguinte equação.

$$
\dot{S}_{k}^{a}=\dot{V}_{k}^{a} \sum_{m \Omega k} \dot{I}_{k m}^{a^{*}}
$$

Onde $\dot{V}_{k}^{a}$ é a tensão complexa na fase a da barra $k, \dot{I}_{k m}^{a^{*}}$ é a corrente complexa conjugada na fase a da barra $k$ até a barra $m$ qualquer e $m \Omega k$ representa todas 
as barras adjacentes a barra $k$. Expandindo a equação acima na forma polinomial têm-se:

$$
\dot{S}_{k m}^{a}=\left(V_{r, k}^{a}+j V_{x, k}^{a}\right) \sum_{m \Omega k}\left(I_{r, k m}^{a}+j I_{x, k m}^{a}\right)^{*} .
$$

Logo, as funções que relacionam uma medição de injeção com as variáveis de estado são definidas conforme abaixo.

$$
\begin{aligned}
& P_{k}^{a}=V_{r, k}^{a} \sum_{m \Omega k} I_{r, k m}^{a}+V_{x, k}^{a} \sum_{m \Omega k} I_{x, k m}^{a} \\
& Q_{k}^{a}=-V_{r, k}^{a} \sum_{m \Omega k} I_{x, k m}^{a}+V_{x, k}^{a} \sum_{m \Omega k} I_{r, k m}^{a},
\end{aligned}
$$

As derivadas parciais que formarão a matriz Jacobiana são obtidas da seguinte forma:

a) Quando a variável de estado é de um segmento de rede que está conectado à barra $k$ (um trecho $k m$ qualquer onde $m$ é uma barra adjacente à barra $k$ ) e as duas estão na mesma fase, $a=f$, então se tem as seguintes derivadas parciais.

$$
\begin{array}{lll}
\frac{\partial P_{k}^{a}}{\partial \boldsymbol{I}_{r, k m}^{f}}=V_{r, k}^{a} & \frac{\partial Q_{k}^{a}}{\partial \boldsymbol{I}_{r, k m}^{f}}=V_{x, k}^{a} & \\
\frac{\partial P_{k}^{a}}{\partial \boldsymbol{I}_{x, k m}^{f}}=V_{x, k}^{a} & \frac{\partial Q_{k}^{a}}{\partial \boldsymbol{I}_{x, k m}^{f}}=-V_{r, k}^{a} &
\end{array} \quad \forall m \in m \Omega k
$$

b) Quando a variável de estado é de um segmento de rede que não está conectado à barra $k$ ou as duas não estão em uma mesma fase, então se tem que todas as outras derivadas parciais são nulas.

\section{- Medição de módulo de tensão}

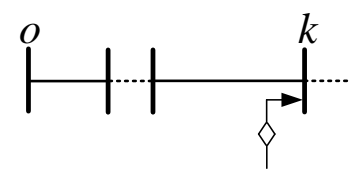

Figura 4.8: Representação de medição em barra 
A tensão elétrica em uma barra qualquer de um alimentador radial é igual à tensão na barra da subestação menos a queda de tensão no trecho de rede entre a subestação e esta barra. Desta forma, supondo-se uma medição em uma barra $k$, representada pela figura 4.8, onde existem $n t$ trechos de rede que conecta esta barra à subestação, designada por barra o. Logo, pode-se calcular a tensão na barra $k$ como:

$$
\dot{V}_{k}=\dot{V}_{o}-\sum_{l=1}^{n t} \dot{Z}_{l} \dot{I}_{l}
$$

Onde $\dot{V}_{k}$ é a tensão na barra $k, \dot{V}_{o}$ é a tensão na barra da subestação, $\dot{Z}_{l}$ é a matriz de impedância do trecho $I, \dot{I}_{l}$ é o vetor de corrente do trecho $l$ e nt é o número de trechos que interliga a barra k à barra origem.

Contudo, as medições de tensão nas redes de distribuição são medições de módulo. Assim, o modelo matemático deve ser desenvolvido em função do módulo da tensão.

Outro fator importante que se verifica na equação (4.22) é o acoplamento entre as fases. Todas as outras medições aqui equacionadas possuem acoplamento entre fases nulo, exceto as medições de tensão.

Todavia, a impedância mutua entre as fases é muito pequena comparada a impedância própria das fases. Isto permite ignorar o acoplamento entre as fases no caso das medições de módulo de tensão, a fim de garantir um processamento computacional eficiente, sem trazer prejuízo ao estimador de estado, pois o processo iterativo irá anular os efeitos desta simplificação.

Desta forma, após desenvolver a equação (4.22) de forma desacoplada entre as fases. Então que a equação que relaciona uma medição de módulo de tensão em uma determinada barra $k$ com as variáveis de estado do sistema é definida conforme a seguir:

Seja:

$$
\begin{aligned}
& \mathfrak{R}^{a}=\dot{V}_{r, o}^{a}-\sum_{l=1}^{n t} I_{r, l}^{a} Z_{r, l}^{a}-I_{x, l}^{a} Z_{x, l}^{a} \\
& \mathfrak{I}^{a}=\dot{V}_{x, o}^{a}-\sum_{l=1}^{n t} I_{r, l}^{a} Z_{x, l}^{a}+I_{x, l}^{a} Z_{r, l}^{a},
\end{aligned}
$$


Onde $Z_{r, l}$ é a parte real da impedância do trecho $/$ e $Z_{x, l}$ é a parte imaginária da impedância deste mesmo trecho. O módulo da tensão é calculado como:

$$
\left|\dot{V}_{k}^{a}\right|=\sqrt{\mathfrak{R}^{2}+\mathfrak{J}^{2}}
$$

As derivadas parciais desta equação para compor a matriz Jacobiana são:

a) Quando a derivada parcial for função de uma variável de estado que representa a corrente em um trecho que pertence ao segmento de rede que conecta a barra $k$ à subestação (qualquer trecho st que pertence ao conjunto dos trechos que formam o caminho $\overrightarrow{o k}$ ) e a medição de tensão e a variável de estado estão na mesma fase, $a=f$.

$$
\begin{array}{ll}
\frac{\partial\left|\dot{V}_{k}^{a}\right|}{\partial I_{r, s t}^{f}}=-Z_{r, s t}^{a} \cos (\alpha)-Z_{x, s t}^{a} \sin (\alpha) & \forall s t \in \overrightarrow{o k} \\
\frac{\partial\left|\dot{V}_{k}^{a}\right|}{\partial I_{x, s t}^{f}}=Z_{x, s t}^{a} \cos (\alpha)-Z_{r, s t}^{a} \sin (\alpha) &
\end{array}
$$

Onde,

$$
\alpha=\tan ^{-1}\left(\frac{\mathfrak{I}}{\mathfrak{R}}\right)
$$

b) A matriz Jacobiana terá entrada nula quando as derivadas parciais forem em função de variáveis de estado associadas a um trecho que não pertence ao conjunto de trechos $\overrightarrow{o k}$.

c) Quando as variáveis de estado estão associadas a um trecho que pertence ao conjunto de segmentos $\overrightarrow{o k}$, mas a medição de módulo de tensão e estas variáveis de estado não estão na mesma fase, as derivadas parciais referente a estas variáveis de estado serão nulas. Isso para satisfazer a aproximação de desacoplamento entre fases, citada acima, no caso de medições de módulo de tensão.

Devido às aproximações e suposições realizadas, as medições de módulo de tensão serão utilizadas no processo de estimação de estado somente quando a rede de distribuição em análise for radial. 


\subsubsection{Equacionamento matricial}

O vetor de funções $h($.$) , equação (4.27), é constituído das funções não lineares e$ que relaciona as medidas com as variáveis de estado, tem dimensão (mx1), sendo $m$ o número de medidas do sistema. Já o seu Jacobiano, $H\left(I_{r i}, I_{x i}\right)$, equação (4.28), é construído através das derivadas parciais em relação ás variáveis de estado, apresentadas anteriormente, tem dimensão $(2 n-2 \times \mathrm{m})$, sendo $n$ o número de barras do sistema.

$$
\begin{gathered}
h=\left[\left|V_{k}^{a}\right| \cdots\left|I_{k}^{a}\right| \cdots P_{k m}^{a} \cdots Q_{k m}^{a} \cdots P_{k}^{a} \cdots Q_{k}^{a}\right]^{T} \\
H\left(I_{r i}, I_{x i}\right)=\left[\begin{array}{ccc}
\frac{\partial\left|V_{k}^{a}\right|}{\partial I_{r, s t}^{f}} & \cdots & \frac{\partial\left|V_{k}^{a}\right|}{\partial I_{x, s t}^{f}} \\
\vdots & \cdots & \vdots \\
\frac{\partial\left|I_{k}^{a}\right|}{\partial I_{r, s t}^{f}} & \cdots & \frac{\partial\left|I_{k}^{a}\right|}{\partial I_{x, s t}^{f}} \\
\vdots & \cdots & \vdots \\
\frac{\partial P_{k m}^{a}}{\partial I_{r, s t}^{f}} & \cdots & \frac{\partial P_{k m}^{a}}{\partial I_{x, s t}^{f}} \\
\vdots & \cdots & \vdots \\
\frac{\partial Q_{k m}^{a}}{\partial I_{r, s t}^{f}} & \cdots & \frac{\partial Q_{k m}^{a}}{\partial I_{x, s t}^{f}} \\
\vdots & \cdots & \vdots \\
\frac{\partial P_{k}^{a}}{\partial I_{r, s t}^{f}} & \cdots & \frac{\partial P_{k}^{a}}{\partial I_{x, s t}^{f}} \\
\vdots & \cdots & \vdots \\
\frac{\partial Q_{k}^{a}}{\partial I_{r, s t}^{f}} & \cdots & \frac{\partial Q_{k}^{a}}{\partial I_{x, s t}^{f}}
\end{array}\right]
\end{gathered}
$$

A matriz Jacobiano é uma matriz significativamente esparsa, pois o número de elementos não nulos da matriz é muito reduzido, porque cada medida envolve um número limitado de variáveis de estado.

Embora menos esparsa que a matriz Jacobiano, a matriz ganho $G$ possui um grande número de elementos nulos e sua inversão pode causar problemas de convergência e deterioração dos resultados do EE. Assim, o cálculo da matriz 
ganho, equação (2.5), é determinado pela decomposição de Cholesky, detalhada no Anexo A.

\subsubsection{Atualização das demandas das cargas}

Devido ao elevado número de pseudomedições utilizadas na estimação de estado de redes de distribuição, é necessária a atualização dos valores de demanda, pois, devido às incertezas associadas às demandas das cargas, os erros associados a elas são bem maiores do que os dos valores medidos.

Assim, para satisfazer as restrições das medições, as demandas das cargas devem ser modificadas (DENG, HE; ZHANG, 2002).

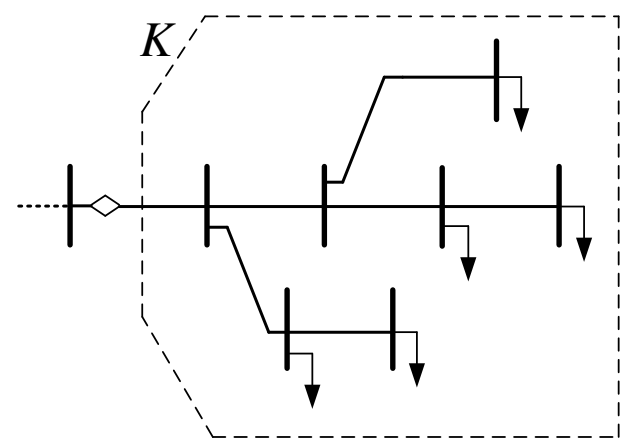

Figura 4.9 - Representação de uma zona de medição

Para cada zona de medição, tomando-se como exemplo a zona K exemplificada na figura 4.9, a atualização do conjunto de pseudomedições pertencentes à ela é realizada pela minimização da seguinte equação.

$$
\begin{gathered}
\min J\left(r_{P}, r_{Q}\right)=\sum_{j=1}^{n_{p}} w_{P j} r_{P j}^{2}+w_{Q j} r_{Q j}^{2}, \quad n_{p} \in K \\
\text { s.a. } P_{K}^{\prime}-\sum_{j=1}^{n_{p}}\left(P_{j}+r_{P j}\right)-P_{\text {loss }}\left(r_{P}, r_{Q}\right)=0 \\
Q_{K}^{\prime}-\sum_{i=1}^{n_{p}}\left(Q_{j}+r_{Q j}\right)-Q_{\text {loss }}\left(r_{P}, r_{Q}\right)=0
\end{gathered}
$$


Onde $P_{K}^{\prime}$ e $Q_{K}^{\prime}$ são os valores modificados das medições na zona $K, r_{P}$ e $r_{Q}$ representam o vetor de resíduos das pseudomedidas, $P_{\text {loss }}\left(r_{P}, r_{Q}\right)$ e $Q_{\text {loss }}\left(r_{P}, r_{Q}\right)$ representam as perdas no sistema (nos trechos da zona $K$ ) causadas pelos resíduos das pseudomedidas, $w_{P}$ e $w_{Q}$ são os pesos das pseudomedidas e $n_{p}$ é o conjunto de pseudomedições pertencentes à zona $K$.

Como os pesos são valores positivos, e ignorando a parte diferencial de $r_{P}$ e $r_{Q}$ de $P_{\text {loss }}\left(r_{P}, r_{Q}\right)$ e $Q_{\text {loss }}\left(r_{P}, r_{Q}\right)$, obtemos o mínimo da equação (4.29) pela Desigualdade de Cauchy:

$$
\begin{aligned}
J\left(r_{P}, r_{Q}\right) & =\sum_{j=1}^{n_{p}} w_{P j} r_{P j}^{2}+w_{Q j} r_{Q j}^{2}, \quad n_{p} \in K \\
& \geq \frac{\left(\sum_{\mathrm{j}=1}^{n_{p}} \mathrm{r}_{\mathrm{Pj}}\right)^{2}}{\sum_{\mathrm{j}=1}^{n_{p}} \frac{1}{\mathrm{w}_{\mathrm{Pj}}}}+\frac{\left(\sum_{\mathrm{j}=1}^{n_{p}} \mathrm{r}_{\mathrm{Qj}}\right)^{2}}{\sum_{\mathrm{j}=1}^{n_{p}} \frac{1}{\mathrm{w}_{\mathrm{Qj}}}}
\end{aligned}
$$

Os $r_{P}$ e $r_{Q}$ ótimos são obtidos de:

$$
\begin{aligned}
& w_{P 1} \hat{r}_{P 1}=w_{P 2} \hat{r}_{P 2}=\cdots=w_{P n_{b}} \hat{r}_{P n_{b}} \\
& w_{Q 1} \hat{r}_{Q 1}=w_{Q 2} \hat{r}_{Q 2}=\cdots=w_{Q n_{b}} \hat{r}_{Q n_{b}}
\end{aligned}
$$

Então:

$$
\begin{gathered}
\hat{r}_{P i}=\frac{P_{K}^{\prime}-\sum_{j=1}^{n_{p}} P_{j}-P_{\text {loss }}}{\left(\sum_{j=1}^{n_{p}} \frac{1}{w_{P j}}\right) \cdot w_{P i}} \\
\hat{r}_{Q i}=\frac{Q_{K}^{\prime}-\sum_{j=1}^{n_{p}} Q_{j}-Q_{\text {loss }}}{\left(\sum_{j=1}^{n_{b}} \frac{1}{w_{Q j}}\right) \cdot w_{Q i}}
\end{gathered}
$$

Onde $i$ é cada barra contendo pseudomedição da zona $K$ e $j=1,2, \ldots, n_{p} \in K$.

Com a solução da equação (4.32), as pseudomedidas são atualizadas, na iteração $k+1$, por:

$$
\begin{aligned}
& P_{i}^{(k+1)}=P_{i}^{(k)}+\hat{r}_{P i}{ }^{(k)} \\
& Q_{i}^{(k+1)}=Q_{i}^{(k)}+\hat{r}_{Q i}{ }^{(k)}
\end{aligned} \quad i=1,2, \ldots, n_{p} \in K
$$


Para medições de módulo de corrente, a atualização das demandas das cargas é feita da mesma forma, somente sendo modificados os valores dos pesos associados às medidas através da propagação das incertezas, pois, as funções que relacionam a corrente com as potências em um trecho por fase são:

$$
\begin{gathered}
P=V_{r} I_{r}+V_{x} I_{x} \\
Q=-V_{r} I_{x}+V_{x} I_{r}
\end{gathered}
$$

Em que as componentes reais e imaginárias da corrente medida são calculadas por:

$$
\begin{aligned}
& I_{r}=\left|I_{\text {med }}\right| \operatorname{sen} \varphi \\
& I_{x}=\left|I_{\text {med }}\right| \cos \varphi
\end{aligned}
$$

Onde $\varphi$ é o ângulo de fase da corrente, calculado pelo fluxo de carga.

Assim seus pesos são:

$$
\begin{aligned}
& w_{I_{r}}=w_{I_{\text {med }}}(\cos \varphi)^{2} \\
& w_{I_{x}}=w_{I_{\text {med }}}(\operatorname{sen} \varphi)^{2}
\end{aligned}
$$

O que resulta nos pesos $w_{P}$ e $w_{Q}$ calculados da seguinte maneira:

$$
\begin{aligned}
& w_{P}=w_{I_{\text {med }}}\left[V_{r}^{2}(\cos \varphi)^{2}+V_{x}^{2}(\operatorname{sen} \varphi)^{2}\right] \\
& w_{Q}=w_{I_{\text {med }}}\left[V_{r}^{2}(\operatorname{sen} \varphi)^{2}+V_{x}^{2}(\cos \varphi)^{2}\right]
\end{aligned}
$$

Observa-se que esta metodologia atualiza os valores de demanda das cargas utilizando os valores da variância das mesmas, representadas pelos pesos. Isto possibilita uma maior correção das cargas com maiores desvios (menos precisas) e a não alteração, ou pouca alteração, daquelas com desvios baixos (mais precisas). 


\subsection{ESTIMADOR PARA REDE BT}

Depois de efetuada a estimação de estado da rede MT, obtêm-se então uma análise do sistema no qual se identifica as possíveis regiões problemáticas, ou seja, onde se encontrou um alto nível de perdas não técnicas. Então, pode-se efetuar a estimação de estado para a rede BT, que identificará mais precisamente a localização do problema.

Entretanto, devido às características deste método de estimação de estado, sua aplicação no cálculo do estado estimado das redes BT poderia ser comprometida. Isto se deve ao fato que a modelagem desenvolvida para medições de tensão, no caso de utilizarem-se como variáveis de estado a corrente complexa nos trechos de rede, só é válida para redes radiais.

Apesar de que as redes de baixa tensão, em sua grande maioria sejam radiais, em alguns poucos casos pode haver malha e como as únicas medições encontradas nas redes BT são de tensão, optou-se por não utilizar o método descrito acima. Em vez disso, será utilizado um método de estimação de estado tradicional.

Assim sendo, com a indicação da região problemática, a concessionária de distribuição deverá implantar um programa de campanha de medidas para dar subsídio ao estimador, ou seja, melhorar a observabilidade do estimador BT.

Será aplicado, então, um método de estimação de estado com modelagem trifásica e que utiliza como variáveis de estado a tensão complexa nas barras do sistema, assim como apresentado em Baran e Kelley (1994). Com isso, o método lidará com as assimetrias das redes de baixa tensão e não será prejudicado no caso de haver redes malhadas.

Um dos problemas dos estimadores de estado tradicionais quando se utilizando a modelagem trifásica de rede é que a ordem de grandeza do problema aumenta consideravelmente quando comparado aos métodos destinados aos sistemas de transmissão, o que exige um maior tempo de processamento computacional. Entretanto, como as redes de baixa tensão em sua maioria são de pequeno porte, esta característica não será impeditiva para a aplicação deste método. 
- Modelo de representação da rede

O modelo de representação da rede BT é análogo ao da rede primária, ou seja, representa-se a rede trecho a trecho, por meio de seus condutores de fase e neutro (fases $A$, B e $\mathrm{C}$ e neutro $\mathrm{N}$ ), assim como os equipamentos.

\subsubsection{Equacionamento das funções de medição}

Os principais tipos de medições encontradas nas redes de distribuição de baixa tensão são as medições do módulo da tensão em um ponto do sistema e as medições de injeção de potência. A seguir serão desenvolvidos os modelos matemáticos para representar estes tipos de medições no estimador de estado proposto para rede BT.

- Medição de módulo de tensão

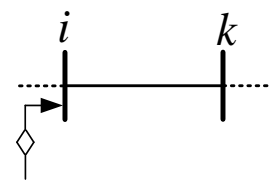

Figura 4.10: Representação de medição em barra BT

O valor do módulo de tensão medido na barra $i$, representada pela figura 4.13, é igual ao da tensão real somada a um erro e, equação (4.38).

$$
V_{i}^{e s p}=V_{i}+e_{i}
$$

Assim, a derivada parcial dessa tensão com relação às variáveis de estado temse que:

$$
\frac{\partial V_{i}^{e s p}}{\partial V_{i}}=1
$$


As demais derivadas associadas a essa medida de tensão são nulas.

\section{- Medição de injeção de potência}

É assumido como medição de injeção de potência, e por conseqüência, tratada conforme a metodologia que será apresentada a seguir, a demanda estimada dos consumidores através dos dados históricos e de curvas típicas.

A potência injetada na fase $p$ da barra $i$, também representada pela figura 4.10, pode ser calculada conforme equações 4.40 ,

$$
\begin{aligned}
& P_{i}^{p}=V_{i}^{p} \sum_{k=1}^{n} \sum_{m=1}^{3} V_{k}^{m}\left[G_{i k}^{p m} \cos \theta_{i k}^{p m}+B_{i k}^{p m} \operatorname{sen} \theta_{i k}^{p m}\right], \\
& Q_{i}^{p}=V_{i}^{p} \sum_{K=1}^{n} \sum_{m=1}^{3} V_{k}^{m}\left[G_{i k}^{p m} \operatorname{sen} \theta_{i k}^{p m}-B_{i k}^{p m} \cos \theta_{i k}^{p m}\right]
\end{aligned}
$$

Onde $n$ é o número de barras da rede, $V_{k}^{m}$ é o módulo da tensão da fase $m$ da barra $k, G_{i k}^{p m}$ é a condutância entre as fases $p$ e $m$ do ramo alocado entre as barras $i$ e $k, \theta_{i k}^{p m}$ é a diferença entre o ângulo da fase $p$ da barra $i$ e o ângulo da fase $m$ da barra $k$, ou seja, $\theta_{i k}^{p m}=\theta_{i}^{p}-\theta_{k}^{m}$ e $B_{i k}^{p m}$ é a susceptância entre as fases $p$ e $m$ do ramo alocado entre as barras $i$ e $k$.

O conjunto $K$ contém todas as barras do sistema e os parâmetros $G_{i k}^{p m}$ e $B_{i k}^{p m}$ são não nulos sempre que houver conexão física entre a barra $i$ e às linhas que sofrem os efeitos de acoplamento mútuos com outras linhas.

As derivadas parciais destas equações são definidas como:

a) Quando a medição e a variável de estado estão em fases diferentes, $m \neq p$, e/ou em barras diferentes, $i \neq k$.

$$
\begin{gathered}
\frac{\partial P_{i}^{p}}{\partial \theta_{k}^{m}}=V_{i}^{p} V_{k}^{m}\left[G_{i k}^{p m} \operatorname{sen} \theta_{i k}^{p m}-B_{i k}^{p m} \cos \theta_{i k}^{p m}\right], \\
\frac{\partial P_{i}^{p}}{\partial V_{k}^{m}}=V_{i}^{p}\left[G_{i k}^{p m} \cos \theta_{i k}^{p m}+B_{i k}^{p m} \operatorname{sen} \theta_{i k}^{p m}\right]
\end{gathered}
$$




$$
\begin{gathered}
\frac{\partial Q_{i}^{p}}{\partial \theta_{k}^{m}}=-V_{i}^{p} V_{k}^{m}\left[G_{i k}^{p m} \cos \theta_{i k}^{p m}+B_{i k}^{p m} \operatorname{sen} \theta_{i k}^{p m}\right], \\
\frac{\partial Q_{i}^{p}}{\partial V_{k}^{m}}=V_{i}^{p}\left[G_{i k}^{p m} \operatorname{sen} \theta_{i k}^{p m}-B_{i k}^{p m} \cos \theta_{i k}^{p m}\right]
\end{gathered}
$$

b) Quando a medição e a variável de estado estão nas mesmas fases, $m=p$, e nas mesmas barras, $i=k$.

$$
\begin{gathered}
\frac{\partial P_{i}^{p}}{\partial \theta_{k}^{m}}=-B_{i i}^{p p}\left(V_{i}^{p}\right)^{2}-V_{i}^{p} \sum_{K=1}^{n} \sum_{m=1}^{3} V_{k}^{m}\left[G_{i k}^{p m} \operatorname{sen} \theta_{i k}^{p m}-B_{i k}^{p m} \cos \theta_{i k}^{p m}\right], \\
\frac{\partial P_{i}^{p}}{\partial V_{k}^{m}}=\frac{\left[\left(V_{i}^{p}\right)^{2} G_{i i}^{p p}+P_{i}^{p}\right]}{V_{i}^{p}} \\
\frac{\partial Q_{i}^{p}}{\partial \theta_{k}^{m}}=-G_{i i}^{p p}\left(V_{i}^{p}\right)^{2}+P_{i}^{p}, \\
\frac{\partial Q_{i}^{p}}{\partial V_{k}^{m}}=\frac{-\left[\left(V_{i}^{p}\right)^{2} B_{i i}^{p p}+Q_{i}^{p}\right]}{V_{i}^{p}}
\end{gathered}
$$

\subsubsection{Equacionamento matricial}

O vetor de funções $h($.$) , equação (4.45), é constituído das funções não lineares e$ que relaciona as medidas com as variáveis de estado, tem dimensão $(m \times 1)$, sendo $m$ o número de medidas do sistema BT. Já o seu Jacobiano, $H(\theta, V)$, equação (4.46), é construído através das derivadas parciais em relação ás variáveis de estado, tem dimensão $(6 n-3 \times 7 m)$, sendo $n$ o número de barras do sistema.

$$
h=[|V| \cdots P \cdots Q]^{T}
$$




$$
H(\theta, V)=\left[\begin{array}{ccc}
\frac{\partial|V|}{\partial \theta} & \ldots & \frac{\partial|V|}{\partial V} \\
\vdots & \cdots & \vdots \\
\frac{\partial P}{\partial \theta} & \cdots & \frac{\partial P}{\partial V} \\
\vdots & \cdots & \vdots \\
\frac{\partial Q}{\partial \theta} & \cdots & \frac{\partial Q}{\partial V}
\end{array}\right]
$$

\subsection{ALGORITMO PROPOSTO}

Devido às características encontradas nas redes MT e redes BT, verificou-se a necessidade de desenvolver um algoritmo de estimação de estado específico para cada um dos casos. Portanto, o processo de estimação de estado completo nas redes de distribuição possui duas etapas. Inicialmente estima-se o estado da rede $\mathrm{MT}$, onde a carga $\mathrm{BT}$ será agrupada nos transformadores de distribuição através do cálculo de fluxo de carga previamente realizado. Posteriormente realiza-se o processo de estimação separadamente para a rede BT com os valores atualizados de demandas.

Devido à nova formulação, tomando como variável de estado a corrente nos ramos da rede de distribuição $M T$, a matriz ganho $G$ é independente dos parâmetros de impedância nos trechos da rede (exceto no caso das medições de tensão). Ou seja, esta nova modelagem eliminou os problemas encontrados nos métodos de estimação de estado estatísticos relacionados aos parâmetros da rede, como por exemplo, o mau condicionamento da matriz ganho e pontos de alavancamento.

O processo de cálculo do estimador proposto para as redes MT e BT, dá-se segundo o algoritmo apresentado na figura 4.11: 


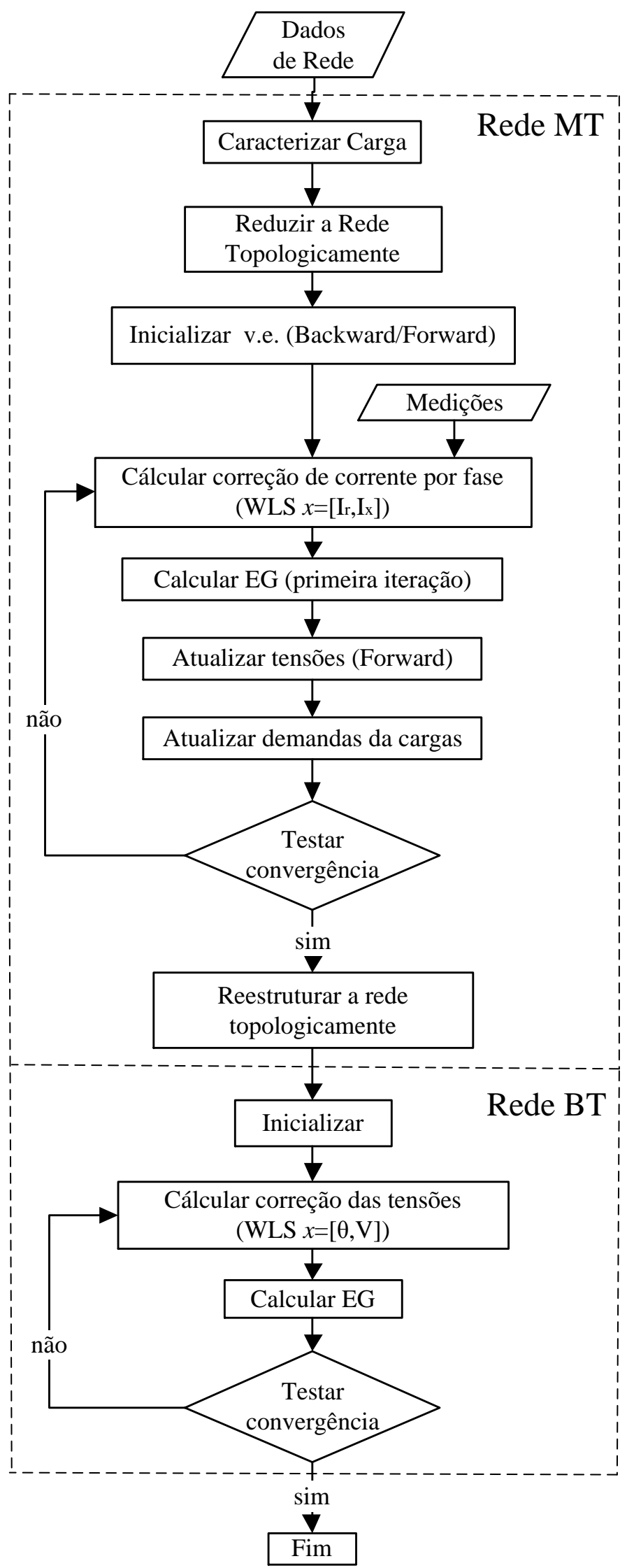

Figura 4.11: Algoritmo proposto 
Este algoritmo utiliza as técnicas descritas neste capítulo, que podem ser sumarizadas da seguinte forma:

a) Método de estimação WLS:

O método de estimação de estados utilizado é o método estatístico WLS, que possibilita o cálculo da estimação de estados em sistemas de distribuição de energia mesmo quando se leva em consideração as características intrínsecas destes sistemas.

b) Caracterização da carga:

A caracterização da carga (empregada na geração das pseudomedições), realizada através dos dados de faturamento associados às curvas típicas de carga, restabelece a observabilidade do sistema permitindo o cálculo mesmo com um número muito baixo de medições.

c) Redução topológica:

A redução topológica soluciona o problema do mau condicionamento matricial por eliminar os valores nulos na matriz Ganho, o que impossibilitaria o cálculo de sua inversa.

d) Inicialização das variáveis de estado e atualização dos valores de tensão:

Realizados através do cálculo de fluxo de carga Backward/Forward, que foi adaptado pela inserção do cálculo do estado estimado no cálculo das correstes nos ramos.

e) Atualização dos valores de demanda das cargas:

A atualização dos valores de demanda das cargas é empregada para 0 ajuste das pseudomedições introduzidas, isto devido ao alto valor das incertezas associadas a elas.

f) Identificação dos EG:

A identificação dos EG dá-se pelo cálculo dos resíduos normalizados. Contudo, devido à baixa redundância de medições que causa a elevação da correlação entre elas, a análise de sensibilidade do vetor de resíduos estimados fica comprometida. Assim sendo, a análise dos resíduos normalizados não é utilizada na identificação dos EG, mas sim na indicação das possíveis regiões portadoras de perdas não técnicas. 


\section{RESULTADOS}

conjunto de testes e os resultados foram alcançados aplicando-se os modelos desenvolvidos neste trabalho. Inicialmente tem-se um exemplo numérico para a explicação do uso da metodologia do cálculo do estado estimado WLS, descrita no capítulo 4. A validação dos resultados é realizada através de testes em alimentadores reais de distribuição de energia, comparando-se com a aplicação das metodologias de estimação de estados proporcional com medição única auferida no início do alimentador, comumente utilizada nas distribuidoras de energia, e da estimação de estados proporcional genérica, apresentada no capítulo 1.

Os testes são realizados através da implementação computacional da metodologia de estimação de estados da rede de média tensão, apresentada na sessão 4.1. A supressão da implementação da metodologia de estimação de estados tradicional, a ser aplicada nas redes de baixa tensão, deve-se ao fato de que esta metodologia já estar sedimentada por muitos estudos que comprovam o sucesso desta técnica, assim este trabalho tem por foco a utilização da metodologia aplicada à rede de média tensão.

Para tornar viável a aplicação da metodologia, a implementação computacional foi desenvolvida dentro de um sistema computacional de planejamento de redes MT/BT, o software Interplan ${ }^{1}$.

Para estudos de planejamento, em geral são considerados alguns patamares de carga, por exemplo, madrugada, manhã, tarde e noite, onde são assumidos quatro instantes (horas do dia) característicos de cada patamar de carga. Assim, as demandas podem ser somadas em cada instante, levando-se em conta a diversidade da carga. Nos testes realizados, o patamar utilizado foi o de maior carregamento, para a análise da metodologia sob o pior cenário.

A análise das perdas nos sistemas de distribuição é realizada através da investigação dos resíduos normalizados, que indica as regiões (zonas de

\footnotetext{
${ }^{1}$ Interplan é um sistema computacional para estudos de planejamento de redes de distribuição MT/BT desenvolvido pela empresa Daimon Engenharia e Sistemas.
} 
medição) portadoras de perdas não técnicas. As perdas técnicas podem ser obtidas utilizando-se os valores estimados de tensão nas barras, corrente nos trechos e a modelagem dos componentes do sistema.

\subsection{EXEMPLO NUMÉRICO}

O exemplo numérico será efetuado utilizando-se o alimentador fictício de 12 barras com dois pontos de medição, identificadas por \#1 e \#2, blocos de cargas nas barras 9, 10 e 12 e trechos de 300 metros e cabo 1/0CAA, representado pelo diagrama unifilar apresentado na figura 5.1.

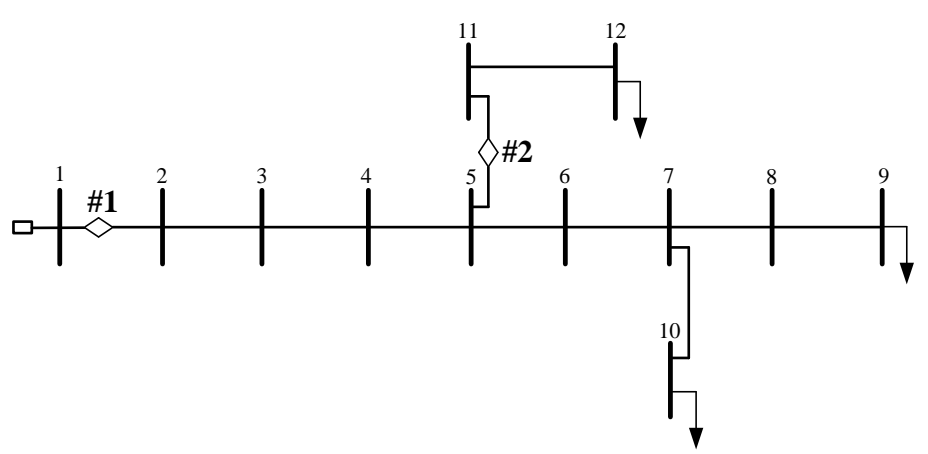

Figura 5.1: Diagrama unifilar do alimentador fictício

A figura 5.2 apresenta a tela principal do Interplan, na qual é possível editar a rede, calcular a demanda, o fluxo de carga e também os cálculos de correção de demanda, estimação proporcional e estimação de estados WLS.

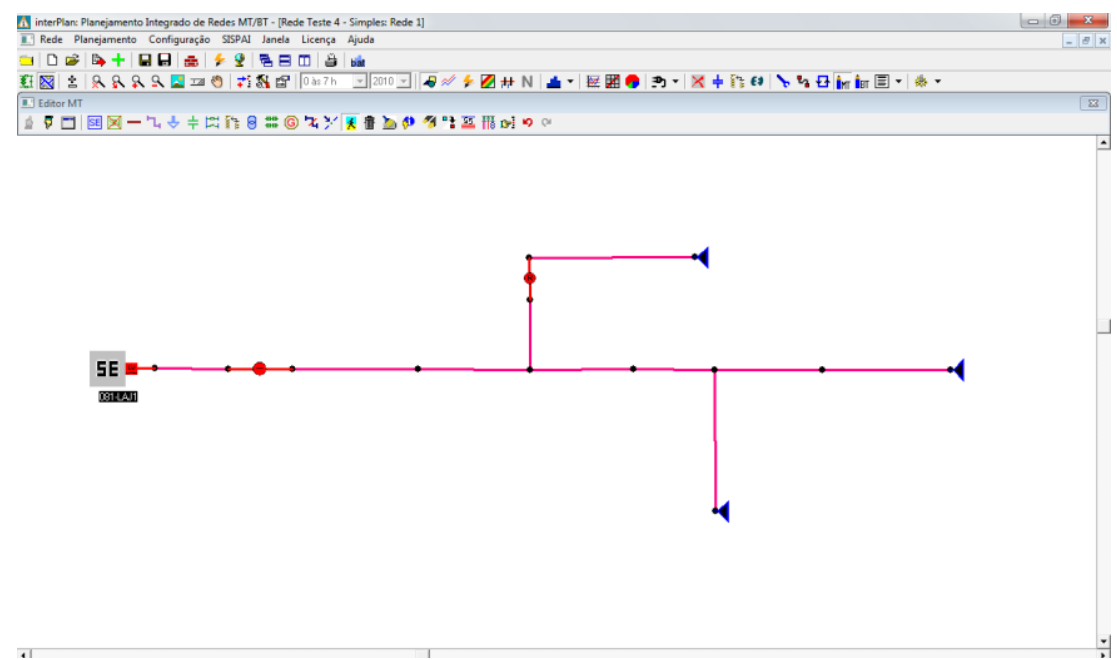

Figura 5.2: Interplan 
Para simplificação, as cargas são trifásicas balanceadas, assim os cálculos efetuados para as três fases são idênticos, não sendo, então, necessário explicitar o cálculo de todas as fases. Os valores das demandas dos blocos de cargas são apresentados na tabela 5.1 .

Tabela 5.1 - Demandas dos blocos de carga

\begin{tabular}{c|c|c}
\hline Barra & $P(k W)$ & $Q(k V A r)$ \\
\hline 9 & 100 & 66,67 \\
\hline 10 & 200 & 133,33 \\
\hline 12 & 200 & 133,33 \\
\hline
\end{tabular}

As medições inseridas neste alimentador são apresentadas na tabela 5.2.

Tabela 5.2 - Medições do alimentador fictício para cada fase

\begin{tabular}{c|c}
\hline Medidor & \multicolumn{2}{c}{ Valor } \\
\hline$\# 1$ & $55 \mathrm{~A}$ \\
\hline \multirow{2}{*}{$\# 2$} & $300 \mathrm{~kW}$ \\
\cline { 2 - 2 } & $200 \mathrm{kVAr}$ \\
\hline
\end{tabular}

Em se tratando de um exemplo fictício, assume-se que os valores dos blocos de carga não contêm desvio, ou seja, são valores faturados exatos. Assim sendo, fica explícito que a diferença entre a medição \#2 e a demanda do bloco da barra 12 se trata de perda não técnica, pois não foi contabilizada em sua demanda. Seguem-se, então, a execução das diferentes metodologias e posteriormente a análise comparativa.

a) Estimação proporcional com medição única:

A aplicação da correção de demanda da carga através da utilização da medição no início do alimentador faz com que todos os blocos de carga sejam corrigidos igualmente pelo fator $k=1,221$, tanto para potências ativas e reativas, como mostra a tabela 5.3. 
Tabela 5.3 - Resultado da estimação por medição única

\begin{tabular}{c|c|c}
\hline Barra & $P(k W)$ & $Q(k V A r)$ \\
\hline 9 & 122,15 & 81,43 \\
\hline 10 & 244,30 & 162,87 \\
\hline 12 & 244,30 & 162,87 \\
\hline
\end{tabular}

b) Estimação proporcional genérica:

A estimação proporcional genérica, que faz uso da totalidade de medições existentes, apesar de apresentar melhores resultados que a aplicação da correção por medição única, faz a correção dos valores das demandas dos blocos de carga também de forma indiscriminada, aplicando diretamente os fatores para zona \#1 $\mathrm{k}_{P Q}=1,016$, e para zona \#2 $\mathrm{k}_{P Q}=1,300$ na primeira iteração e $\mathrm{k}_{P}=$ $1,158, k_{Q}=1,157$ na segunda iteração, como mostra a tabela 5.4.

Tabela 5.4 - Resultado da estimação proporcional

\begin{tabular}{c|c|c}
\hline Barra & $P(k W)$ & $Q(k V A r)$ \\
\hline 9 & 101,61 & 67,74 \\
\hline 10 & 203,22 & 135,48 \\
\hline 12 & 306,11 & 203,82 \\
\hline
\end{tabular}

Nota-se que a medição \#2 corrigiu a demanda do bloco de cargas da barra 12, contudo não é possível afirmar se esta correção é correta, pois esta metodologia não produz nenhuma informação acerca disto. A não exatidão dos valores medidos e calculados se deve às perdas técnicas intrínsecas ao sistema, que é contabilizada no cálculo.

c) Estimação WLS proposta:

A metodologia de estimação de estados WLS, auxiliada pelas técnicas apresentadas anteriormente, também faz a correção de demanda por zonas de medição, contudo é possível a identificação das possíveis áreas detentoras de 
perdas não técnicas. Com o intuito de explicitar a utilização desta metodologia, apresenta-se a seguir sua execução passo a passo.

Como se trata de uma rede fictícia, não é necessário a caracterização da carga, pois são utilizados blocos de carga fictícios. Assim, o primeiro passo realizado é a redução topológica, representada pela figura 5.3, em que se observa a redução do total de 12 para 6 barras.

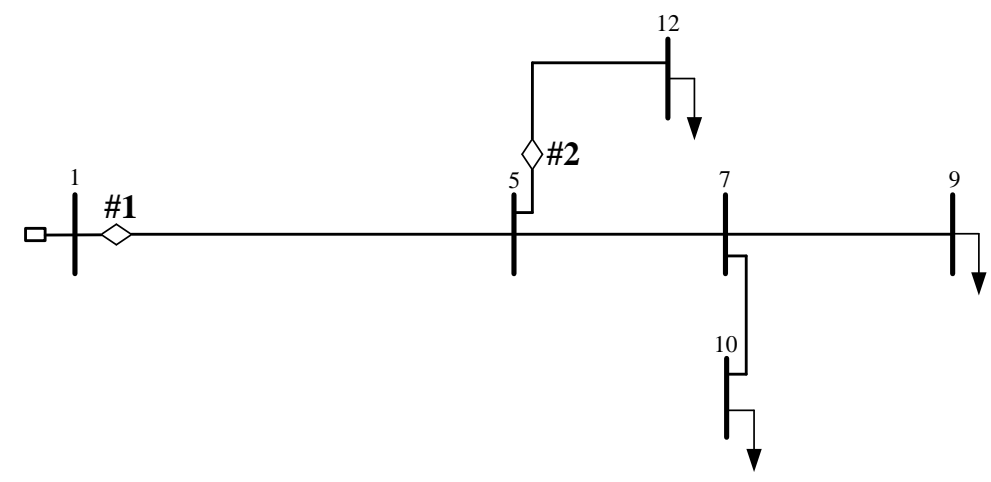

Figura 5.3: Diagrama unifilar do alimentador fictício reduzido topologicamente

Com a redução topológica, a rede apresenta 10 variáveis de estado, duas para cada trecho, e 12 medições, conforma mostra a tabela 5.5.

Tabela 5.5 - Medições do alimentador fictício para cada fase

\begin{tabular}{|c|c|c|}
\hline Tipo & Local & Valor Medido \\
\hline \multirow{3}{*}{$\begin{array}{l}\text { Medida } \\
\text { auferida }\end{array}$} & Trecho 1-5 & $55,00 \mathrm{~A}$ \\
\hline & \multirow{2}{*}{ Trecho 5-12 } & $300,00 \mathrm{~kW}$ \\
\hline & & $200,00 \mathrm{kVAr}$ \\
\hline \multirow{6}{*}{ Pseudomedida } & \multirow{2}{*}{ Barra 9} & 100,00 kW \\
\hline & & $66,67 \mathrm{kVAr}$ \\
\hline & \multirow{2}{*}{ Barra 10} & 200,00 kW \\
\hline & & $133,33 \mathrm{kVAr}$ \\
\hline & \multirow{2}{*}{ Barra 12} & 200,00 kW \\
\hline & & $133,33 \mathrm{kVAr}$ \\
\hline \multirow{4}{*}{ Virtual } & \multirow{2}{*}{ Barra 5} & $498,7 \mathrm{~kW}$ \\
\hline & & $332,80 \mathrm{kVAr}$ \\
\hline & \multirow{2}{*}{ Barra 7} & 298,80 kW \\
\hline & & 199,36 kVAr \\
\hline
\end{tabular}


Inicia-se, então, o cálculo estatístico da EE com a montagem das matrizes e o cálculo WLS.

A seguir seguem os vetores e as matrizes da primeira iteração, sendo $R_{\text {diag }}$ a matriz diagonal das variâncias das medições, $\mathrm{h}$ o vetor dos valores das saídas das funções de medição, $G$ a matriz ganho e Jacob a matriz Jacobiano.

$$
R_{\text {diag }}=\left|\begin{array}{c}
1^{*} 10^{-3} \\
1,00 \\
1,00 \\
0,81 \\
0,36 \\
2500,00 \\
1111,10 \\
1,00 \\
1,00 \\
625,00 \\
277,78 \\
2500,00 \\
1111,10
\end{array}\right| \quad h=\left|\begin{array}{c}
45,03 \\
498,26 \\
332,47 \\
199,26 \\
132,84 \\
199,26 \\
132,84 \\
298,69 \\
199,28 \\
99,56 \\
66,37 \\
199,11 \\
132,74
\end{array}\right|
$$

$$
G=\left|\begin{array}{cccccccccc}
804,80 & 0,00 & 0,00 & 0,00 & 0,00 & -419,05 & 0.00 & 0,00 & 0,00 & 0,00 \\
0,00 & 218,31 & 0,00 & 0,00 & 0,00 & 0,00 & 0,16 & 0,00 & 0,00 & 0,00 \\
0,00 & 0,00 & 176,66 & 0,00 & 0,00 & 0,00 & 0,00 & 0,00 & 0,00 & 0,00 \\
0,00 & 0,00 & 0,00 & 0,28 & 0,00 & 0,00 & 0,00 & 0,00 & 3.10^{-3} & 0,00 \\
0,00 & 0,00 & 0,00 & 0,00 & 0,07 & 0,00 & 0,00 & 0,00 & 0,00 & 0,00 \\
-419,05 & 0,00 & 0,00 & 0,00 & 0,00 & 456,68 & 0,00 & 0,00 & 0,00 & 0,00 \\
0,00 & 0,16 & 0,00 & 0,00 & 0,00 & 0,00 & 491,19 & 0,00 & 0,00 & 0,00 \\
0,00 & 0,00 & 0,00 & 0,00 & 0,00 & 0,00 & 0,00 & 176,66 & 0,00 & 0,00 \\
0,00 & 0,00 & 0,00 & 3.10^{-3} & 0,00 & 0,00 & 0,00 & 0.00 & 0,64 & 0,00 \\
0,00 & 0,00 & 0,00 & 0,00 & 0,00 & 0,00 & 0,00 & 0,00 & 0,00 & 0,16
\end{array}\right|
$$




$$
\text { Jacob }=\left|\begin{array}{cccccccccc}
0,83 & 0,00 & 0,00 & 0,00 & 0,00 & -0,55 & 0,00 & 0,00 & 0,00 & 0,00 \\
13,30 & 0,00 & 0,00 & 0,00 & 0,00 & -0,001 & 0,00 & 0,00 & 0,00 & 0,00 \\
-0,001 & 0,00 & 0,00 & 0,00 & 0,00 & -13,30 & 0,00 & 0,00 & 0,00 & 0,00 \\
0,00 & 13,29 & 0,00 & 0,00 & 0,00 & 0,00 & -0,007 & 0,00 & 0,00 & 0,00 \\
0,00 & -0,007 & 0,00 & 0,00 & 0,00 & 0,00 & -13,29 & 0,00 & 0,00 & 0,00 \\
0,00 & 13,29 & 0,00 & 0,00 & 0,00 & 0,00 & -0,007 & 0,00 & 0,00 & 0,00 \\
0,00 & -0,007 & 0,00 & 0,00 & 0,00 & 0,00 & -13,29 & 0,00 & 0,00 & 0,00 \\
0,00 & 0,00 & 13,29 & 0,00 & 0,00 & 0,00 & 0,00 & -0,002 & 0,00 & 0,00 \\
0,00 & 0,00 & -0,002 & 0,00 & 0,00 & 0,00 & 0,00 & -13,29 & 0,00 & 0,00 \\
0,00 & 0,00 & 0,00 & 13,28 & 0,00 & 0,00 & 0,00 & 0,00 & -0,006 & 0,00 \\
0,00 & 0,00 & 0,00 & -0,006 & 0,00 & 0,00 & 0,00 & 0,00 & -13,28 & 0,00 \\
0,00 & 0,00 & 0,00 & 0,00 & 13,28 & 0,00 & 0,00 & 0,00 & 0,00 & -0,007 \\
0,00 & 0,00 & 0,00 & 0,00 & -0,007 & 0,00 & 0,00 & 0,00 & 0,00 & -13,28
\end{array}\right|
$$

Resultando em:

$$
\begin{aligned}
\text { Erro }= & {\left[\begin{array}{lllllllllllll}
9,97 & 0.00 & 0.00 & 100,74 & 67,16 & 0,741 & 0,49 & 0.00 & 0.00 & 0,44 & 0,29 & 0,88 & 0,59
\end{array}\right]^{\prime} } \\
& \Delta x=
\end{aligned}
$$

Por conseguinte, as atualizações das demandas das cargas são:

Tabela 5.6 - Atualização das demandas cargas

\begin{tabular}{c|c}
\hline \multicolumn{1}{c}{ Bloco } & \multicolumn{1}{c}{ Valor } \\
\hline \multirow{2}{*}{ Barra 9 } & $-1,88 \mathrm{~kW}$ \\
\cline { 2 - 2 } & $-1,17 \mathrm{kVAr}$ \\
\hline \multirow{2}{*}{ Barra 10 } & $-7,55 \mathrm{~kW}$ \\
\cline { 2 - 2 } & $-4,69 \mathrm{kVAr}$ \\
\hline \multirow{2}{*}{ Barra 12 } & $99,76 \mathrm{~kW}$ \\
\cline { 2 - 2 } & $66,24 \mathrm{kVAr}$ \\
\hline
\end{tabular}


O cálculo convergiu na terceira iteração, resultando em:

Tabela 5.7 - Resultados da EE por fase

\begin{tabular}{|c|c|c|c|}
\hline Tipo & Local & Valor & Desvio \\
\hline \multirow{3}{*}{ Medida } & Trecho 1-5 & $53,54 \mathrm{~A}$ & $1.46 \mathrm{~A}$ \\
\hline & \multirow{2}{*}{ Trecho 5-12 } & $298,75 \mathrm{~kW}$ & $1.25 \mathrm{~kW}$ \\
\hline & & $199,45 \mathrm{kVAr}$ & $0.55 \mathrm{kVAr}$ \\
\hline \multirow{6}{*}{ Pseudomedida } & \multirow{2}{*}{ Barra 9} & $99,70 \mathrm{~kW}$ & $\overline{N A}$ \\
\hline & & $66,54 \mathrm{kVAr}$ & NA \\
\hline & \multirow{2}{*}{ Barra 10} & $198,79 \mathrm{~kW}$ & NA \\
\hline & & $132,81 \mathrm{kVAr}$ & NA \\
\hline & \multirow{2}{*}{ Barra 12} & $300,00 \mathrm{~kW}$ & NA \\
\hline & & $200,00 \mathrm{kVAr}$ & NA \\
\hline \multirow{4}{*}{ Virtual } & \multirow{2}{*}{ Barra 5} & $594,14 \mathrm{~kW}$ & $\overline{N A}$ \\
\hline & & $393,59 \mathrm{kVAr}$ & NA \\
\hline & \multirow{2}{*}{ Barra 7} & $294,65 \mathrm{~kW}$ & NA \\
\hline & & $193,58 \mathrm{kVAr}$ & NA \\
\hline
\end{tabular}

Tabela 5.8 - Resíduos normalizados

\begin{tabular}{c|c}
\hline \multicolumn{1}{c}{ Medição } & Valor \\
\hline$\# 1(\mathrm{~A})$ & 743,74 \\
\hline$\# 2(\mathrm{~kW})$ & 503704,48 \\
\hline$\# 2(\mathrm{kVAr})$ & 223867,74 \\
\hline
\end{tabular}

Os resultados mostram que as correções das demandas das cargas devido às medições foram corretas, somente com um pequeno desvio.

Nota-se que a medição \#2, no ramal 5-12, apontava uma grande diferença na potência demandada pelo bloco de cargas da barra 12, o que foi corrigido pela estimação WLS e, consequentemente, as cargas nas barras 9 e 10 tiveram seus valores pouco modificados. A não aplicabilidade dos cálculos dos desvios de pseudomedições e medições virtuais deve-se ao fato da não representatividade desse desvio, pois estas medições são atualizadas a cada iteração.

É possível observar que a utilização da medição na saída do alimentador faz a correção indiscriminada dos valores das demandas das cargas. A estimação 
proporcional genérica, apesar de fazer a correção pelas zonas de medição, não traz nenhuma informação sobre as mesmas. Já a estimação WLS, além de tratar as zonas de medição, aponta que a medição \#2, através de seu valor elevado do resíduo normalizado, é detentora de perdas não técnicas, como mostrou a tabela 5.8.

Para validação dos resultados apresentados, a seguir seguem os testes realizados em 2 alimentadores de maiores dimensões.

\subsection{APLICAÇÃO EM ALIMENTADORES REAIS}

Os testes realizados em alimentadores reais utilizam várias medições, tais como medições de módulo de corrente (medição na saída de alimentador), medições de fluxo de potência (medição em ramais feitas por equipamentos de rede tais como chaves telecomandadas e religadores) e medições de injeção de potência (medições de clientes A4). A não utilização de medições de tensão se deve ao fato da não convergência da EE WLS quando introduzidas este tipo de medida. $A$ introdução de medições de tensão causou mau condicionamento da matriz ganho, não sendo possível calcular sua inversa.

\subsubsection{Alimentador 1}

O alimentador 1 , possui um total de 353 trechos, 61 barras de carga e 8 medições, sendo uma na saída do alimentador (módulo de corrente), quatro em ramais (fluxo de potência) e três de clientes $A 4$, representadas pelos números como mostra a figura 5.4. Os valores das medições são apresentados no Anexo B. 


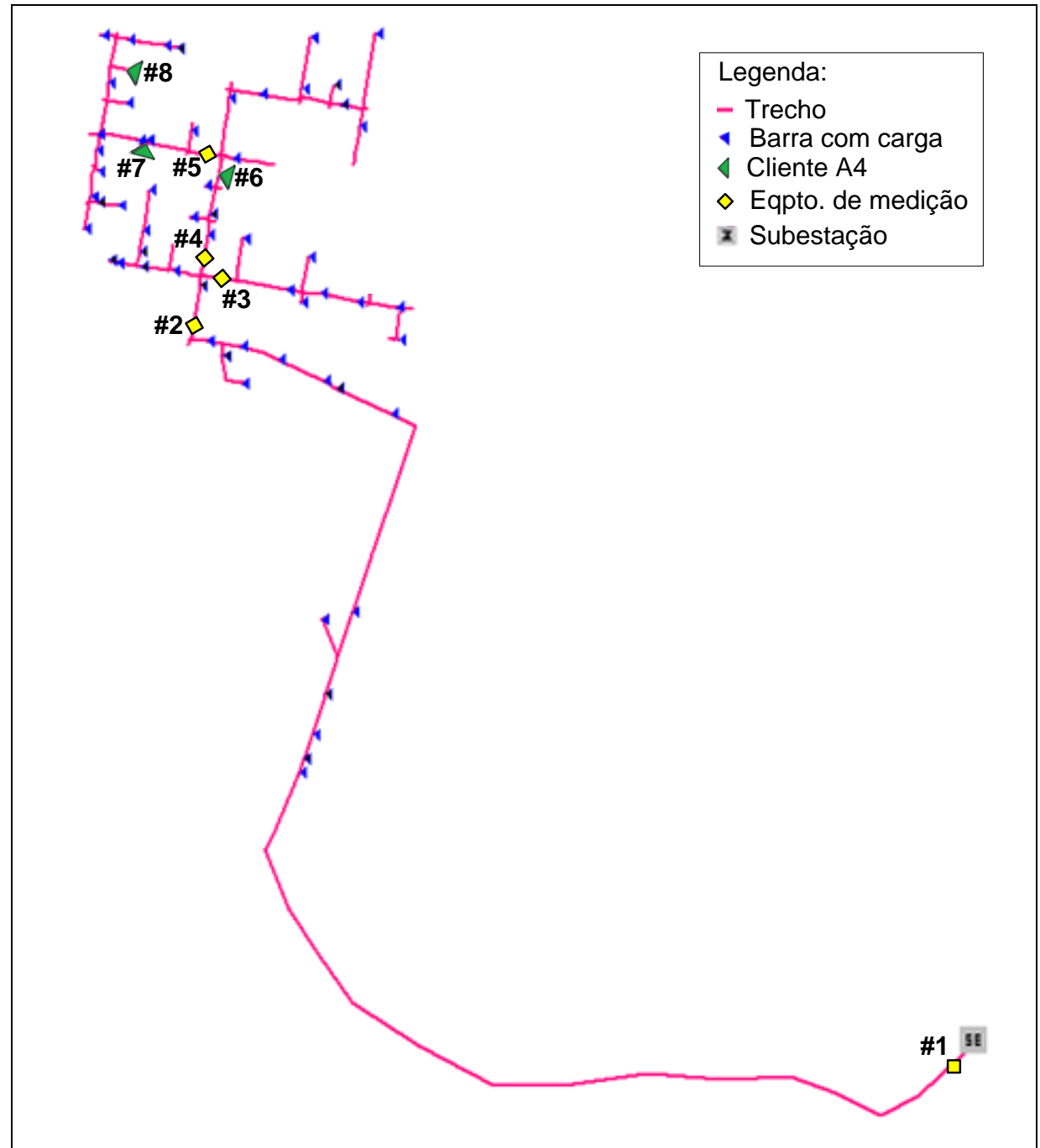

Figura 5.4: Representação da topologia do alimentador 1

Após a redução topológica, o número total de trechos utilizados pela EE foi de 201, significando uma redução de 43\%. Esta redução, além de melhorar a utilização da memória do computador, auxilia na redução do número de medições virtuais necessárias pela EE, que requer uma medição por variável de estado.

A convergência ocorreu na quarta iteração. Os resultados são apresentados no Anexo B.

A seguir, apresentam-se os resultados comparativos da aplicação das metodologias de EE aplicadas no alimentador 1. 


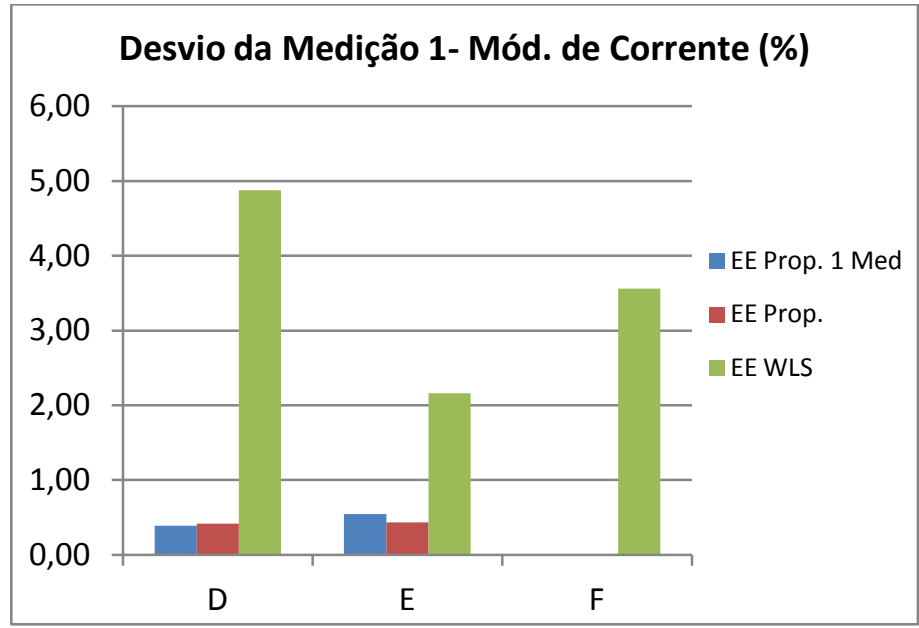

Figura 5.5: Comparação dos desvios dos cálculos da medição de módulo de corrente 1

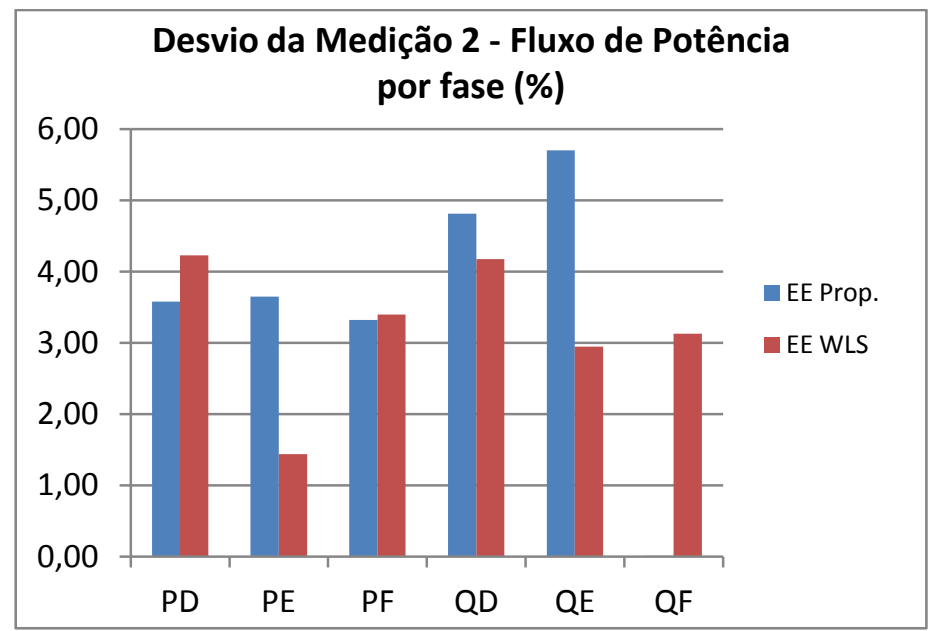

Figura 5.6: Comparação dos desvios dos cálculos da medição de fluxo de potência 2

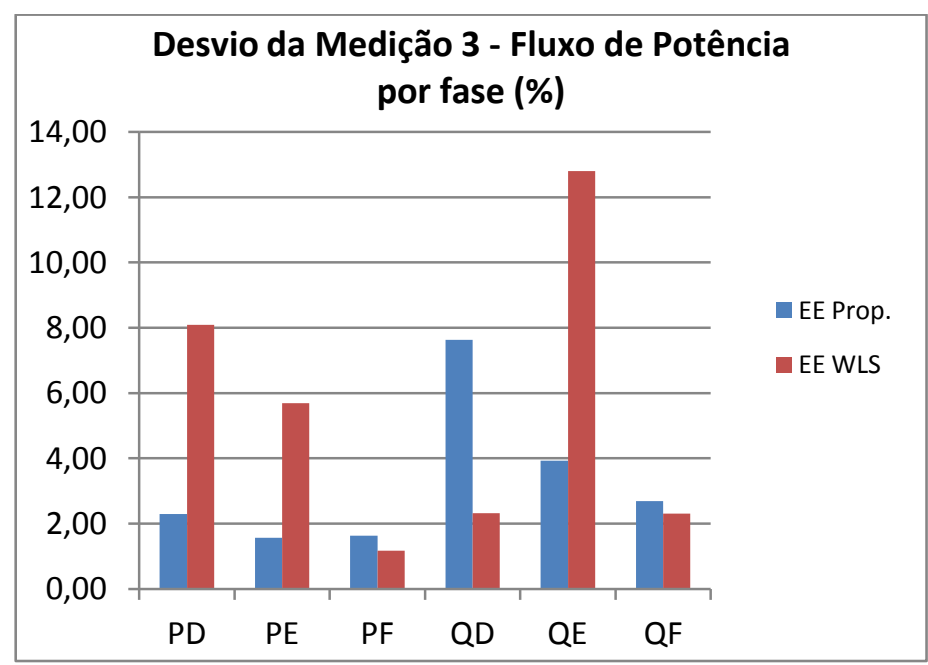

Figura 5.7: Comparação dos desvios dos cálculos da medição de fluxo de potência 3 


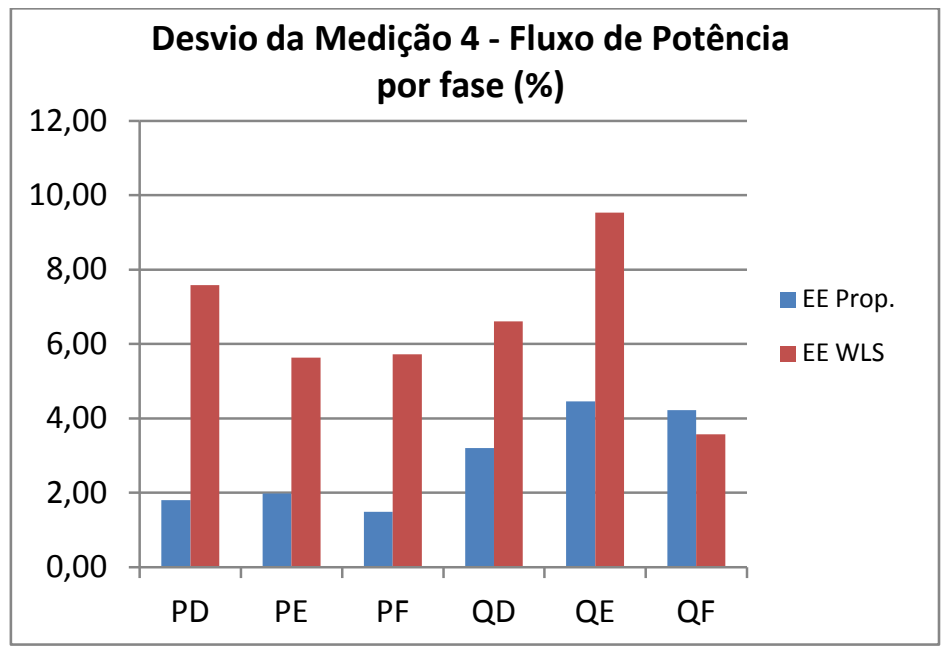

Figura 5.8: Comparação dos desvios dos cálculos da medição de fluxo de potência 4

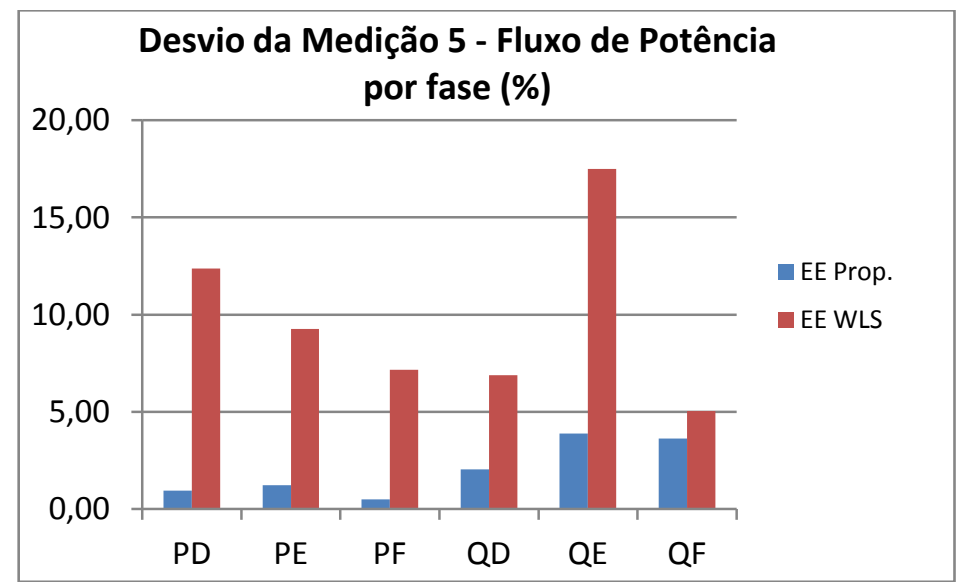

Figura 5.9: Comparação dos desvios dos cálculos da medição de fluxo de potência 5

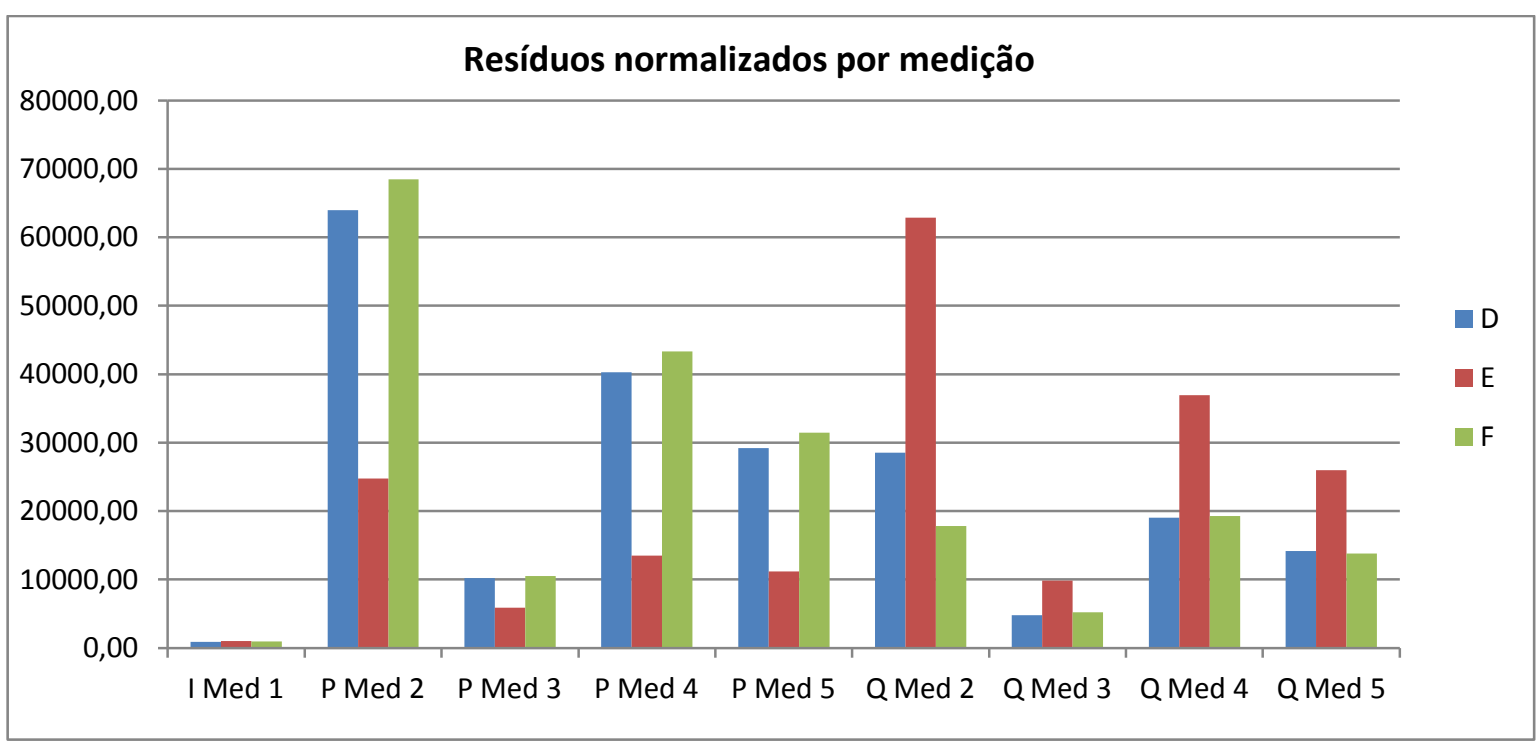

Figura 5.10: Resíduos normalizados do alimentador 1 
Analisando-se os gráficos que traduzem os resultados obtidos pelas metodologias implementadas, pode-se observar que apesar de apresentar diferenças entre os desvios percentuais, os mesmos são baixos, demonstrando a precisão das metodologias.

A metodologia de EE Proporcional, aplicada em sua forma genérica e quando utiliza medição única no início do alimentador, apresentou os menores desvios percentuais. Entretanto, esta metodologia ao corrigir as demandas das cargas de forma proporcional oculta informações sobre as medições e sobre a própria rede, não sendo possível a identificação e o tratamento de possíveis problemas.

A metodologia proposta neste trabalho demonstrou-se eficaz e precisa em seus resultados e, mesmo com desvios relativamente maiores que a EE Proporcional, apresenta o diferencial da investigação das perdas pela análise dos resíduos normalizados.

Inicialmente, observa-se que os resíduos normalizados apresentaram um baixo grau de redundância entre as medições (valores muito acima de 3), que se mostra correto pela comparação entre número de variáveis de estado (trechos) e o número de medições.

Ainda assim, comparando-se os resíduos normalizados obtidos é possível perceber que as medições \#2, \#4 e \#5 apresentam valores bem maiores (até oito vezes) do que os apresentados pela medição \#3, como mostra a figura 5.10 . Isto se deve ao fato da conformação dos erros de medições eletricamente próximas, causando o encadeamento dos erros normalizados (aumento do valor nas medições a montante das zonas extremas) entre as medições \#2, \#4 e \#5, o que não ocorreu na medida \#1, por estar distante eletricamente. Todavia, ainda é possível apontar que, das medições mais extremas (sem influência de outras medições à sua montante), a medição \#5 apresenta a indicação de sua zona conter perdas não técnicas, quando comparada com a medição \#3, pela grande diferença entre seus resíduos normalizados.

Além da análise do percentual de desvio entre os valores medidos e os calculados pelas diferentes metodologias, também se pode comparar os valores corrigidos em cada carga (transformador de distribuição que agrega os consumidores de baixa tensão), que foram utilizadas como pseudomedições. 
Utilizou-se como exemplo a zona da medição \#3, que contém 8 transformadores de distribuição, apresentada na figura 5.11.

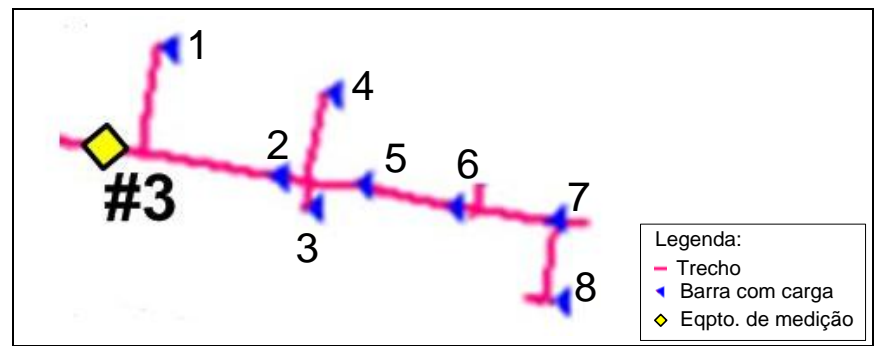

Figura 5.11: Zona tratada pela medição \#3

A estimação proporcional aplicou o valor de $\mathrm{k}=1,015$ tanto para demanda ativa como reativa, quando utilizada somente a medição de módulo de corrente na saída do alimentador, corrigindo todas as cargas por este fator. Quando aplicada a estimação proporcional genérica, para cada zona de medição são calculados os fatores, sendo estes de $k_{P}=1,002$ e $k_{Q}=1,003$ na zona \#3. A estimação WLS proposta calcula os fatores de acordo com os desvios padrões dos consumidores de baixa tensão acumulados no transformador em cada iteração, como apresentado na seção 4.1.6. Os resultados das correções de cada metodologia se encontram no Anexo B.

A seguir, na figura 5.12 encontra-se o resultado comparativo entre as metodologias.

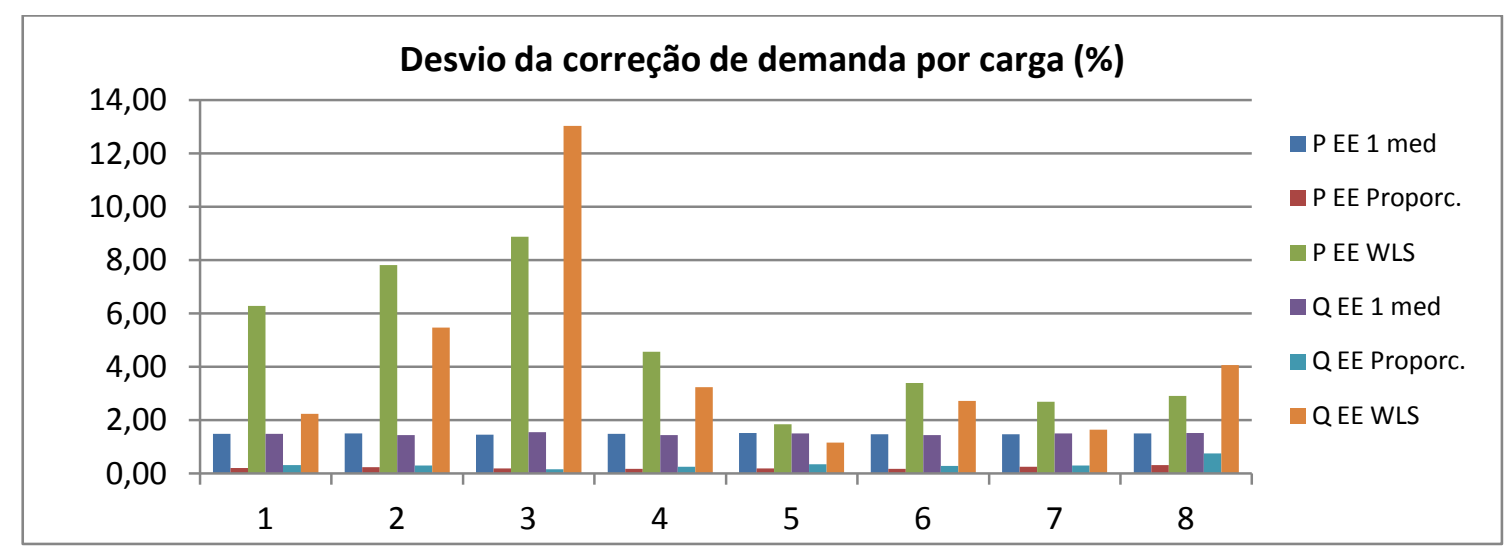

Figura 5.12: Desvios da correção de demanda por carga

Como é possível observar, a correção das demandas através da metodologia proposta é diferente para cada carga, pois utiliza a informação de desvio acumulado obtida no processo de caracterização da carga, resultando em uma correção mais confiável. 


\subsubsection{Alimentador 2}

O alimentador 2, apresentado na figura 5.13, possui um total de 1396 trechos, 242 barras de carga e 10 medições, sendo uma na saída do alimentador (módulo de corrente), seis em ramais (fluxo de potência) e três de clientes A4, representadas pelos números como mostra a figura 5.14. Os valores das medições são apresentados no Anexo B.

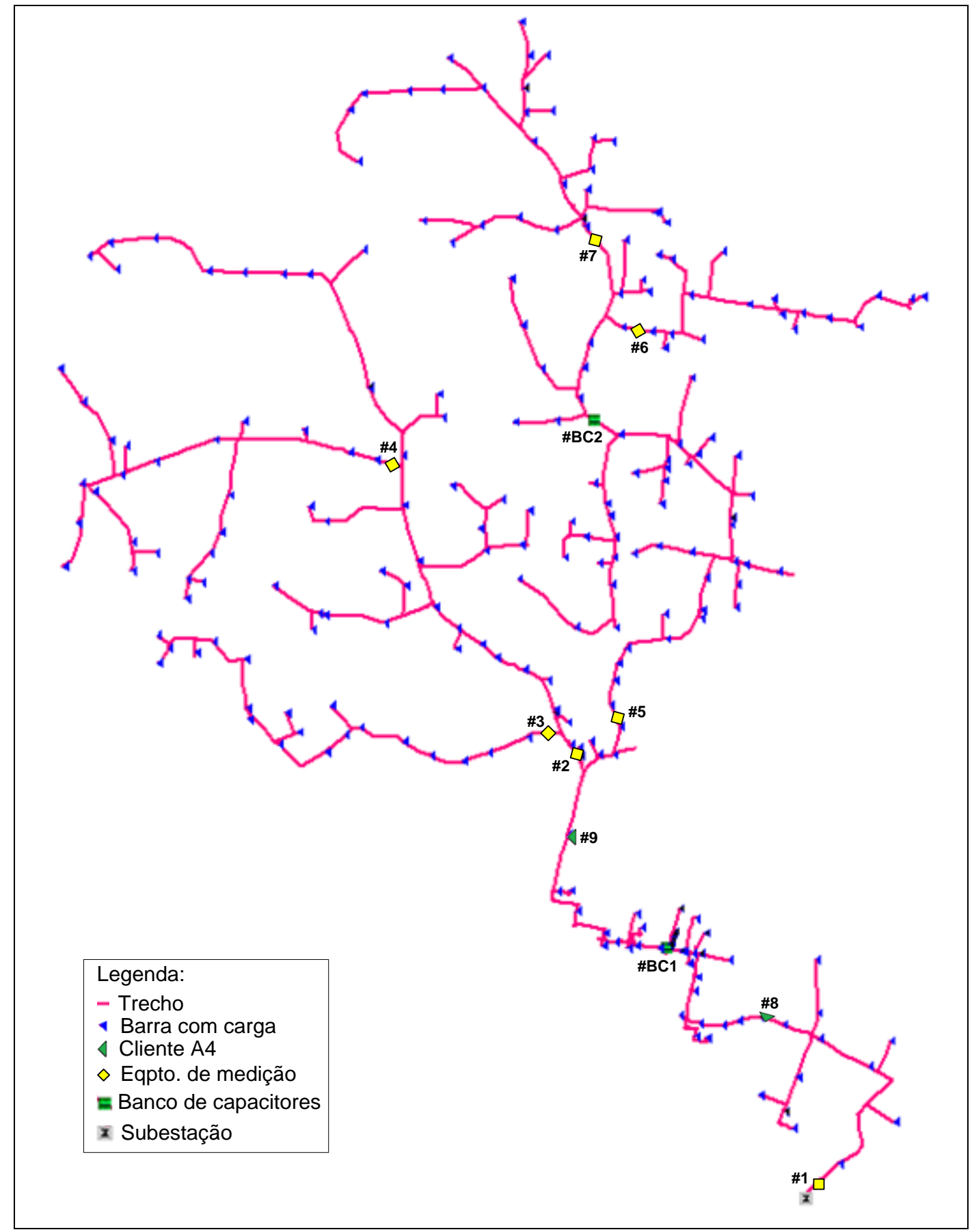

Figura 5.13: Representação da topologia do alimentador 2 
Após a redução topológica, o número de total de trechos utilizados na EE foi de 708, significando uma redução de 49\%. A convergência ocorreu na quinta iteração para todas as fases. Os resultados são apresentados no Anexo B. A seguir, apresentam-se os resultados comparativos da aplicação das metodologias de EE no alimentador 2.

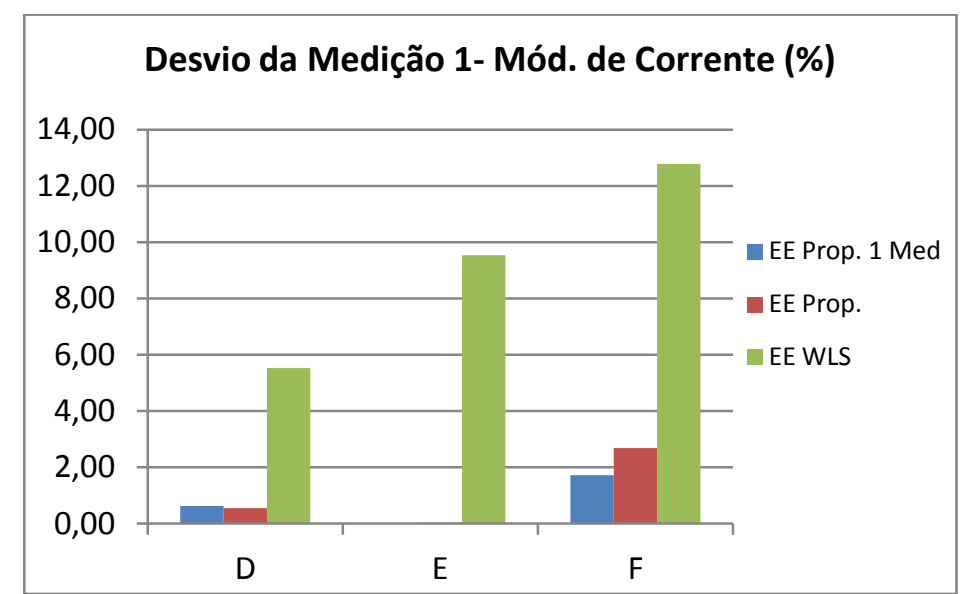

Figura 5.14: Comparação dos desvios dos cálculos da medição de módulo de corrente 1

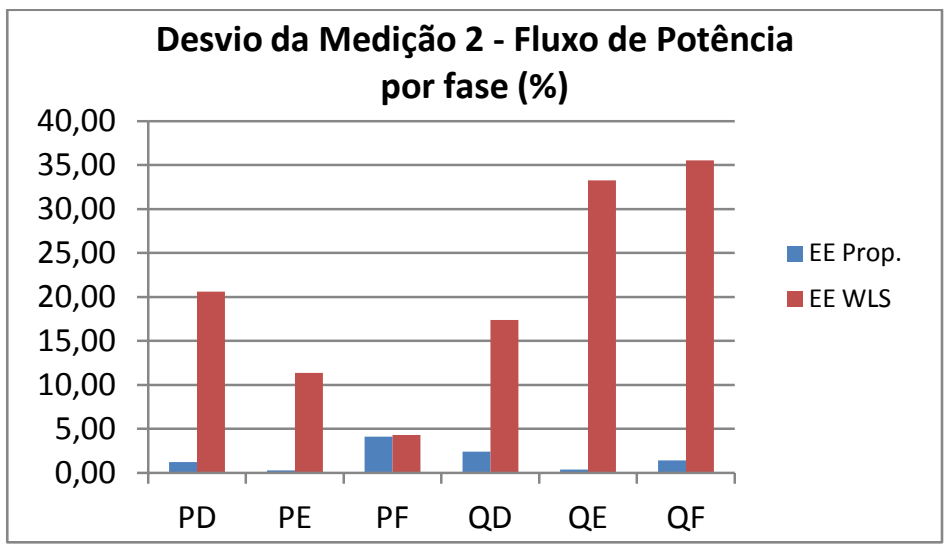

Figura 5.15: Comparação dos desvios dos cálculos da medição de fluxo de potência 2

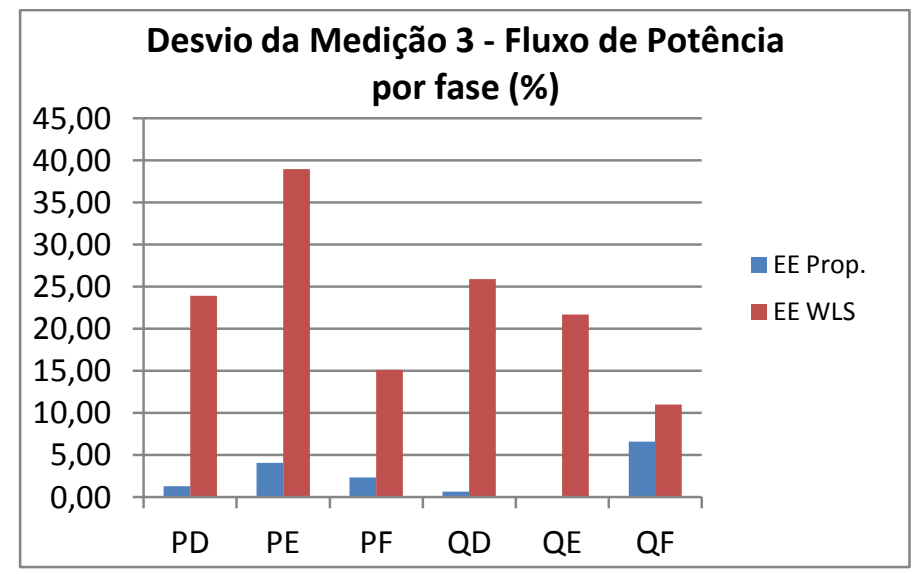

Figura 5.16: Comparação dos desvios dos cálculos da medição de fluxo de potência 3 


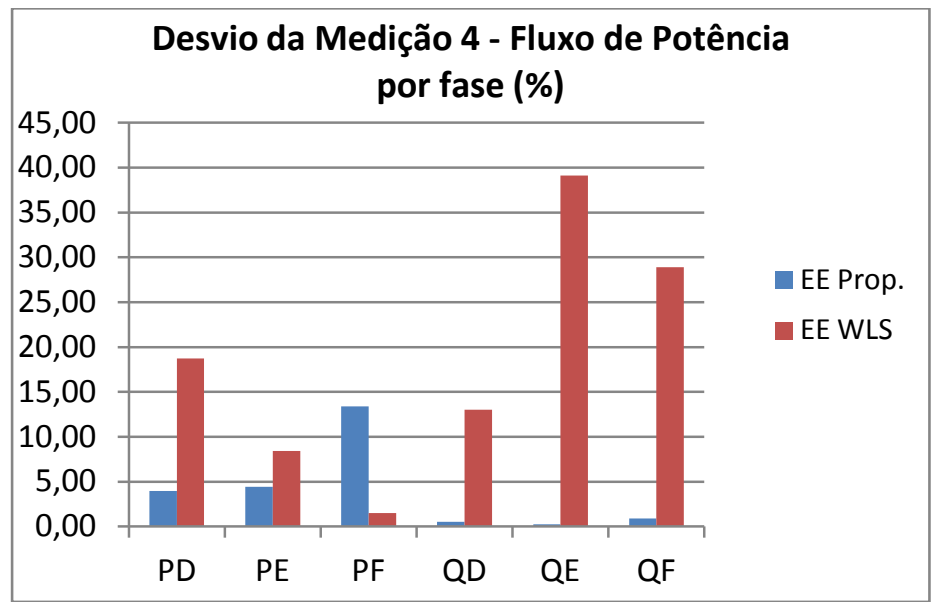

Figura 5.17: Comparação dos desvios dos cálculos da medição de fluxo de potência 4

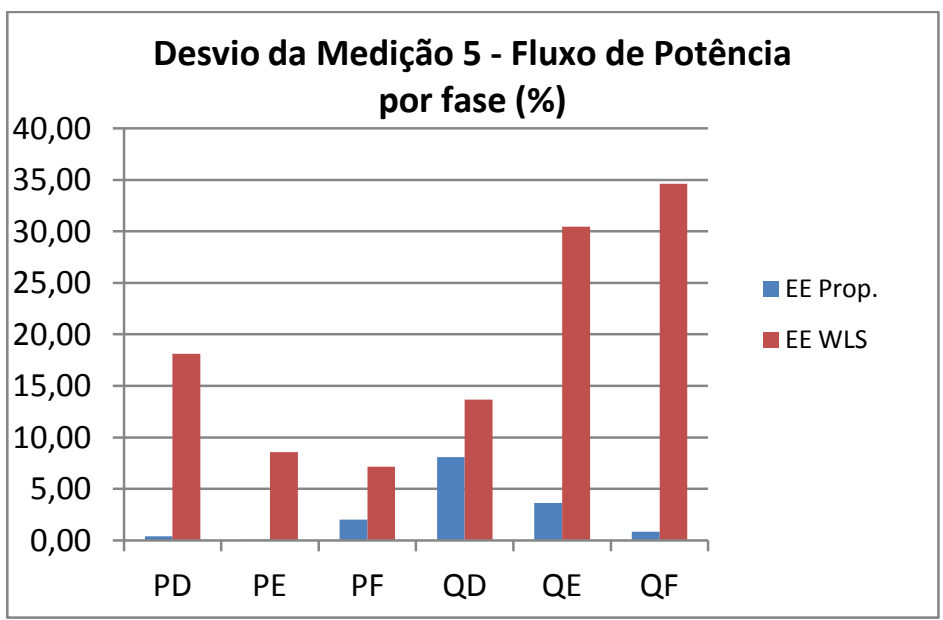

Figura 5.18: Comparação dos desvios dos cálculos da medição de fluxo de potência 5

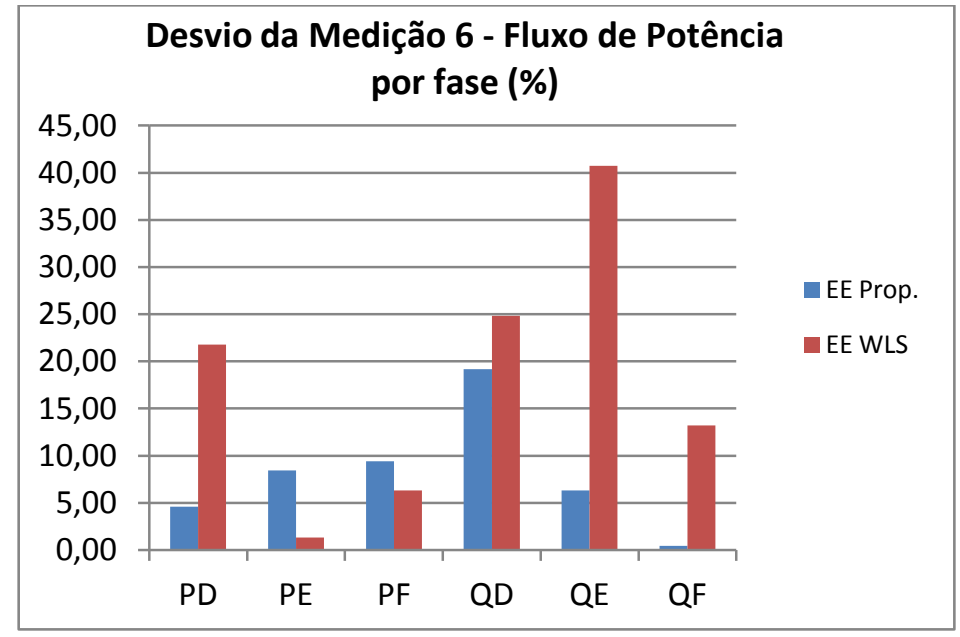

Figura 5.19: Comparação dos desvios dos cálculos da medição de fluxo de potência 6 


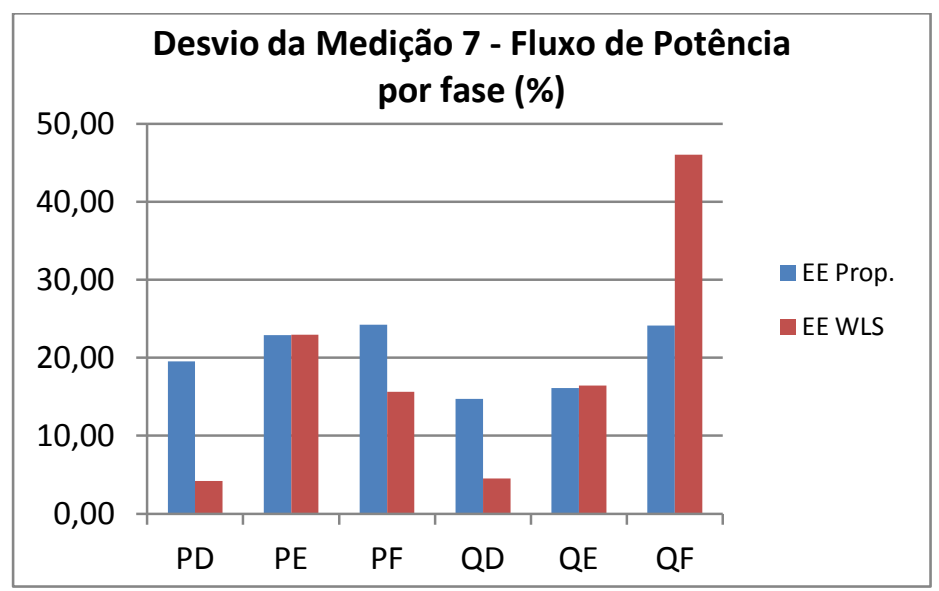

Figura 5.20: Comparação dos desvios dos cálculos da medição de fluxo de potência 7

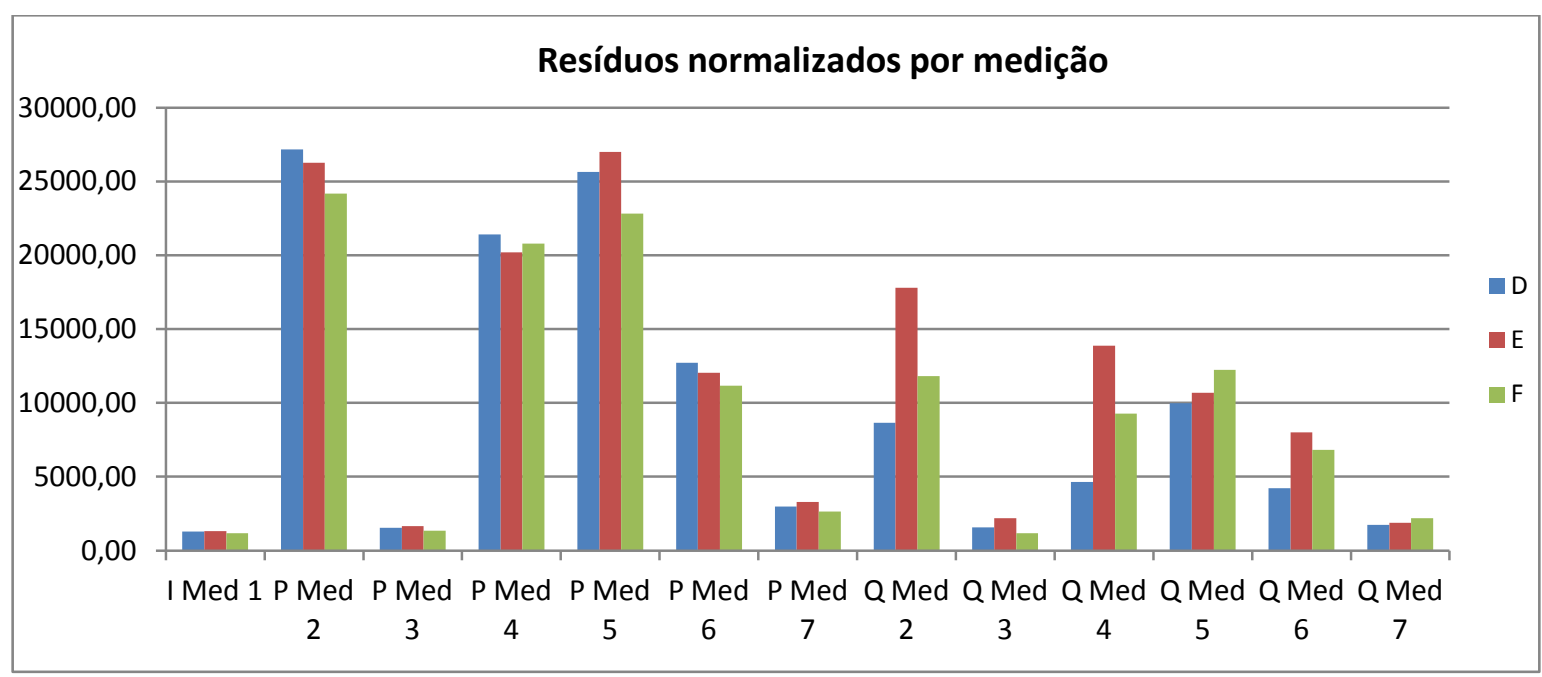

Figura 5.21: Resíduos normalizados do alimentador 2

A mesma análise feita ao alimentador 1 pode ser feita ao alimentador 2, levando às mesmas conclusões.

Novamente a metodologia de EE Proporcional, aplicada em sua forma genérica e quando utiliza medição única no início do alimentador, apresentou os menores desvios percentuais, isto sendo devido à natureza estatística da metodologia proposta, contudo a análise das perdas não pode ser efetuada.

Já na metodologia proposta, com a análise dos resíduos normalizados, é possível identificar que as medições \#2 e \#5 apontam suas zonas como possíveis regiões contendo perdas não técnicas, devido aos seus respectivos valores de resíduos normalizados serem os maiores. Contudo, cada qual engloba zonas de outros medidores. Assim sendo, a comparação entre os resíduos das medições \#3 e \#4, dentro da zona na medição \#2, mostra que a zona restrita da medição \#4 é a 
possível detentora das perdas não técnicas nesta região de fornecimento. $O$ mesmo acontece com as medições \#6 e \#7, apontando a zona da medição \#6 a possível detentora das perdas não técnicas nesta outra região de fornecimento. Isto devido novamente ao encadeamento dos resíduos entre as medições mais a montante.

Os valores dos resíduos normalizados das medições \#2 e \#5 também podem indicar a possibilidade de conterem perdas não técnicas em ramais sem medições, mas não sendo possível indicar a região específica por suas zonas de medição serem muito grandes.

Isto mostra que nesta rede é necessária a implantação de um número maior de medidores para se obter uma análise mais completa.

A comparação da correção das demandas das cargas pode ser realizada pela análise co carregamento do alimentador, devido à grande dimensão do alimentador 2. A tabela 5.9 apresenta os valores de carregamento calculados pelas diferentes metodologias.

Tabela 5.9 - Carregamento do alimentador 2

\begin{tabular}{c|c|c}
\hline \multicolumn{2}{c}{ Metodologia } & \multicolumn{2}{c}{ Valor } \\
\hline & $\mathrm{P}(\mathrm{MW})$ & $\mathrm{Q}(\mathrm{MVAr})$ \\
\hline EE Prop. 1 Medição & 1,811 & 0,229 \\
\hline EE Proporcional & 1,805 & 0,223 \\
\hline EE WLS & 1,809 & 0,225 \\
\hline
\end{tabular}

É possível perceber, então, que a correção das demandas das cargas é similar entre as metodologias aplicadas, contudo vale ressaltar que a metodologia proposta faz a correção de modo a favorecer as cargas melhor caracterizadas, utilizando os valores de desvio padrão obtidos previamente. 


\section{CONCLUSÃo}

A motivação para o desenvolvimento deste trabalho foi a proposição de uma metodologia de estimação de estados para sistemas de distribuição de energia que auxilie na análise de perdas.

Para isso, foi realizado o estudo do estado da arte em estimação de estados e a investigação de um conjunto de técnicas que permitem a aplicação da estimação em sistemas de distribuição de energia.

Dentre todos os métodos encontrados na literatura, pode-se observar que o método WLS destaca-se entre eles. Isto se deve ao fato de possuir as características necessárias ao processo de estimação de estado em sistemas de energia, como a identificação de erros grosseiros e a utilização de pseudomedidas.

Os sistemas de distribuição de energia apresentam baixa redundância de medições, as cargas supridas por este sistema são desbalanceadas por natureza e sua configuração radial pode levar os métodos de fluxo de carga ao mal condicionamento numérico. Por isso, para um bom desempenho dos métodos de estimação de estado é necessário o uso de pseudomedidas, dados históricos, o uso de medidas de magnitude de corrente, a aplicação de uma modelagem trifásica da rede e a utilização de métodos de fluxo de carga específicos para este tipo de sistema.

Nos trabalhos mais recentes sobre estimação de estado em redes de distribuição de energia, percebe-se uma forte tendência no desenvolvimento de modelos híbridos, que combinam aproximações tradicionais com técnicas inteligentes, evidenciando-se o método de estimação WLS para estimação de estado em sistemas de distribuição de energia.

No estimador proposto, foi utilizado como variável de estado a corrente complexa nos trechos de linha, em vez de utilizar as tensões complexas nas barras como nos métodos tradicionais, o que torna o estimador de estado menos sensível aos parâmetros de rede, o que melhora a desempenho de convergência do método e o tratamento de medições com erros. 
O desacoplamento entre as fases, obtido devido à escolha das variáveis de estado, permite um processo de estimação de estado individual entre as fases, o que aumenta a eficiência computacional do método.

A falta de medições disponíveis nas redes de distribuição é um fator limitante ao processo de estimação de estado. Portanto foi proposta a utilização de dados históricos e projeções de demanda dos clientes como pseudomedições. Para isso, os dados de faturamento dos clientes, são associados às curvas típicas de carga, a fim de determinar a curva de demanda destes clientes que então é utilizada como pseudomedição no processo de estimação de estado.

Contudo, com o elevado número de pseudomedições aplicadas, é necessária a atualização dos valores de demanda das cargas, pois os erros associados a elas são bem maiores do que os dos valores medidos. Para isso, após cada iteração da EE, é aplicado o cálculo de atualização das demandas das cargas.

Após a convergência do cálculo de EE, inicia-se o estudo da identificação das possíveis regiões detentoras de perdas não técnicas através dos resíduos normalizados. Este estudo deve ser efetuado através de uma análise criteriosa, pois, devido à dimensão das redes de distribuição, a grande distância elétrica entre cada medição pode produzir indicativos errôneos, assim como a baixa redundância de medições pode causar a elevação dos valores dos resíduos normalizados devido à alta correlação entre elas.

A fim de testar a eficiência desses procedimentos, foram executados testes da metodologia proposta submetida a diversas condições de carga. Os erros se apresentaram dentro dos valores esperados, quando foram utilizadas medições de corrente, fluxo de potência e injeção de potência.

As comparações com as metodologias de EE Proporcional apontaram o diferencial da metodologia proposta devido ao indicativo das possíveis regiões detentoras de perdas não técnicas e à atualização das demandas das cargas de modo a favorecer as cargas melhor caracterizadas.

Assim, a utilização da metodologia de EE WLS juntamente com técnicas auxiliares demonstra-se ser de grande valia na análise de perdas pelas concessionárias de distribuição de energia, pois somente a análise de fluxo de carga, através da modelagem de cargas feita pelo faturamento da própria, ou a utilização das metodologias de atualização das demandas das cargas através da 
medição na saída do alimentador ou a estimação proporcional pode mascarar o estado real do sistema. Com a utilização de medições na EE, é possível identificar as possíveis áreas com perdas não técnicas. Esta indicação pode significar que esta região contém perdas comerciais, ou que o modelo de cargas previamente adotado não esteja correto, norteando assim, as possíveis ações que devem ser adotadas no seu combate.

Como apontado anteriormente, vale ressaltar que, apesar de este trabalho tratar da solução de um problema energético, ou seja, a falta de faturamento da energia distribuída, o estudo em demanda, realizado pela metodologia de estimação de estados proposta, permite esta análise quando executada por período de estudo, utilizando-se os valores médios das medições, ou mesmo pela composição de vários resultados momentâneos.

Destarte, a flexibilidade dos procedimentos empregados, capazes de absorver diferentes quantidades e qualidades de informações, proporciona maior abrangência da metodologia proposta e a análise dos resultados em estudo de caso demonstra sua validade e aplicação prática.

\subsection{TRABALHOS FUTUROS}

Os esforços de pesquisa deste trabalho mostram que alguns tópicos relevantes no que diz respeito à metodologia utilizada ainda necessitam de mais investigações, destacando-se:

- A implementação da metodologia de EE WLS tradicional para a rede de baixa tensão.

- A investigação dos problemas que levaram a não convergência da EE WLS quando utilizada medição de módulo de tensão.

- A alteração do fluxo de carga utilizado pelo estimador, que possa levar em consideração a introdução da modelagem de geração distribuída e o tratamento de redes de média tensão fracamente malhadas. 
- A utilização de técnicas para tratamento de matrizes esparsas, que poderão melhorar o desempenho do estimador, como por exemplo, a representação por linhas ou a utilização do conjunto de listas encadeadas.

- A aplicação de uma metodologia heurística, como por exemplo, um EE Fuzzy.

- O desenvolvimento de uma ferramenta que permita realizar análises de viabilidade técnico-econômica de ações que tenham por objetivo a redução das perdas. Essa ferramenta poderia utilizar os resultados obtidos com o sistema computacional desenvolvido neste trabalho. 


\section{REFERÊNCIAS BIBLIOGRÁFICAS}

ASSOCIAÇÃO BRASILEIRA DE NORMAS TÉCNICAS. NBR 6855. Transformadores de potencial indutivos. Rio de Janeiro, 2009.

AMERICAN NATIONAL STANDARDS INSTITUTE. C57.13. Standard Requirements for Instrument Transformers. 2008.

ABBASY, N. H.; EL-HASSAWY, W. Power system State Estimation: ANN Application to bad data detection and identification. Stellenbosch: IEEE, 1996, pp 611-615.

ABBASY, N. H. Neural Network Aided Design for Metering System of Power System State Estimation, Stellenbosch: Proceddings of 4th IEEE AFRICON, vol. 2, pp. $607-610$, sept. 1996.

ABUR, A. A Bad Data Identification for Linear Programming State Estimation. Journal: IEEE, PWRS-5, n3, pp. 894-901, aug. 1990.

ABUR, A.; EXPÓSITO, A. G. Power System State Estimation: Theory and Implementation. New York: Marcel \& Dekker Publishers, 324, 2004.

ABUR, A.; EXPÓSITO, A. G. Bad Data Identification when using Ampere Measurements. IEEE Transactions on Power Systems, v. 12, n. 2, p. 831-836, may. 1997.

ALDENDERFER, M.S., BLASHFIELD, R.K. Cluster Analysis, Series: Quantitative Applications in the Social Sciences. SAGE publications, 1984. ISBN-10: 0803923767.

ALMEIDA, M. A. D. Um Algoritmo para Estimação de Estado em Alimentadores de Distribuição de Energia Elétrica com Base no Método da Soma de Potências. Rio Grande do Norte: Tese (Doutorado em Energia Elétrica) - Universidade Federal do Rio Grande do Norte, dez. de 2003, 153 f. 
ANTONIO, A. B., TORREÃO, J. R. A., DO COUTTO FILHO, M. B. Meter Placement for Power System State Estimation Using Simulated Annealing. Portugal: IEEE Proceedings of Porto Power Tech. Conference, vol. 3, 5 pp., sept. 2001.

BARAN, M. E. Challenges in State Estimation on Distribution Systems. Canada: Power Engineering Society Summer Meeting, Proceedings p. 429-433, 2001.

BARAN, M. E.; KELLEY, A. W. State Estimation for Real-Time Monitoring of Distribution Systems. IEEE Transactions on Power Systems, v. 9, n. 3, p. 16011609, aug. 1994. ISSN : 0885-8950.

BARAN, M. E.; KELLEY, A. W. A branch-current-based state estimation method for distribution systems. IEEE Transactions on Power Systems, Vol. 10, No. 1, feb. 1995. ISSN : 0885-8950

BARAN, M. E.; Zhu, J.; KELLEY, A. W. Meter Placement for Real-Time Monitoring of Distribution Feeders. IEEE Transactions on Power Systems, v. 11, n.1, p. 332-337, feb. 1996. INSPEC Accession Number: 5079960.

BENEDITO, R. A. S. Avaliação da Qualidade e Redundância das Medidas para Estimação de Estado em Sistemas Elétricos de Potência. São Carlos: Tese (Mestrado em Engenharia Elétrica). Escola de Engenharia de São Carlos da Universidade de São Paulo, 195 f., 2007.

CELIK, M. K.; LIU, W. H. E. A Practical Distribution State Calculation Algorithm. Power Engineering Society 1999 Winter Meeting, IEEE. Vol. 1, pp. 442 - 447, jan. 1999. INSPEC Accession Number: 6209741.

DENG Y.; HE Y.; ZHANG B. A Branch-Estimation-Based State Estimation Method for Radial Distribution Systems. Transactions on Power Systems Delivery, Vol. 17, NO. 4, oct. 2002. ISSN : 0272-1724. 
DOPAZO, J.F.; KLITIN, O.; VAN SLYCK, L.S. Implementation of the AEP RealTime Monotoring System. Proc. of the IEEE/PES Winter Meeting and Tesla Symposium, New York, jan. 1976. ISSN : 0018-9510.

EL-KEIB, A.; SING, H. Fast Linear Programming State Estimation Using the Dual Formulation. New York: IEEE Transactions on Power Systems. vol. 7. no. 2, may. 1992.

EMINOGLU, U.; HOCAOGLU, M. A Robust Power Flow Algorithm for Radial Distribution Systems. IEEE Power Tech, 2005 Russia, pp. 1 - 7, jun. 2005. INSPEC Accession Number: 9925016.

FARIDOON S.; NADIPURAN R. P.; HOWARD A. S. A fuzzy-logicsupported weighted least squares state estimation. ELSEVIER- Electric Power Systems Research (39), pp. 55-60, 1996. ISSN : 0885-8950.

FALCÃO, D.; ASSIS, S. Linear Programming State Estimation: Error Analysis and Gross Error Identification. IEEE Transactions on Power Systems, Vol. 3, No. 3, aug. 1988. ISSN : 0885-8950.

FALCÃO, D. M. e M. A. ARIAS. State estimation and observability analysis based on echelon forms of the linearized measurement models. IEEE Transactions on Power Systems, v.9, n.2, p.979-987, 1994. ISSN : 0885-8950.

GEISLER, K. I. Ampere Magnitude Line Measurements for Power System State Estimation. Dallas: IEEE Transactions on Power Apparatus and Systems, v. PAS-103, n. 8, p. 1962-1969, aug. 1984.

GHOSY, A.; LUBKEMAN, D.; JONES R. Load Modeling for Distribution Circuit State Estimation. Los Angeles: IEEE Transactions on Power Delivery, v. 12, no. 2, apr. 1997. 
HANSEN, C. W.; DEBS, A. S. Power System State Estimation using ThreePhase Models. San Francisco: IEEE Transactions on Power Systems, v. 10, n. 2, p. 818-824, may. 1995.

JAÉN, A. de la V.; EXPÓSITO, A. G. Including Ampere Measurements in Generalized State Estimators. IEEE Transactions on Power Systems, v. 20, n. 2, p. 603-610, may 2005. ISSN : 0885-8950.

IRVING, M. R.; OWEN, R. C.; STERLING, M. J. H. Power System State Estimation Using Linear Program. Proc. Inst. Electr. Eng., v.125, p.879-885, 1978. ISSN : 0020-3270.

KENNEDY, J.; EBERHART, R. Particle swarm optimization. Perth, Australia: Proceedings IEEE Int. Conf. Neural Networks, pp. 1942-1948, vol. 4, 1995.

KOTIUGA, W. W.; M. VIDYASAGAR. Bad Data Rejection Properties of Weighted Least Absolute Value Techniques Applied to Static State Estimation. IEEE Transactions on Power Apparatus and Systems, v.PAS-101, n.4, p.844-853, 1982. ISSN: 0272-1724.

LI, K. State Estimation for Power Distribution System and Measurement Impacts. Portland: IEEE Transactions on Power Systems, v. 11, n. 2, p. 911-916, may 1996.

LIN, W. M.; TENG, J. H.; CHEN, S. J. A Highly Efficient Algorithm in Treating Current Measurements for the Branch-Current-Based Distribution State Estimation. IEEE Trans. on Power Systems, vol. 16, no. 3, pp. 433-439, jul. 2001. ISSN : 0885-8977.

LU, C. N.; TENG, J. H.; LIU, W. H. E. Distribution System State Estimation. New York: IEEE Transactions on Power Systems, Vol. 10, No. I, feb. 1995. 
LUBKEMAN. D. L. et al. Field Results for a Distribution Circuit State Estimator Implementation. IEEE Transactions on Power Delivery, v. 15, no 1, jan. 2000. ISSN: 0885-8977.

MELIOPOULOS, A. P.; ZHANG, F. Multiphase Power Flow and State Estimation for Power Distribution System. Portland: IEEE Transactions on Power Systems, v. 11, n. 2, p. 939-946, may 1996.

MÉfFE, A. Cálculo de Perdas Técnicas em Sistemas de Distribuição Modelos Adequáveis às Características do Sistema e à Disponibilidade de Informações. São Paulo, Tese de Doutorado, EPUSP, 2007.

MILI, L.; ChENIAE, M. G.; ROUSSEEW, P. J. Robust state estimation of electric power systems. IEEE Transactions on Circuits and Systems I: Fundamental Theory and Applications, v.41, n.5, p.349-358, 1994. ISSN : 10577122.

MILI, L., PHANIRAJ, V.; ROUSSEEW, P. J. Least median of squares estimation in power systems. IEEE Transactions on Power Systems v.6, n.2, p.511-523, 1991. ISSN: 0885-8950

MILI, L.; VAN CUTSEN, T.; RIBBENS-PAVELLA, M. Hypothesis Testing Identification: A New Method For Bad Data Analysis In Power System State Estimation. IEEE Transactions on Power Apparatus and Systems, v.PAS-103, n.11, p.3239-3252, 1984. ISSN: 0018-9510.

MONTICELLI, A. State Estimation in Electric Power Systems: A Generalized Approach. Massachusetts: Kluwer Academic Publishers, 1999

MUÑOS, J. M. R.; EXPÓSITO, A. G. A Line-Current Measurement Based State Estimator. San Diego: IEEE Transactions on Power Systems, v. 7, n. 2, p. 513519, may 1992. 
NANNI, M. Estimador de Estado Robusto Baseado no Método da Mínima Mediana. São Carlos: Tese (Mestrado em Engenharia Elétrica). Escola de Engenharia de São Carlos da Universidade de São Paulo, 145 f., abr. 2009.

NAKA, S.; GENJI, T.; FUKUYAMA, Y. A hybrid particle swarm optimization for distribution state estimation. IEEE Transaction on Power Systems, Vol. 18, No. 1, feb. 2003. INSPEC Accession Number: 7992583.

NAKA, S. et al. Practical Distribution State Estimation Using Hybrid Particle Swarm Optimization. Columbus, Ohio: IEEE Power Engineering Society Winter Meeting, pp. 815-820, 2001.

OLIVEIRA, C. C. B; MÉFFE, A.; CAMPOS, M. B. M. Implantação em área piloto e treinamento para utilização do software, Relatório Técnico 04, Projeto de P\&D: Metodologia e Determinação do Nível Ótimo de Perdas em um Sistema de Distribuição de Energia, São Paulo, 2005.

PAPOULIS, A. Probability, Random Variables and Stochastic Processes. New York : McGraw- Hill Publishing Company Ltd, 1969

PROCEDIMENTOS DE DISTRIBUIÇÃO DE ENERGIA ELÉTRICA NO SISTEMA ELÉTRICO NACIONAL. PRODIST Módulo 5: Sistemas de Medição. 2010

SARIC, A. T.; CIRIC, R. M. Integrated Fuzzy State Estimation and Load Flow Analysis in Distribution Networks. IEEE Transaction on Power Delivery, Vol. 18, No.2, apr. 2003. ISSN : 0885-8977.

SINGH, R.; PAL, B.; JABUR, R. Choice of estimator for distribution system state estimation. IET Generation, Transmission \& Distribution, Vol. 3, Iss. 7, pp. 666-678, 2009. ISSN : 1751-8687. 
RAMÍREZ J.M.; BAROCIO. E.E. Solving State Estimation in Power Systems by an Interior Point method. Vancouver: ELSEVIER- International Journal of Electrical Power \& Energy Systems, no. 22, pp. 355-365, jun. 2000.

RAKPENTHAI, C.; PREMRUDEEPREECHACHARN, S.; UATRONGJIT, S.; WATSON, N. R. Measurement Placement for Power System State Estimation using Decomposition Technique. Electric Power Systems Research, Elsevier, vol. 75, no. 1, pp. 41 - 49, jul. 2005, INSPEC Accession Number: 8332124.

SCHWEPPE, F. C.; WILDES, J. Power System Static-State Estimation, Part I: Exact Model. IEEE Transactions on Power Apparatus and Systems, v.PAS-89, n.1, p.120-125, 1970. ISSN: 0018-9510.

SCHWEPPE, F. C.; ROM, D. B. Power System Static-State Estimation, Part II: Approximate Model. IEEE Transactions on Power Apparatus and Systems, v.PAS-89, n.1, p.125-130, 1970. ISSN: 0018-9510.

SCHWEPPE, F. C. Power System Static-State Estimation, Part III: Implementation. IEEE Transactions on Power Apparatus and Systems, v.PAS89, n.1, p.130-135, 1970. ISSN: 0018-9510.

SHAFIU, A.; JENKINS, N.; STRBAC, G. Measurement Location for State Estimation of Distribution Networks with Generation. IEE Proceedings on Generation, Transmission and Distribution,, vol. 152, no. 2, pp. 240-246, march 2005. ISSN: $1350-2360$.

SUN, H.B.; ZHANG, B.M. Distribution Matching Power Flow: A New Technique for Distribution System State Estimation. IEEE Power Engineering Review, jun. 2002. ISSN: 0272-1724.

TENG, J. H. Handling Current-Magnitude Measurement in Transmission and Distribution System State Estimator. IEE Proceedings - Generation, 
Transmission and Distribution, v. 147, n. 4, p. 202-206, jul. 2000. ISSN: 13502360.

THUKARAM, D.; JOVITHA, J.; SURAPONG, C. A robust three-phase state estimation algorithm for distribution networks. Electric Power Systems Research, Volume 55, Issue 3, Pages 191-200, sep. 2000.

VUOLO, J. H. Fundamentos da Teoria dos Erros. São Paulo: Editora Edgard Blücher, 2. ed., 249 p., 1996.

WANG, W.; SCHULZ, N. A Revised Branch Current-Based Distribution System State Estimation Algorithm and Meter Placement Impact. IEEE Transactions on Power Systems, vol. 19, no. 1, feb. 2004. ISSN : 0885-8950.

ZIMMERMAN, H. J., Fuzzy Set Theory - and Its Application. Boston: KluwerNijhoff Publishing, 3rd Edition, pp. 281, 1984. 


\section{ANEXO A - MÉdoto de CHOLESKY}

O método de Cholesky é utilizado para se encontrar a solução numérica de equações lineares:

$$
A x=B
$$

Se $A$ é simétrica e definida positiva, então $A$ pode ser decomposta em:

$$
A=L \cdot L^{T}
$$

Sendo a equação D.2 conhecida por fatoração de Cholesky em que é a matriz triangular inferior e a sua transposta. A aplicação da fatoração de Cholesky resolve o sistema de equações:

$$
\begin{gathered}
L \cdot y=b \\
L^{T} \cdot x=y
\end{gathered}
$$

Onde,

$$
b=L \cdot y=L \cdot\left(L^{T} \cdot x\right)=\left(L \cdot L^{T}\right) \cdot x=A \cdot x
$$

Portanto, a vantagem desta fatoração consiste em só ser necessário determinar a matriz $L$, pois uma matriz simétrica e definida positiva pode ser representada pela forma

$A=L \cdot L^{T}$. Isto significa que o número de operações para resolver um sistema linear fica reduzido a cerca de metade, quando se aplica o método de Cholesky. 
ANEXO B - Tabelas de Medições e Resultados

Tabela B.1 - Medições do alimentador 1 por fase

\begin{tabular}{c|c|c|c|c|c|c}
\hline \multicolumn{2}{c|}{ Medidor } & \multicolumn{2}{c}{ D } & \multicolumn{2}{c}{ E } & \multicolumn{2}{c}{$F$} \\
\cline { 2 - 7 } \#1 (A) & \multicolumn{2}{c}{87,00} & \multicolumn{2}{c}{88,00} & \multicolumn{2}{c}{89,00} \\
\hline \#2 (KW)(KVAr) & 552.48 & 565.65 & 565.17 & 240.05 & 232.04 & 678.22 \\
\hline \#3 (KW)(KVAr) & 93.66 & 98.22 & 91.65 & 36.57 & 41.35 & 42.91 \\
\hline \#4 (KW)(KVAr) & 386.66 & 385.83 & 395.82 & 172.44 & 160.69 & 165.83 \\
\hline \#5 (KW)(KVAr) & 248.65 & 244.40 & 256.61 & 113.88 & 101.81 & 104.14 \\
\hline \#6 (KW)(KVAr) & 10.00 & 9.00 & 1.70 & 4.30 & 4.00 & 3.50 \\
\hline \#7 (KW)(KVAr) & 0.50 & 0.50 & 0.50 & 0.25 & 0.25 & 0.25 \\
\hline \#8 (KW)(KVAr) & 18.00 & 18.00 & 18.00 & 8.00 & 8.00 & 8.00 \\
\hline
\end{tabular}

Tabela B.2 - Resultados dos cálculos EE Proporcional do alimentador 1 por fase

\begin{tabular}{c|c|c|c|c|c|c}
\hline \multicolumn{2}{c|}{ Medidor } & \multicolumn{2}{|c|}{$\mathrm{D}$} & \multicolumn{2}{c}{ E } & \multicolumn{2}{c}{$\mathrm{F}$} \\
\cline { 2 - 7 } \#1 (A)(Med única) & \multicolumn{2}{|c|}{87.34} & \multicolumn{2}{c}{88.48} & \multicolumn{2}{c}{88.99} \\
\hline \#1 (A) & \multicolumn{2}{|c|}{87.36} & \multicolumn{2}{c}{88.38} & \multicolumn{2}{c}{89.00} \\
\hline \#2 (KW)(KVAr) & 532.71 & 228.50 & 545.03 & 218.81 & 228.50 & 234.19 \\
\hline$\# 3(\mathrm{KW})(\mathrm{KVAr})$ & 87.00 & 33.78 & 91.57 & 38.57 & 33.78 & 40.12 \\
\hline$\# 4(\mathrm{KW})(\mathrm{KVAr})$ & 379.71 & 166.92 & 378.20 & 153.52 & 166.92 & 158.82 \\
\hline$\# 5(\mathrm{KW})(\mathrm{KVAr})$ & 246.33 & 111.56 & 241.43 & 97.86 & 111.56 & 100.37 \\
\hline$\# 6(\mathrm{KW})(\mathrm{KVAr})$ & 3.27 & 1.36 & 9.28 & 3.85 & 1.36 & 3.62 \\
\hline$\# 7(\mathrm{KW})(\mathrm{KVAr})$ & 0.26 & 0.11 & 0.26 & 0.11 & 0.11 & 0.11 \\
\hline \#8 (KW)(KVAr) & 18.57 & 7.74 & 18.57 & 7.74 & 7.74 & 7.74 \\
\hline
\end{tabular}


Tabela B.3 - Resultados dos cálculos EE WLS do alimentador 1 por fase

\begin{tabular}{c|c|c|c|c|c|c}
\hline \multicolumn{2}{c|}{ Medidor } & \multicolumn{2}{c|}{ D } & \multicolumn{2}{c}{ E } & \multicolumn{2}{c}{ Falor } \\
\hline \multirow{2}{*}{ \#1 (A) } & \multicolumn{2}{|c|}{91.24} & \multicolumn{2}{c}{89.90} & \multicolumn{2}{c}{92.17} \\
\hline \#2 (KW)(KVAr) & 575.82 & 250.07 & 573.79 & 238.88 & 584.35 & 241.53 \\
\hline \#3 (KW)(KVAr) & 81.85 & 35.72 & 87.74 & 35.01 & 85.39 & 40.28 \\
\hline \#4 (KW)(KVAr) & 415.99 & 183.83 & 407.58 & 176.00 & 418.46 & 171.75 \\
\hline \#5 (KW)(KVAr) & 279.39 & 121.72 & 267.04 & 119.61 & 274.99 & 109.38 \\
\hline \#6 (KW)(KVAr) & 3.50 & 1.70 & 10.00 & 4.30 & 9.00 & 4.00 \\
\hline \#7 (KW)(KVAr) & 0.50 & 0.25 & 0.50 & 0.25 & 0.50 & 0.25 \\
\hline \#8 (KW)(KVAr) & 18.00 & 8.00 & 18.00 & 8.00 & 18.00 & 8.00 \\
\hline
\end{tabular}

Tabela B.4 - Resíduo normalizado do cálculo EE WLS do alimentador 1 por fase

\begin{tabular}{c|c|c|c|c|c|c}
\hline Medidor & \multicolumn{5}{c}{ Resíduo normalizado } \\
\hline \multirow{2}{*}{$\# 1$} & \multicolumn{2}{|c|}{$\mathrm{D}$} & \multicolumn{2}{c}{$\mathrm{E}$} & \multicolumn{2}{c}{$\mathrm{F}$} \\
\cline { 2 - 7 } & \multicolumn{2}{|c|}{913.32} & \multicolumn{2}{c}{1003.17} & \multicolumn{2}{c}{945.30} \\
\hline$\# 2$ & 63994.04 & 28532.09 & 24785.04 & 62881.01 & 68450.91 & 17806.05 \\
\hline$\# 3$ & 10203.30 & 4783.99 & 5856.20 & 9873.40 & 10523.61 & 5215.97 \\
\hline$\# 4$ & 40303.33 & 19056.16 & 13508.98 & 36918.60 & 43301.34 & 19252.42 \\
\hline$\# 5$ & 29232.27 & 14148.51 & 11181.86 & 25996.46 & 31438.69 & 13820.78 \\
\hline
\end{tabular}

Tabela B.5 - Demanda das carga da zona \#3 do alimentador 1 calculada pela caracterização de carga

\begin{tabular}{c|c|c|c|c|c|c}
\hline \multicolumn{7}{l}{ Carga } \\
\hline \multirow{2}{*}{$\mathbf{1}$} & $\mathrm{PD}(\mathrm{kW})$ & $\mathrm{QD}(\mathrm{kVAr})$ & $\mathrm{PE}(\mathrm{kW})$ & $\mathrm{QE}(\mathrm{kVAr})$ & $\mathrm{PF}(\mathrm{kW})$ & $\mathrm{QF}(\mathrm{kVAr})$ \\
\cline { 2 - 7 } & 22.37 & 9.53 & 17.53 & 7.47 & 20.03 & 8.53 \\
\hline $\mathbf{2}$ & 16.77 & 7.15 & 21.26 & 9.06 & 17.24 & 7.35 \\
\hline $\mathbf{3}$ & 4.78 & 2.04 & 5.59 & 2.38 & 4.73 & 2.02 \\
\hline $\mathbf{4}$ & 9.00 & 3.84 & 10.05 & 4.28 & 8.53 & 3.63 \\
\hline $\mathbf{5}$ & 20.52 & 8.74 & 19.65 & 8.37 & 20.53 & 8.75 \\
\hline $\mathbf{6}$ & 14.45 & 6.16 & 11.52 & 4.91 & 6.68 & 2.85 \\
\hline $\mathbf{7}$ & 3.73 & 1.59 & 7.98 & 3.40 & 3.92 & 1.67 \\
\hline $\mathbf{8}$ & 3.36 & 1.43 & 2.89 & 1.23 & 3.01 & 1.28 \\
\hline
\end{tabular}


Tabela B.6 - Demanda das carga da zona \#3 do alimentador 1 corrigida pela EE proporcional com medição única

\begin{tabular}{c|c|c|c|c|c|c}
\hline \multicolumn{7}{l}{ Carga } \\
\hline \multirow{2}{*}{$\mathbf{1}$} & PD $(\mathrm{kW})$ & QD(kVAr) & $\mathrm{PE}(\mathrm{kW})$ & $\mathrm{QE}(\mathrm{kVAr})$ & $\mathrm{PF}(\mathrm{kW})$ & $\mathrm{QF}(\mathrm{kVAr})$ \\
\cline { 2 - 7 } & 22.70 & 9.67 & 17.79 & 7.58 & 20.33 & 8.66 \\
\hline $\mathbf{2}$ & 17.02 & 7.25 & 21.58 & 9.19 & 17.50 & 7.46 \\
\hline $\mathbf{3}$ & 4.85 & 2.07 & 5.67 & 2.42 & 4.80 & 2.05 \\
\hline $\mathbf{4}$ & 9.14 & 3.89 & 10.20 & 4.34 & 8.65 & 3.69 \\
\hline $\mathbf{5}$ & 20.83 & 8.87 & 19.95 & 8.50 & 20.84 & 8.88 \\
\hline $\mathbf{6}$ & 14.66 & 6.25 & 11.69 & 4.98 & 6.78 & 2.89 \\
\hline $\mathbf{7}$ & 3.78 & 1.61 & 8.10 & 3.45 & 3.98 & 1.70 \\
\hline $\mathbf{8}$ & 3.41 & 1.45 & 2.94 & 1.25 & 3.05 & 1.30 \\
\hline
\end{tabular}

Tabela B.7 - Demanda das carga da zona \#3 do alimentador 1 corrigida pela EE proporcional genérica

\begin{tabular}{r|c|c|c|c|c|c}
\hline \multicolumn{1}{l}{ Carga } \\
\cline { 2 - 7 } & $\mathrm{PD}(\mathrm{kW})$ & $\mathrm{QD}(\mathrm{kVAr})$ & $\mathrm{PE}(\mathrm{kW})$ & $\mathrm{QE}(\mathrm{kVAr})$ & $\mathrm{PF}(\mathrm{kW})$ & $\mathrm{QF}(\mathrm{kVAr})$ \\
\cline { 2 - 7 } 1 & 22.41 & 9.56 & 17.57 & 7.49 & 20.07 & 8.56 \\
\hline 2 & 16.81 & 7.17 & 21.31 & 9.09 & 17.28 & 7.37 \\
\hline 3 & 4.79 & 2.04 & 5.60 & 2.39 & 4.74 & 2.02 \\
\hline 4 & 9.02 & 3.85 & 10.07 & 4.29 & 8.54 & 3.64 \\
\hline 5 & 20.56 & 8.77 & 19.69 & 8.40 & 20.57 & 8.78 \\
\hline 6 & 14.48 & 6.18 & 11.54 & 4.92 & 6.69 & 2.86 \\
\hline 7 & 3.74 & 1.59 & 8.00 & 3.41 & 3.93 & 1.68 \\
\hline 8 & 3.37 & 1.44 & 2.90 & 1.24 & 3.02 & 1.29 \\
\hline
\end{tabular}


Tabela B.8 - Demanda das carga da zona \#3 do alimentador 1 corrigida pela EE WLS

\begin{tabular}{r|c|r|r|r|r|r}
\hline \multicolumn{1}{l}{ Carga } & \multicolumn{5}{c}{ Valor } \\
\hline & PD(kW) & QD(kVAr) & PE(kW) & QE(kVAr) & PF(kW) & QF(kVAr) \\
\cline { 2 - 7 } 1 & 20.62 & 8.24 & 14.76 & 6.32 & 20.78 & 10.40 \\
\hline 2 & 14.97 & 5.85 & 19.18 & 8.23 & 16.80 & 8.19 \\
\hline 3 & 4.37 & 1.76 & 7.29 & 3.22 & 4.78 & 2.30 \\
\hline 4 & 8.16 & 3.37 & 9.68 & 4.14 & 8.48 & 3.86 \\
\hline 5 & 20.05 & 8.33 & 18.72 & 8.04 & 20.81 & 9.79 \\
\hline 6 & 14.12 & 5.65 & 12.59 & 5.45 & 7.05 & 3.20 \\
\hline 7 & 3.29 & 1.38 & 7.82 & 3.35 & 4.10 & 1.82 \\
\hline 8 & 3.40 & 1.42 & 2.94 & 1.25 & 3.19 & 1.43 \\
\hline
\end{tabular}

Tabela B.9 - Medições do alimentador 2 por fase

\begin{tabular}{c|c|c|c|c|c|c}
\hline \multicolumn{2}{c}{ Medidor } & \multicolumn{2}{c}{ D } & \multicolumn{2}{c}{ E } & \multicolumn{2}{c}{ F lor } \\
\cline { 2 - 7 }$\# 1$ (A) & \multicolumn{2}{c}{82.00} & \multicolumn{2}{c}{84.00} & \multicolumn{2}{c}{66.00} \\
\hline \#2 (KW)(KVAr) & 183.00 & 41.00 & 169.00 & 105.00 & 127.00 & 63.00 \\
\hline \#3 (KW)(KVAr) & 38.00 & 9.00 & 25.00 & 24.00 & 19.00 & 5.00 \\
\hline \#4 (KW)(KVAr) & 50.00 & 10.00 & 48.00 & 30.00 & 40.00 & 20.00 \\
\hline \#5 (KW)(KVAr) & 180.00 & 45.00 & 170.00 & 95.00 & 130.00 & 65.00 \\
\hline \#6 (KW)(KVAr) & 25.00 & 6.00 & 26.00 & 15.00 & 20.00 & 13.00 \\
\hline \#7 (KW)(KVAr) & 40.00 & 12.00 & 37.00 & 21.00 & 31.00 & 15.00 \\
\hline \#8 (KW)(KVAr) & 6.00 & 3.00 & 10.00 & 5.00 & 5.00 & 8.00 \\
\hline \#9 (KW)(KVAr) & 19.00 & 9.00 & 19.00 & 9.00 & 19.00 & 9.00 \\
\hline \#10 (KW)(KVAr) & 2.00 & 0.50 & 2.00 & 0.50 & 2.00 & 0.50 \\
\hline
\end{tabular}


Tabela B.10 - Resultados dos cálculos EE Proporcional do alimentador 2 por fase

\begin{tabular}{c|c|c|c|c|c|c}
\hline \multicolumn{2}{c}{ Medidor } & \multicolumn{2}{c}{$\mathrm{D}$} & \multicolumn{2}{c}{$\mathrm{E}$} & \multicolumn{2}{c}{$\mathrm{F}$} \\
\cline { 2 - 7 } \#1 (A)(Med única) & \multicolumn{2}{c}{81.48} & \multicolumn{2}{c}{83.98} & \multicolumn{2}{c}{64.86} \\
\hline$\# 1(\mathrm{~A})$ & \multicolumn{2}{|c|}{81.54} & \multicolumn{2}{c}{83.97} & \multicolumn{2}{c}{64.23} \\
\hline \#2 (KW)(KVAr) & 185.23 & 40.01 & 168.56 & 105.38 & 121.75 & 62.10 \\
\hline$\# 3(\mathrm{KW})(\mathrm{KVAr})$ & 38.49 & 9.06 & 23.98 & 24.02 & 18.55 & 4.67 \\
\hline$\# 4(\mathrm{KW})(\mathrm{KVAr})$ & 51.98 & 10.05 & 50.12 & 29.93 & 34.65 & 19.82 \\
\hline$\# 5(\mathrm{KW})(\mathrm{KVAr})$ & 180.71 & 41.36 & 169.86 & 98.46 & 127.39 & 64.45 \\
\hline$\# 6(\mathrm{KW})(\mathrm{KVAr})$ & 26.15 & 4.85 & 28.19 & 15.95 & 18.12 & 13.06 \\
\hline$\# 7(\mathrm{KW})(\mathrm{KVAr})$ & 47.82 & 13.77 & 45.47 & 24.38 & 38.52 & 18.62 \\
\hline$\# 8(\mathrm{KW})(\mathrm{KVAr})$ & 4.90 & 2.09 & 8.16 & 3.48 & 4.01 & 1.71 \\
\hline$\# 9(\mathrm{KW})(\mathrm{KVAr})$ & 14.60 & 6.22 & 14.60 & 6.22 & 14.60 & 6.22 \\
\hline$\# 10(\mathrm{KW})(\mathrm{KVAr})$ & 0.25 & 0.10 & 0.25 & 0.10 & 0.25 & 0.10 \\
\hline
\end{tabular}

Tabela B.11 - Resultados dos cálculos EE WLS do alimentador 2 por fase

\begin{tabular}{|c|c|c|c|c|c|c|}
\hline Medidor & \multicolumn{6}{|c|}{ Valor } \\
\hline$\# 1(\mathrm{~A})$ & \multicolumn{2}{|c|}{77.46} & \multicolumn{2}{|c|}{92.02} & \multicolumn{2}{|c|}{74.44} \\
\hline \#2 (KW)(KVAr) & 145.31 & 33.87 & 188.24 & 70.06 & 132.47 & 91.69 \\
\hline \#3 (KW)(KVAr) & 28.91 & 1.27 & 34.75 & 18.79 & 16.13 & 15.55 \\
\hline$\# 4(\mathrm{KW})(\mathrm{KVAr})$ & 40.63 & 11.30 & 52.03 & 18.26 & 39.40 & 25.78 \\
\hline \#5 (KW)(KVAr) & 147.38 & 38.85 & 184.59 & 66.09 & 139.29 & 87.49 \\
\hline \#6 (KW)(KVAr) & 19.55 & 7.49 & 26.34 & 8.89 & 21.26 & 14.72 \\
\hline$\# 7(\mathrm{KW})(\mathrm{KVAr})$ & 38.33 & 11.46 & 45.49 & 17.55 & 35.85 & 21.91 \\
\hline \#8 (KW)(KVAr) & 6.00 & 3.00 & 10.00 & 5.00 & 5.00 & 8.00 \\
\hline$\# 9$ (KW)(KVAr) & 19.00 & 9.00 & 19.00 & 9.00 & 19.00 & 9.00 \\
\hline$\# 10(\mathrm{KW})(\mathrm{KVAr})$ & 2.00 & 0.50 & 2.00 & 0.50 & 2.00 & 0.50 \\
\hline
\end{tabular}


Tabela B.12 - Resíduo normalizado do cálculo EE WLS do alimentador 2 por fase

\begin{tabular}{c|c|c|c|c|c|c}
\hline \multicolumn{1}{c|}{ Medidor } & \multicolumn{5}{c}{ Resíduo normalizado } \\
\cline { 2 - 7 }$\#$ \#1 & \multicolumn{2}{|c|}{$\mathrm{D}$} & \multicolumn{2}{c}{$\mathrm{E}$} & \multicolumn{2}{c}{$\mathrm{F}$} \\
\cline { 2 - 7 } & 1290.06 & \multicolumn{2}{c}{1309.78} & \multicolumn{2}{c}{1175.19} \\
\hline$\# 2$ & 27169.74 & 8658.58 & 26267.70 & 17804.99 & 24170.06 & 11809.38 \\
\hline$\# 3$ & 1543.81 & 1578.97 & 1661.92 & 2177.95 & 1332.76 & 1183.17 \\
\hline$\# 4$ & 21401.32 & 4653.91 & 20195.91 & 13864.04 & 20792.25 & 9281.93 \\
\hline$\# 5$ & 25659.27 & 9984.71 & 27014.35 & 10688.30 & 22822.45 & 12234.81 \\
\hline$\# 6$ & 12722.73 & 4232.51 & 12048.39 & 8005.68 & 11179.27 & 6825.46 \\
\hline$\# 7$ & 2982.79 & 1739.67 & 3284.36 & 1866.41 & 2636.30 & 2183.94 \\
\hline
\end{tabular}

